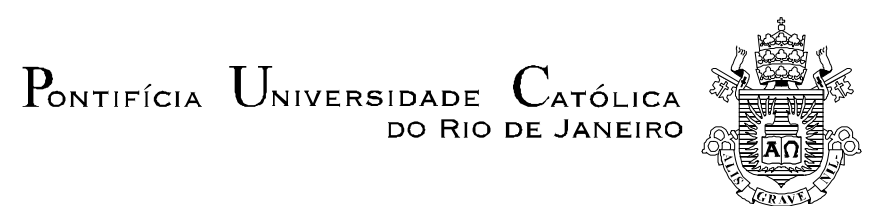

Rebeca Ramos de Oliveira Figueiredo

\title{
Avaliação de um investimento florestal usando a Teoria de Opções Reais
}

Dissertação apresentada como requisito parcial para obtenção do grau de Mestre pelo Programa de Pós-Graduação em Engenharia de Produção da PUC-Rio.

Orientador: Prof. Fernando Luiz Cyrino Oliveira

Rio de Janeiro 


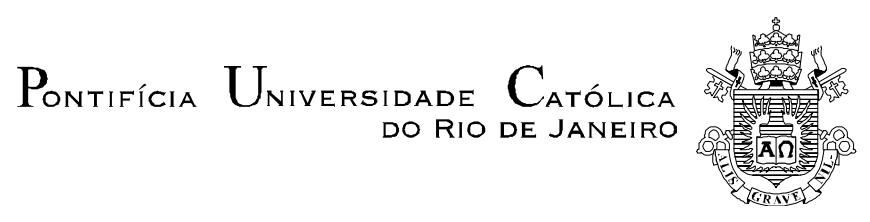

Rebeca Ramos de Oliveira Figueiredo

\section{Avaliação de um investimento florestal usando a Teoria de Opções Reais}

Dissertação apresentada como requisito parcial para obtenção do grau de Mestre pelo Programa de Pós-Graduação em Engenharia de Produção da PUC-Rio. Aprovada pela Comissão Examinadora abaixo assinada.

Prof. Fernando Luiz Cyrino Oliveira Orientador

Departamento de Engenharia Industrial - PUC-Rio

Prof. Frances Fischberg Blank

Departamento de Engenharia Industrial - PUC-Rio

Prof. Marco Antônio Guimarães Dias

Departamento de Engenharia Industrial - PUC-Rio

Prof. Luiz Eduardo Teixeira Brandão Instituto de Administração e Gerência / IAG - PUC-Rio

Prof. Márcio da Silveira Carvalho

Coordenador Setorial do Centro Técnico Científico - PUC-Rio

Rio de Janeiro, 05 de setembro de 2016 
Todos os direitos reservados. É proibida a reprodução total ou parcial do trabalho sem autorização do autor, do orientador e da universidade.

\section{Rebeca Ramos de Oliveira Figueiredo}

Graduou-se em Engenharia de Produção na UFF (Universidade Federal Fluminense) em 2014. Trabalhou como estagiária na empresa Sete Brasil na área de novos negócios e possui um artigo publicado no Encontro Nacional de Engenharia de Produção de 2014.

Ficha Catalográfica

Figueiredo, Rebeca Ramos de Oliveira

Avaliação de um investimento florestal usando a Teoria de Opções Reais / Rebeca Ramos de Oliveira Figueiredo ; orientador: Fernando Luiz Cyrino Oliveira. - 2016.

103 f. : il. ; $30 \mathrm{~cm}$

Dissertação (mestrado) - Pontifícia Universidade Católica do Rio de Janeiro, Departamento de Engenharia Industrial, 2016.

Inclui bibliografia

1. Engenharia Industrial - Teses. 2. Investimento florestal. 3. Teoria de opções reais. 4. Método de diferenças finitas. 5. Equação logística. I. Oliveira, Fernando Luiz Cyrino. II. Pontifícia Universidade Católica do Rio de Janeiro. Departamento de Engenharia Industrial. III. Título. 


\section{Agradecimentos}

A todos que de alguma forma colaboraram com a construção desta dissertação, não tenho como agradecer o empenho e a dedicação que vocês tiveram ao longo das várias etapas do processo de escrita. Aos meus professores da PUC-Rio, levo comigo o exemplo de cada um, vocês contribuíram para meu crescimento profissional e pessoal. Destaco a participação do professor Carlos Samanez (in memoriam), guardarei em meu coração suas últimas palavras a mim referidas: "valeu a pena".

Um agradecimento especial ao professor Marco Antônio Dias que além de ser um excelente professor, me orientou desde os primeiros passos da pesquisa, estando sempre disponível a ajudar quando solicitado.

Esse trabalho não existiria se não fosse o empenho da professora Frances, que apesar de não ter sido minha professora direta, teve grande influência nessa dissertação e no meu desenvolvimento profissional ao longo do projeto.

Agradeço a CAPES pelo apoio financeiro sem o qual tornaria este trabalho inviável.

Agradeço a compreensão da minha família que tanto me apoia. Considero-me privilegiada e presenteada por Deus por ter vocês ao meu lado. Um agradecimento especial ao meu marido, Wiliam, que me encoraja, me suporta e alegra cada um dos meus dias. E além de suas diversas funções e atividades profissionais, se dedicou a ajudar no desenvolvimento do programa aplicado neste trabalho.

O espaço de uma folha não é o suficiente para agradecer a todos os que deveriam ser lembrados, quanto mais o espaço de um parágrafo para agradecer a Deus. Até porque, nem mesmo uma vida inteira seria! A verdade é que nada que dissermos ou fizermos será o suficiente para agradecer. O que me resta é aceitar que por meio da vida dele em mim eu posso tudo. Posso amar, posso ser gentil, posso passar por dificuldade, posso perder tudo e todos. E posso inclusive ter a grande ousadia de dizer a Ele obrigada. Para àquele que me ensinou tudo que é eterno, àquele que me fez renascer, àquele que é meu amado. Meu Deus, meu Pai e meu Amigo. 


\section{Resumo}

Figueiredo, Rebeca Ramos de Oliveira; Oliveira, Fernando Luiz Cyrino (Orientador). Avaliação de um investimento florestal usando a Teoria de Opções Reais. Rio de Janeiro, 2016. 103p. Dissertação de Mestrado Departamento de Engenharia Industrial, Pontifícia Universidade Católica do Rio de Janeiro.

Para avaliar projetos de investimento florestal, a Teoria de Opções Reais é utilizada com o propósito de incorporar questões relacionadas a incertezas e flexibilidades gerenciais. O objetivo desta dissertação é desenvolver uma modelagem para valoração de um projeto florestal, no qual a variação do estoque de árvores se aproxima do crescimento real de uma floresta, utilizando uma adaptação da equação logística. Desta forma, para um determinado nível de saturação, o estoque se estabiliza. Adicionalmente, o trabalho busca quantificar os benefícios econômicos de uma política ótima de produção a partir do corte de árvores. Para a análise proposta, os resultados são obtidos através do método de diferenças finitas explícitas. O problema apresenta três variáveis independentes - estoque, tempo e preço, sendo este modelado como um Movimento Geométrico Browniano - e duas variáveis dependentes - a taxa de corte e o valor da opção de investimento. É apresentada uma aplicação para uma floresta de eucalipto e os resultados são comparados considerando outras alternativas para a evolução do estoque de árvores, bem como para a decisão da quantidade a ser cortada. Para esta comparação, avalia-se o caso em que o estoque segue um modelo estocástico e o caso em que a taxa de corte é fixa. Os resultados mostram que é vantajoso adotar uma política ótima de corte, corroborando resultados obtidos em trabalhos anteriores de opções reais na área florestal. Além disso, o maior valor da opção é obtido quando o estoque é modelado pela equação logística para o crescimento.

\section{Palavras Chave}

Investimento Florestal; Teoria de Opções Reais; Método de Diferenças Finitas; Equação Logística. 


\section{Abstract}

Figueiredo, Rebeca Ramos de Oliveira; Oliveira, Fernando Luiz Cyrino (Advisor). Valuation of a forestry investment using the Real Options Theory. Rio de Janeiro, 2016. 103p. MSc. Dissertation - Departamento de Engenharia Industrial, Pontifícia Universidade Católica do Rio de Janeiro.

In order to incorporate uncertainty and managerial flexibilities in forestry investment projects, financial literature uses the real options approach. The aim of this work is to develop a model for valuation of a forestry project, in which the inventory growth of trees follows a logistic equation based in the estimated real growth of a forest. Thus, for a given level of saturation, the inventory stabilizes. In addition, this dissertation aims to quantify the economic benefits of an optimal production policy from cutting trees. For the proposal analysis, the results are obtained by the finite difference method in the explicit form. The problem has three independent variables

- inventory, time and price, which is modeled as a Geometric Brownian Motion - and two dependent variables - the cutting rate and the value of the investment option. An application for an eucalyptus forest is presented and the results are compared considering other alternatives for the evolution of the inventory and for the decision on the cutting amount. For this purpose, two different assumptions are made, considering a stochastic model for the inventory and a fixed shear rate. The results show that it is advantageous to adopt a optimal cutting policy, confirming results obtained in previous studies of real options in forestry. Moreover, the greatest option value is obtained when the inventory is modeled by logistic equation for growth.

\section{Keywords}

Forestry Investment; Real Options Theory; Finite Difference Method; Logistic Function. 


\section{Sumário}

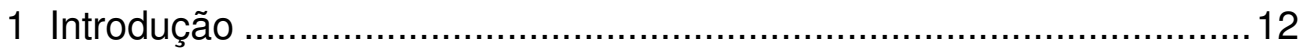

1.1. Posicionamento acadêmico da dissertação ............................................. 14

1.2. Relevância do Estudo ................................................................... 14

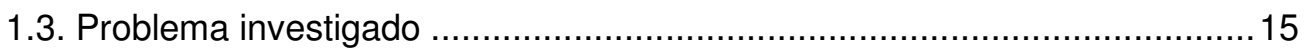

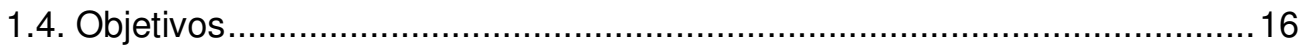

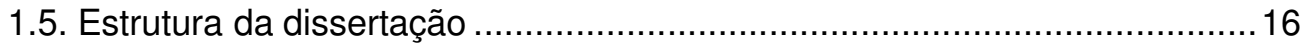

2 Investimento Florestal ........................................................ 18

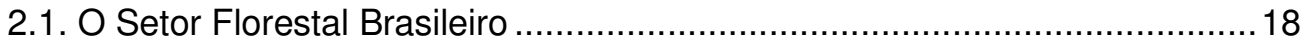

2.2. Setor de Madeira Processada Mecanicamente........................................ 19

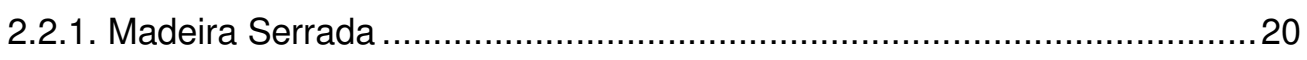

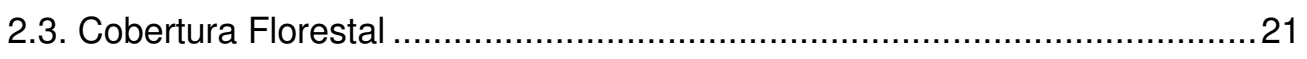

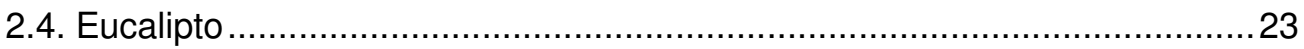

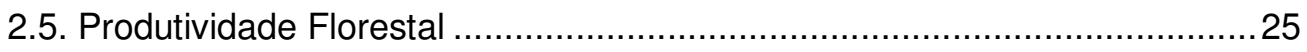

2.6. Modelagem de crescimento de uma floresta.........................................27

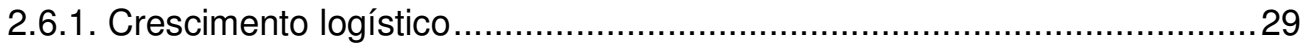

2.6.2. Modelos de crescimento determinísticos versus modelos estocásticos ...32

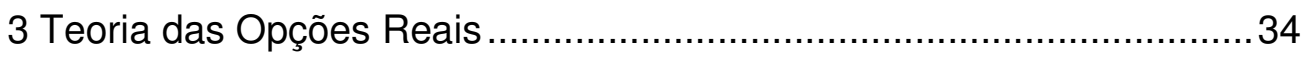

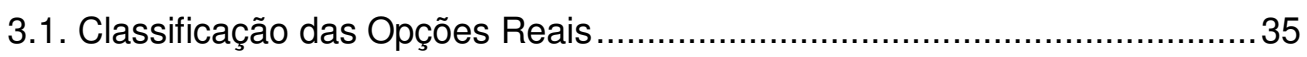

3.2. Métodos de Avaliação de Ativos ...................................................... 38

3.2.1. Solução numérica com diferenças finitas ............................................ 38

3.2.2. Método de diferenças finitas explícitas aplicado a Opções Reais.............. 42

3.3. Opções Reais no mercado de recursos renováveis .................................. 46

4 Modelo com estoque dado pela equação logística.............................58

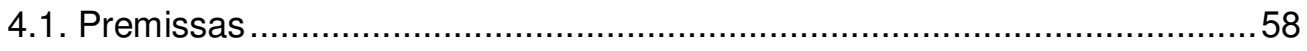

4.2. Modelagem da opção de cortar árvores ..............................................59

4.2.1. Modelagem do Preço .......................................................................6 60

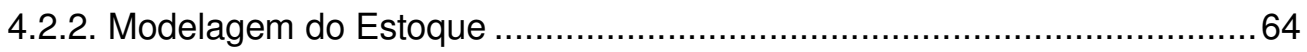

4.3. Cálculo do valor de um investimento florestal ........................................67

4.4. Aplicação do Método de Diferenças Finitas ........................................... 70 


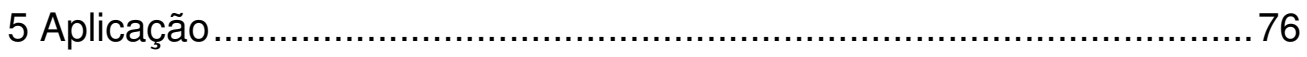

5.1. Estudo hipotético de um investimento florestal ....................................... 76

5.2. Resultados para o modelo logístico .................................................... 79

5.3. Resultados para o modelo logístico com componente estocástica...............85

5.4. Análise Comparativa dos modelos ............................................................ 92

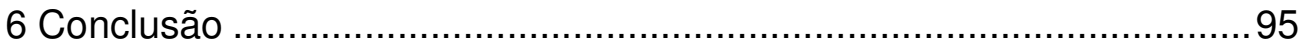

7 Referências bibliográficas ....................................................... 99

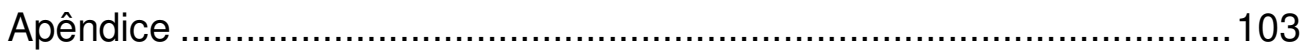




\section{Lista de Figuras}

Figura 2.1 - Modelo simplificado da cadeia produtiva do setor florestal............. 18

Figura 2.2 - Principais produtos do segmento de madeira serrada .....................20

Figura 2.3 - Distribuição da produção potencial madeireira

por região do Brasil, 2012

Figura 2.4 - Evolução da produtividade do eucalipto no

estado de São Paulo, Brasil.

Figura 2.5 - Produtividade florestal no Brasil em comparação com

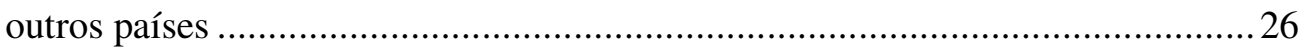

Figura 2.6 - Forma típica da curva de crescimento de uma árvore ......................228

Figura 2.7 - Curva de Crescimento Logístico..................................................2 29

Figura 2.8 - Curva de crescimento exponencial e logístico............................... 30

Figura 3.1 - Classificação dos tipos de opções reais .......................................... 35

Figura 3.2 - Grid P x t: Discretização do Método das Diferenças Finitas

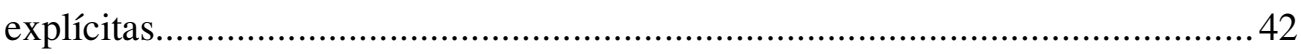

Figura 3.3 - Grid das Diferenças Finitas ..................................................... 43

Figura 4.1 - Série histórica de preços médios de eucaliptos no Brasil.................60

Figura 4.2 - Série histórica de preços deflacionados de eucaliptos no Brasil ...... 61

Figura 4.3-Crescimento Logístico para diferentes valores iniciais para

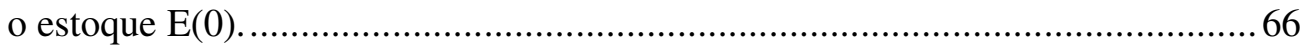

Figura 4.4 - Grid das Diferenças Finitas - Preço vs. Tempo ............................. 71

Figura 4.5 - Grid das Diferenças Finitas - Estoque vs. Tempo.......................... 71 
Figura 5.1 - Taxa de corte vs. Tempo para diferentes níveis de estoques iniciais 80 Figura 5.2 - Taxa de corte vs. Tempo para diferentes níveis de preços iniciais .. 81 Figura 5.3 - Taxa de corte vs. Tempo para diferentes níveis de volatilidade 81 Figura 5.4 - Valor da Opção em mil R\$ por hectare vs. Preço para diferentes estoques iniciais.

Figura 5.5 - Valor da Opção em mil R\$ por hectare vs. Preço para

diferentes velocidades de reversão à média

Figura 5.6 - Valor da Opção em mil R\$ por hectare vs. Preço para

diferentes volatilidade do preço.

Figura 5.7 - Valor da Opção em mil R \$ por hectare vs. Preço para

diferentes tempos de expiração.

Figura 5.8 - Valor da Opção em mil R\$ por hectare vs. Preço para diferentes custos variáveis lineares

Figura 5.9 - Valor da Opção em mil R \$ por hectare vs. Preço para

diferentes custos variáveis quadráticos

Figura 5.10 - Taxa de corte vs. Tempo para diferentes níveis de

estoques iniciais

Figura 5.11 - Taxa de corte vs. Tempo para diferentes níveis de preço iniciais... 86

Figura 5.12 - Taxa de corte vs. Tempo para diferentes níveis de

volatilidade do preço.

Figura 5.13 - Taxa de corte vs. Tempo para diferentes níveis de custos variáveis lineares.

Figura 5.14 - Taxa de corte vs. Tempo para diferentes níveis de custos variáveis quadráticos

Figura 5.15 - Taxa de corte vs. Tempo para diferentes níveis de volatilidade do estoque

Figura 5.16 - Valor da Opção em mil R\$ por hectare vs. Preço

para diferentes Estoques iniciais

Figura 5.17 - Valor da Opção em mil R\$ por hectare vs. Preço

para diferentes velocidades de reversão à média.

Figura 5.18 - Valor da Opção em mil R\$ por hectare vs. Preço

para diferentes taxas de conveniência.

Figura 5.19 - Valor da Opção em mil R \$ por hectare vs. Estoque

inicial para diferentes volatilidades do estoque. 
Figura 5.20 - Valor da Opção em mil R\$ por hectare vs. Estoque

inicial para diferentes preços inicias ............................................................. 91

Figura 5.21 - Valor da Opção em mil R\$ por hectare vs. Preço

inicial para diferentes modelos

.93

\section{Lista de Tabelas}

Tabela 2.1 - Grupos de produtores florestais ................................................ 19

Tabela 2.2 - Evolução da área ocupada com árvores de eucalipto, 2006-2014....22

Tabela 2.3 - Área de árvores plantadas por estado e espécie, 2014 .................... 22

Tabela 2.4 - Consumo de madeira in natura $\left(\mathrm{m}^{3}\right)$........................................ 24

Tabela 3.1 - Principais referências de opções reais da área de

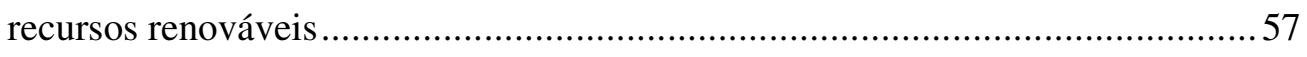

Tabela 5.1 - Parâmetros utilizados para análise dos resultados do modelo.......... 77

Tabela 5.2 - Valor de Mercado em milhares de reais para diferentes

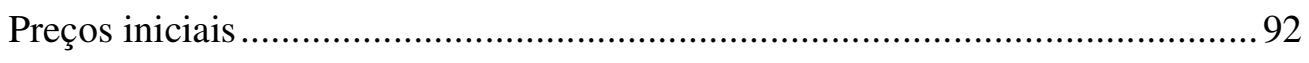




\section{1 Introdução}

A Teoria das Opções Reais, método de avaliação baseado em apreçamento de opções aplicado a ativos reais, incorpora o efeito de um gerenciamento eficiente relacionado a incertezas econômicas e a presença de flexibilidades nos projetos. Sua aplicação tem se tornado cada vez mais difundida no meio acadêmico, e também no meio corporativo, como forma de incorporar tais características que os métodos tradicionais não são capazes de capturar. Os métodos tradicionais não incorporam as flexibilidades e as incertezas intrínsecas a diferentes variáveis de um projeto de investimento, o que acaba por subavaliá-lo e, muitas vezes, rejeitá-lo do ponto de vista de sua viabilidade econômica.

A análise por opções reais busca incorporar aos métodos tradicionais três características comuns aos projetos de investimento: a irreversibilidade, as flexibilidades gerenciais refletidas na definição do momento de exercício de uma opção e a combinação das incertezas dos projetos. Ressalta-se que a avaliação por opções reais no que tange as incertezas de um projeto é muito influenciada pela escolha adequada dos processos que define as variáveis do problema. Muitas vezes, na operacionalização desta análise, recorre-se a métodos numéricos ou à simulação para a incorporação das diferentes incertezas.

Neste contexto, esta dissertação apresenta o estudo de projetos na área florestal e propõe o uso da Teoria das Opções Reais para sua avaliação. Particularmente na área de projetos florestais, a incerteza pode estar relacionada ao preço de venda da madeira bem como à quantidade de árvores que crescem em uma floresta. O gerenciamento produtivo proposto envolve, neste caso, poder definir o número de árvores sendo cortadas a cada período. Por exemplo, de acordo com a oscilação do preço da madeira, a gerência pode definir a quantidade ótima de madeira a ser cortada a cada período; ou se uma quantidade inesperada de árvores é encontrada, o investidor tem a opção de aumentar a taxa de corte.

Considerando a variação dos preços de madeira, o investidor racional irá maximizar o valor do projeto escolhendo uma política de corte ótima de acordo com o preço corrente de madeira, estoque e tempo. Desta forma, calcula-se o valor de 
mercado do projeto florestal assumindo a taxa de corte ótima a ser adotada pelo investidor. No projeto avaliado nesta dissertação, observa-se que esse valor é maior do que em qualquer outra análise.

Muitos trabalhos que analisam o valor de mercado de recursos naturais aplicando a teoria das opções reais são encontrados na literatura tanto no mercado internacional como no mercado nacional (Pindyck,1984; Brennan and Schwartz, 1985; Morck, Schwartz e Stangeland, 1989; Rocha et al, 2004).

Essa dissertação amplia o modelo aplicado por Morck, Schwartz e Stangeland (1989) a um projeto de investimento florestal que tem a flexibilidade de empregar uma política ótima de corte dependente do preço e o estoque. É proposto um processo alternativo para evolução temporal do estoque baseado na equação logística de crescimento. A metodologia para avaliação do valor do projeto incorporando as características de opções reais segue a mesma abordagem de Rocha et al (2004), determinando o seu valor pelo método de diferenças finitas explícitas.

Como se trata de um trabalho metodológico, o objetivo é calcular o valor de mercado de um projeto florestal, que depende do conjunto de parâmetros escolhidos. Esses parâmetros são selecionados de maneira que possam refletir diferentes perspectivas a respeito da produtividade e da evolução do mercado. Os resultados são a melhor estimação para o valor do projeto condicionado aos parâmetros adotados e, por isso, irão, sobretudo, indicar como se pode avaliar um projeto florestal considerando a otimização da quantidade a ser produzida.

É importante mencionar que o uso de conceitos puramente econômicos na avaliação de recursos naturais é uma análise simplificada. Um estudo mais abrangente sobre os custos e benefícios sociais são requeridos para valorar os benefícios gerados ao meio ambiente, que não são refletidos no valor da floresta (como absorção de carbono, contribuição global, regional e local para a estabilidade climática; a preservação da biodiversidade; manutenção do balanço de água). Essas questões ambientais porém, não são consideradas na análise desse estudo, que se restringe à questão da determinação do valor econômico de um projeto de investimento florestal. Por outro lado, a avaliação puramente por aspectos econômicos tem algumas vantagens: (i) mais fácil entendimento com menor propensão de gerar controvérsias; (ii) não há necessidade de estimar os valores subjetivos relacionados com os benefícios sociais; (iii) resultados que são facilmente compreendidos e aplicados a um cenário real incorporando penalidades impostas por quaisquer efeitos nocivos através 
de impostos ou royalties, gerando receita financeira que visa a sustentabilidade futura de uma concessão florestal ${ }^{1}$.

\section{1.}

Posicionamento acadêmico da dissertação

Esta dissertação insere-se no contexto de pesquisa de análise de investimentos sob condições de incerteza, considerando o arcabouço teórico da teoria das opções reais para a correta modelagem de incertezas e avaliação de flexibilidades gerenciais.

\section{2. \\ Relevância do Estudo}

O propósito deste trabalho é apresentar uma forma em que abordagem de opções reais pode ser usada, estendendo a aplicação feita por Morck, Schwartz e Stangeland (1989). A metodologia apresenta uma solução geral para um problema de controle de produção ótimo para investimentos de recursos renováveis, como para florestas, ou seja, qual a taxa de corte ótimo e qual o valor de um projeto de investimento florestal. Assume-se que o preço da madeira segue o movimento geométrico browniano, como comumente proposto em trabalhos similares; porém, a taxa de crescimento natural da floresta proposta segue a equação de crescimento logístico, sendo uma contribuição deste trabalho à literatura.

O modelo é proposto para cálculo do valor de um projeto florestal incluindo opção de cortar árvores a uma taxa ótima. Como a equação diferencial para o valor da opção de investimento não possui solução analítica, o trabalho propõe a utilização do método de diferenças finitas, que transforma a equação diferencial

${ }^{1}$ O termo concessão florestal está sendo usado de forma mais ampla nesta dissertação. Segundo a definição formal brasileira, para tipo de projeto, seria necessário considerar adicionalmente na aplicação apresentada algumas características próprias da concessão no Brasiltal como a exigência de manutenção da vegetação nativa. Por outro lado, há muitas caracteristicas da aplicação prática apresentada que assemelham com uma concessão, dentre elas o prazo de término e a manutenção de um estoque mínimo. 
parcial e as condições de contorno em equações diferenciais que podem ser resolvidas numericamente. Esse método resolve as equações de diferenças finitas e converge quando se aplicam as condições necessárias para a estabilidade. O método proposto foi aplicado de acordo com a abordagem utilizada por Rocha et al. (2004).

A principal contribuição desta dissertação é assumir um modelo que incorpora o crescimento natural de árvores aplicado na literatura florestal. Uma importante consideração do modelo é o nível máximo de saturação, o que implica numa abordagem mais realista já que os recursos naturais são finitos. De acordo com a pesquisa realizada, a suposição de crescimento logístico empregada ao modelo e ao método de valoração do projeto florestal ainda não foi explorada na literatura.

Este tipo de análise realizada no trabalho pode interessar tanto a empresas do setor florestal quanto a governos na tomada de decisão sobre políticas públicas, seja para precificar melhor as concessões seja para incluir informações socioambientais na análise.

\section{3. Problema investigado}

Nesta dissertação, investiga-se o valor de uma opção de cortar árvores a uma taxa de corte ótima, onde as variáveis independentes são o preço, estoque e tempo. Avalia-se o caso em que o estoque segue a equação de crescimento logístico (estocástico ou não) e uma aplicação simplificada do mesmo modelo, em que a taxa de corte é definida como um valor fixo. O método numérico de solução é detalhado com base no método de diferenças finitas.

Levando em consideração a modelagem proposta e as variáveis do problema, busca-se responder às seguintes questões centrais:

a) Qual o valor justo que o investidor pode estar disposto a pagar por um investimento florestal que considera as flexibilidades gerenciais de poder cortar a diferentes taxas ao longo do tempo?

b) Qual é a política de corte ótima para um projeto florestal? 


\section{4 . \\ Objetivos}

O objetivo geral deste trabalho é demonstrar o valor de uma opção de cortar árvores pela abordagem das opções reais quantificando a flexibilidade gerencial na avaliação de um projeto de investimento e modelando a decisão ótima da taxa de corte de árvores.

Os objetivos específicos são:

a) Mostrar a base de literatura florestal que emprega modelo de crescimento logístico para um estoque de árvores.

b) Apresentar uma revisão bibliográfica detalhada de trabalhos que aplicam a teoria de opções reais na área florestal.

c) Apresentar o ferramental necessário para aplicar a teoria das opções reais em um caso prático, de forma a obter o valor de um povoamento de árvores em um projeto de investimento florestal e a política ótima de corte das árvores;

d) Comparar a decisão ótima de colheita obtida para diferentes modelos de crescimento do estoque e para um caso em que a decisão é apenas cortar ou não a uma taxa fixa.

e) Realizar análises de sensibilidade para diferentes parâmetros do modelo e observar os movimentos ocorridos na taxa de corte e no valor da opção.

\section{5.}

\section{Estrutura da dissertação}

A presente dissertação estrutura-se da seguinte forma.

O Capítulo 2 aborda o investimento florestal e aspectos básicos a produção de madeira no Brasil, como situação atual do setor, cobertura florestal e produtividade. Além disso, apresenta o contexto da indústria de madeira serrada e sua crescente relevância no mercado interno e externo. É apresentada também uma pesquisa na literatura florestal a respeito de modelos de crescimento de árvores.

O Capítulo 3 apresenta o embasamento teórico dos conceitos de opções reais através de um levantamento bibliográfico sobre o estado da arte no assunto sobre assuntos diretamente relacionados aos objetivos da dissertação. 
O Capítulo 4 apresenta o modelo proposto e abrange a descrição das premissas, dos procedimentos metodológicos e dos ferramentais aplicados no desenvolvimento da aplicação feita a um caso prático.

O Capítulo 5 apresenta uma discussão dos resultados mais relevantes, à luz do referencial teórico e das limitações apontadas. Inclui análises de sensibilidade para diferentes parâmetros do modelo propiciando a observação dos movimentos ocorridos na taxa de corte e no valor da opção,.

No Capítulo 6 são apresentadas as conclusões deste trabalho, bem como recomendações para futuras pesquisas nesta temática, considerando a aplicação e os resultados obtidos. As referências bibliográficas são apresentadas no Capítulo 7, seguido do apêndice que apresenta informações básicas a respeito do programa desenvolvido para a aplicação da modelagem do problema. 


\section{2 Investimento Florestal}

\section{1.}

\section{O Setor Florestal Brasileiro}

O setor florestal brasileiro contribui com uma parcela importante para a economia nacional. Além de gerar benefícios em diversos níveis, incluindo produção para consumo interno e para exportação, geração de impostos e de empregos, as empresas neste mercado atuam na conservação e na preservação dos recursos naturais. $\mathrm{O}$ desafio de atender à demanda gera oportunidades em muitos países, sendo o Brasil um país de destaque no mercado internacional de commodities agrícolas e florestais.

A cadeia produtiva do setor brasileiro de florestas plantadas caracteriza-se pela grande diversidade de produtos, compreendendo um conjunto de atividades que incluem desde a produção até a transformação da madeira in natura em celulose, papel, painéis de madeira, pisos laminados, madeira serrada, carvão vegetal e móveis, além dos produtos não madeireiros e da prestação de vários serviços ambientais. A Figura 2.1 ilustra o modelo simplificado da produção florestal, enfatizando seus principais produtos e serviços gerados pelo processamento mecânico.

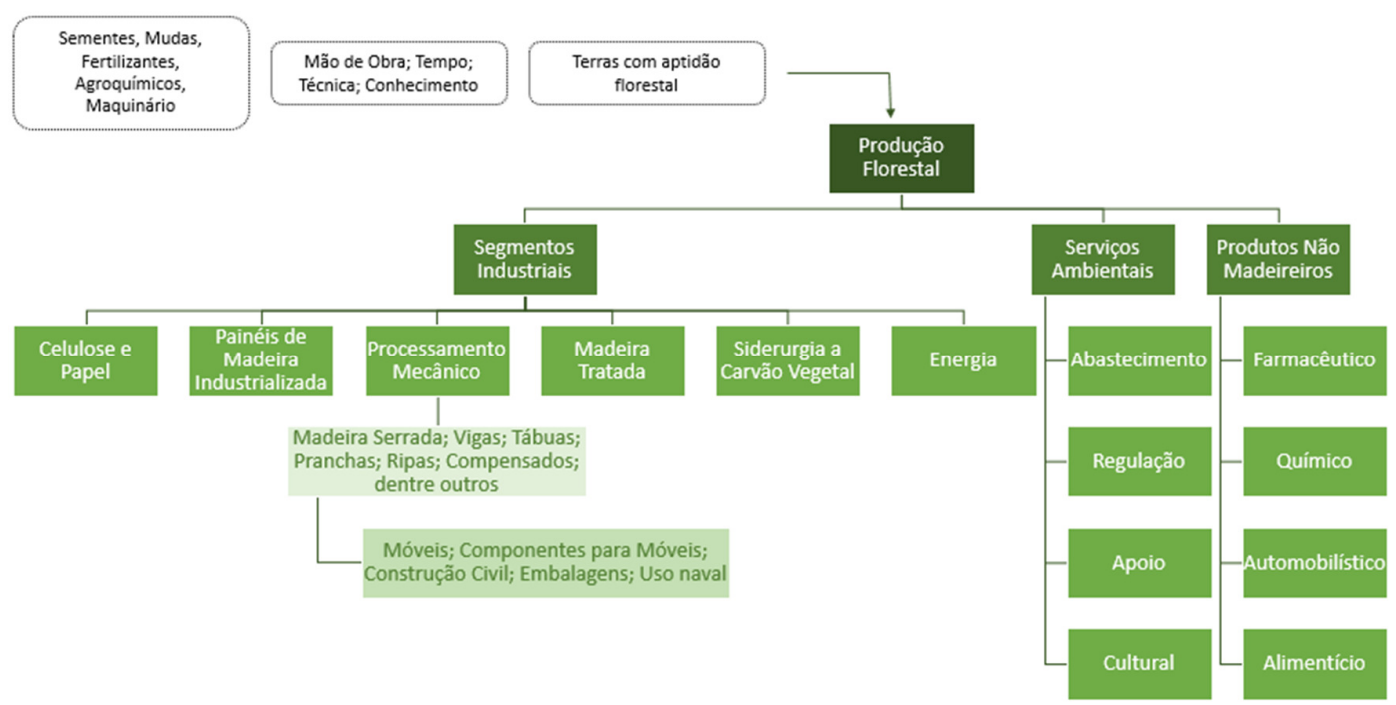

Figura 2.1 - Modelo simplificado da cadeia produtiva do setor florestal.

Fonte: Adaptado de Abraf (2013). 
No Brasil, os produtores florestais estão divididos em três grandes grupos: empresas verticalizadas, produtores independentes e Timber Investment Management Organizations (TIMOs), sendo estes últimos investidores financeiros. As empresas verticalizadas e as TIMOs são consideradas empresas de grande porte, enquanto os produtores independentes, em sua maioria, são classificados como pequenos e médios produtores, conforme mostra a Tabela 2.1 .

Tabela 2.1 - Grupos de produtores florestais

\begin{tabular}{|c|c|c|c|}
\hline Segmentos & $\begin{array}{l}\text { Produtores } \\
\text { Independentes }\end{array}$ & $\begin{array}{c}\text { TIMOs (Timber Investment } \\
\text { Managent Organizations) }\end{array}$ & Empresas Verticalizadas \\
\hline Descrição & $\begin{array}{l}\text { Proprietários de terras } \\
\text { que investem em plantios } \\
\text { florestais como fonte de } \\
\text { renda a partir da } \\
\text { comercialização da } \\
\text { madeira em tora. Podem } \\
\text { estabelecer contratos de } \\
\text { suprimento, sistemas de } \\
\text { parceria operacional ou } \\
\text { atuar independentemente } \\
\text { no mercado. }\end{array}$ & $\begin{array}{l}\text { Empresas de gestão de } \\
\text { investimentos florestais, } \\
\text { vinculadas ou não aos } \\
\text { fundos de pensão } \\
\text { estrangeiros, que adquirem } \\
\text { ativos florestais para atuar } \\
\text { como reflorestadoras } \\
\text { independentes no mercado. } \\
\text { Fazem a intermediação } \\
\text { entre os investidores e os } \\
\text { consumidores de madeira } \\
\text { de florestas plantadas. }\end{array}$ & $\begin{array}{l}\text { Empresas consumidoras de } \\
\text { matéria-prima florestal } \\
\text { própria. Geralmente } \\
\text { possuem equipe própria para } \\
\text { as operações florestais, de } \\
\text { modo a garantir a qualidade } \\
\text { da matéria-prima que será } \\
\text { consumida na fábrica. Os } \\
\text { excedentes de produção } \\
\text { florestal geralmente são } \\
\text { comercializados no mercado. }\end{array}$ \\
\hline
\end{tabular}

Fonte: Adaptado de Abraf (2013)

É importante ressaltar que as TIMOs detêm 10,2\% dos plantios de árvores no Brasil. Hoje, o país já é o segundo principal destino dos investimentos mundiais em ativos florestais, com $29 \%$ do montante total de investimentos na atividade, atrás somente dos Estados Unidos, que concentram 66\% (Ibá, 2015).

\section{2.}

\section{Setor de Madeira Processada Mecanicamente}

O setor de madeira mecanicamente processada é composto pelas indústrias de madeira sólida produtoras de madeira serrada, laminados e compensados, e demais produtos de maior valor agregado - PMVA, tais como portas, janelas, molduras, partes para móveis, entre outros produtos beneficiados.

Um relatório desenvolvido pela Indústria Brasileira de Árvores (Ibá, 2014) mostra que a estrutura produtiva do setor está bastante pulverizada, uma vez que é constituído por um grande número de empresas de pequeno porte com estrutura de 
produção tipicamente familiar. Os principais segmentos consumidores do mercado brasileiro são as indústrias de móveis e da construção civil.

A produção de serrados e compensados é impulsionada pelo consumo interno e externo, em distintas proporções. Os principais fatores que influenciam seu desempenho são a política cambial, o ritmo de crescimento das economias nacional e internacional e a crescente concorrência internacional, principalmente a chinesa.

\subsection{1.}

Madeira Serrada

O segmento industrial de madeira serrada agrupa produtos obtidos por meio do processamento da madeira in natura, como tábuas, pranchas, caibros, sarrafos, viga, ripas e vigotes, ilustradas na Figura 2.2. Normalmente, esses produtos são utilizados na construção civil, no transporte de mercadorias e na produção de móveis de todos os tipos e componentes de decoração.

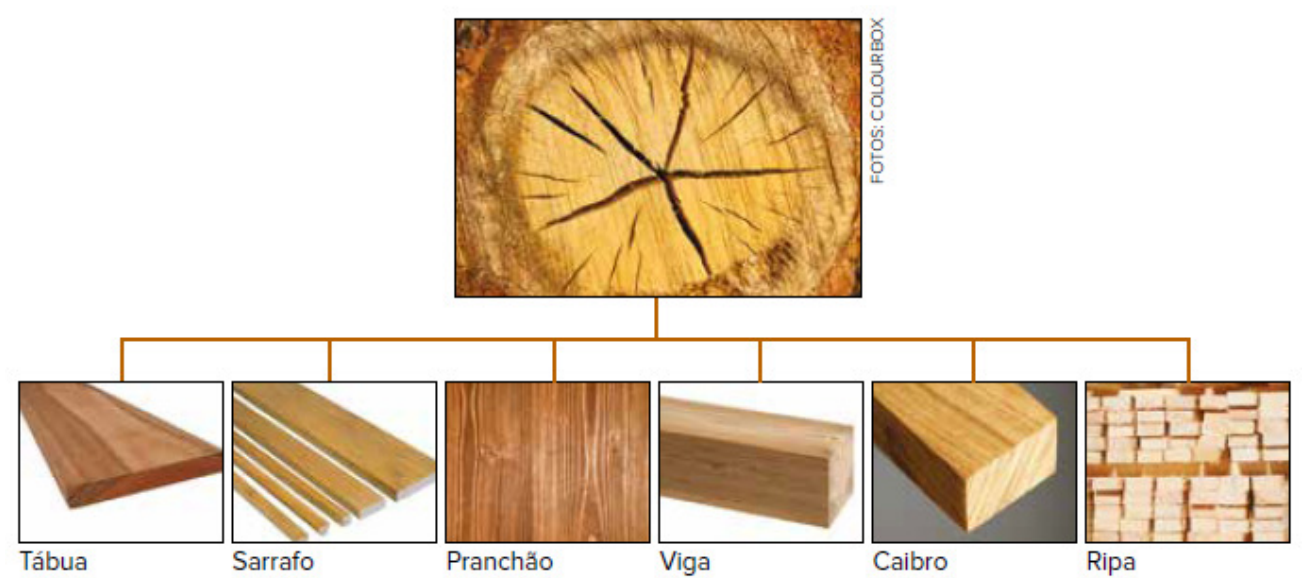

Figura 2.2 - Principais produtos do segmento de madeira serrada

Fonte: Ibá (2014)

No Brasil existem cerca de 1.600 serrarias que processam árvores plantadas, sendo 75\% delas localizadas na Região Sul do País, 17,3\% na Região Sudeste, 4,5\% na Região Centro-Oeste e 2,9\% na Região Nordeste. A demanda global por madeira serrada cresceu $18 \%$ em 2013, em decorrência da melhoria, ainda que modesta, da economia mundial. (Ibá, 2014). Este tipo de produto foi empregado para avaliar um projeto de investimento no Capítulo 5.

Nos últimos anos, o crescimento do consumo de madeira serrada foi influenciado principalmente pelo desenvolvimento do mercado interno, estimulado pelo crescimento da indústria da construção civil e do mercado de embalagens, os quais são fortemente impactados pela política governamental expansionista 
orientada ao crescimento da economia brasileira. A recuperação da economia dos Estados Unidos, o segundo principal país comprador dos produtos florestais brasileiros, contribuiu positivamente para o aumento das exportações de madeira serrada.

\section{3. \\ Cobertura Florestal}

Tendo por base a nomenclatura da Food and Agriculture Organization of the United Nations (FAO, 2010), a Autoridade Florestal Nacional (AFN, 2010), define floresta como a extensão de terreno com área mínima de $5.000 \mathrm{~m}^{2}$ e largura mínima de $20 \mathrm{~m}$, com um grau de cobertura (definido pela razão entre a área da projeção horizontal das copas e a área total da parcela) maior ou igual a 10\%, onde se verifica a presença de arvoredo florestal que, pelas suas características ou forma de exploração, tenha atingido, ou venha a atingir, porte arbóreo (altura superior a 5m). Desse modo, de acordo com Peng (2000), pode-se descrever uma floresta como sistema biológico, dinâmico e de longa duração, que se encontra em constante mudança e cujo crescimento, produção e mortalidade interessa conhecer.

Com área ocupada de apenas 7,74 milhões de hectares, o que corresponde a 0,9\% do território nacional, o setor brasileiro de árvores plantadas é responsável por $91 \%$ de toda a madeira produzida para fins industriais no país - os demais $9 \%$ vêm de florestas nativas legalmente manejadas. A Tabela 2.2 mostra que a área plantada com árvores de eucalipto no Brasil atingiu 5,56 milhões de hectares da área de árvores plantadas do país em 2014, o que representa 71,9\% do total, e estão localizados principalmente nos Estados de Minas Gerais (25,2\%), São Paulo $(17,6 \%)$ e Mato Grosso do Sul (14,5\%). Com um crescimento de 1,6\% em comparação com os 5,43 milhões de hectares registrados em 2013.

Os plantios de árvores de eucalipto representaram 72,0\% do total da área ocupada por árvores e as árvores de pinus, 20,7\%. Acácia, teca, seringueira e paricá estão entre as outras espécies plantadas no Brasil. A Tabela 2.3 revela que em 2014 o percentual de áreas plantadas de eucalipto correspondia a aproximadamente $74 \%$ do total ocupado pelo território nacional. Em todos os estados a área de cultivo de eucalipto é superior à de pinus e demais tipos de árvores. 
Tabela 2.2 - Evolução da área ocupada com árvores de eucalipto, 2006-2014

\begin{tabular}{|c|c|c|c|c|c|c|c|c|}
\hline \multirow{2}{*}{ Estado / State } & \multicolumn{8}{|c|}{ Eucalipto (ha) / Eucalyptus (ha) } \\
\hline & 2007 & 2008 & 2009 & 2010 & 2011 & 2012 & 2013 & 2014 \\
\hline Minas Gerais & 1.218 .212 & 1.278 .210 & 1.300 .000 & 1.400 .000 & 1.401 .787 & 1.438 .971 & 1.404 .429 & 1.400 .232 \\
\hline Säo Paulo & 911.908 & 1.001 .080 & 1.029 .670 & 1.044 .813 & 1.031 .677 & 1.041 .695 & 1.010 .444 & 976.186 \\
\hline Mato Grosso do Sul & 207.687 & 265.250 & 290.890 & 378.195 & 475.528 & 587.310 & 699.128 & 803.699 \\
\hline Bahia & 550.127 & 587.610 & 628.440 & 631.464 & 607.440 & 605.464 & 623.971 & 630.808 \\
\hline Rio Grande do Sul & 222.245 & 277.320 & 271.980 & 273.042 & 280.198 & 284.701 & 316.446 & 309.125 \\
\hline Espirito Santo & 208.819 & 210.410 & 204.570 & 203.885 & 197.512 & 203.349 & 221.559 & 228.781 \\
\hline Paraná & 123.070 & 142.430 & 157.920 & 161.422 & 188.153 & 197.835 & 200.473 & 224.089 \\
\hline Maranhão & 106.802 & 111.120 & 137.360 & 151.403 & 165.717 & 173.324 & 209.249 & 211.334 \\
\hline Mato Grosso & 114.854 & 132.922 & 147.378 & 150.646 & 175.592 & 184.628 & 187.090 & 187.090 \\
\hline Pará & 126.286 & 136.290 & 139.720 & 148.656 & 151.378 & 159.657 & 159.657 & 125.110 \\
\hline Goiás & 102.032 & 113.177 & 115.286 & 116.439 & 118.636 & 115.567 & 121.375 & 124.297 \\
\hline Tocantins & 21.655 & 31.920 & 44.310 & 47.542 & 65.502 & 109.000 & 111.131 & 115.564 \\
\hline Santa Catarina & 74.008 & 77.440 & 100.140 & 102.399 & 104.686 & 106.588 & 107.345 & 112.944 \\
\hline Amapá & 58.874 & 63.310 & 62.880 & 49.369 & 50.099 & 49.506 & 57.169 & 60.025 \\
\hline Piauí & - & - & - & 37.025 & 26.493 & 27.730 & 28.053 & 31.212 \\
\hline Outros / Others & 31.588 & 27.580 & 28.380 & 4.650 & 9.314 & 18.838 & 15.657 & 18.157 \\
\hline Total / Total & 4.078 .168 & 4.456 .069 & 4.658 .924 & 4.900 .949 & 5.049 .714 & 5.304 .164 & 5.473.176 & 5.558 .653 \\
\hline
\end{tabular}

Fonte: Ibá (2014)

Tabela 2.3 - Área de árvores plantadas por estado e espécie, 2014

\begin{tabular}{|c|c|c|c|c|}
\hline \multirow{2}{*}{$\begin{array}{l}\text { Estado } \\
\text { State }\end{array}$} & \multicolumn{4}{|c|}{$\begin{array}{l}\text { Área plantada com árvores (ha) } \\
\text { Area of planted trees (ha) }\end{array}$} \\
\hline & $\begin{array}{l}\text { Eucalipto } \\
\text { Eucalyptus }\end{array}$ & $\begin{array}{l}\text { Pinus } \\
\text { Pine }\end{array}$ & $\begin{array}{l}\text { Outras } \\
\text { Others }\end{array}$ & $\begin{array}{l}\text { Total } \\
\text { Total }\end{array}$ \\
\hline MG & 1.400 .232 & 39.674 & 5.313 & 1.445 .219 \\
\hline SP & 976.186 & 123.996 & 90.147 & 1.190 .329 \\
\hline PR & 224.089 & 673.769 & 16.255 & 914.113 \\
\hline MS & 803.699 & 7.135 & 23.000 & 833.834 \\
\hline BA & 630.808 & 6.499 & 34.000 & 671.307 \\
\hline sc & 112.944 & 541.162 & 6.645 & 660.751 \\
\hline RS & 309.125 & 184.585 & 103.592 & 597.302 \\
\hline MT & 187.090 & - & 113.249 & 300.339 \\
\hline ES & 228.781 & 2.660 & 15.000 & 246.441 \\
\hline MA & 211.334 & - & - & 211.334 \\
\hline PA & 125.110 & - & 72.368 & 197.478 \\
\hline TO & 115.564 & 430 & 45.876 & 161.870 \\
\hline GO & 124.297 & 9.087 & 5.000 & 138.384 \\
\hline AP & 60.025 & - & 1.936 & 61.961 \\
\hline $\mathrm{PI}$ & 31.212 & - & - & 31.212 \\
\hline $\begin{array}{l}\text { Outras } \\
\text { Others }\end{array}$ & 18.157 & - & 56.140 & 74.297 \\
\hline $\begin{array}{l}\text { Total } \\
\text { Total }\end{array}$ & 5.558 .653 & 1.588 .997 & 588.521 & 7.736 .171 \\
\hline
\end{tabular}

Fonte: Ibá (2015) 


\section{4. \\ Eucalipto}

O gênero Eucalyptus é originário da Austrália, Tasmânia e outras ilhas da Oceania. Segundo a Embrapa (2015) são mais de 700 espécies reconhecidas botanicamente. Estas espécies têm propriedades físicas e químicas tão diversas que fazem com que os eucaliptos sejam usados para as mais diversas finalidades como, lenha, estacas, moirões, dormentes, carvão vegetal, celulose e papel, chapas de fibras e de partículas, até movelaria, geração de energia, medicamentos, entre outros.

No Brasil, a cultura de eucalipto teve início nos primeiros anos do século XX, apesar de sua introdução inicial datar do século anterior. No fim da década de 1930, o eucalipto já era plantado em escala comercial, sendo utilizado como dormentes para construção e combustível.

Como mostra a Figura 2.3, grande parte da produção potencial de eucalipto está concentrada na Região Sudeste (54,3\%), em função do significativo número de empresas de Papel e Celulose e Siderurgia a Carvão Vegetal existentes nessa região. Da mesma forma, a maioria da produção potencial de pinus está concentrada próxima às indústrias de painéis, serrados, compensados e produtos de madeira sólida, localizadas na Região Sul $(90,7 \%)$ do país. A produção de teca está dividida entre a Região Norte $(32,6 \%)$ e Centro-Oeste $(67,4 \%)$.

\section{EUCALYPTUS}

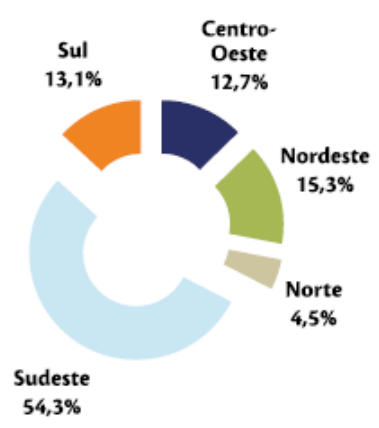

Figura 2.3 - Distribuição da produção potencial madeireira por região do Brasil, 2012

Fonte: Abraf (2013)

A Tabela 2.4 mostra que em 2013, o consumo brasileiro de madeira de árvores plantadas para uso industrial foi de 185,3 milhões de metros cúbicos $\left(\mathrm{m}^{3}\right)$, o que 
representou aumento de 1,8\% em relação ao consumo de 2012. O eucalipto se destaca por sua ampla utilização, seu consumo representa aproximadamente $75 \%$ do total em relação aos demais tipos de madeira.

Tabela 2.4 - Consumo de madeira in natura $\left(\mathrm{m}^{3}\right)$

\begin{tabular}{|c|c|c|c|c|}
\hline \multirow{2}{*}{ SEGMENTO } & \multicolumn{4}{|c|}{ CONSUMO DE MADEIRA IN NATURA $\left(\mathrm{m}^{3}\right)$} \\
\hline & EUCALIPTO & PINUS & OUTRAS & TOTAL \\
\hline CELULOSE E PAPEL & 56.628 .357 & 8.067 .258 & 498.085 & 65.193 .700 \\
\hline PAINÉIS DE MADEIRA & 6.428 .162 & 13.457 .258 & 378.612 & 20.264 .031 \\
\hline $\begin{array}{l}\text { SERRADOS E OUTROS } \\
\text { PRODUTOS SÓLIDOS }\end{array}$ & 6.870 .498 & 15.295 .499 & 357.052 & 22.523 .049 \\
\hline CARVÃO & 23.533 .724 & - & - & 23.533 .724 \\
\hline LENHA INDUSTRIAL & 41.832 .528 & 3.929 .361 & 4.262 .239 & 50.024 .128 \\
\hline MADEIRA TRATADA & 1.824 .012 & - & - & 1.824 .012 \\
\hline $\begin{array}{l}\text { CAVACOS DE MADEIRA } \\
\text { E OUTROS }\end{array}$ & 1.129 .621 & - & 781.200 & 1.910 .821 \\
\hline TOTAL & 138.246 .903 & 40.749 .376 & 6.277 .187 & 185.273 .466 \\
\hline
\end{tabular}

Fonte: Ibá (2014)

Entre as espécies florestais plantadas com fins produtivos, o cultivo do eucalipto é um dos que tem maior disponibilidade de indicações e orientações técnicas. O Eucalipto tem grande importância comercial na economia brasileira. Segundo a Indústria Brasileira de Árvores, são 5,5 milhões de hectares plantados com este gênero, com uma produtividade média de $39 \mathrm{~m} 3 / \mathrm{ha} / \mathrm{ano}$. A produtividade, contudo, depende de diversos fatores, como o local de plantio, os tratos culturais e os insumos disponibilizados.

A elevada produtividade do eucalipto enquanto espécie cultivada é um dos aspectos que o torna atrativo, uma vez que apresenta folhas durante todo o ano e utiliza eficazmente a radiação solar, os nutrientes e a água disponíveis para a produção de biomassa. Este potencial produtivo está altamente correlacionado com a pluviosidade e com as características dos solos (Alves, Pereira, Silva, 2007). Adicionalmente, esta espécie apresenta uma baixa taxa de mortalidade, mas as perdas provocadas pelos fogos e pelas pragas e doenças, que levam à morte das árvores, constituem um sério problema e causam elevados prejuízos. 


\section{5. Produtividade Florestal}

Segundo Gastaldi e Minardi (2012) a produção florestal no Brasil encontrase em expansão, não apenas para atender a demanda por celulose, mas também para usos em siderurgia, como fonte de carbono de alta qualidade nos processos de redução do minério de ferro. Paralelamente, a demanda por energia é crescente e requer que seja produzida minimizando os impactos ambientais, o que reforça o potencial gerador de energia através de biomassa renovável em detrimento a fontes como petróleo, coque e nuclear.

O Brasil, apesar de deter uma pequena parte da área de plantios de árvores do mundo, contribui anualmente com $17 \%$ de toda a madeira colhida, em decorrência da alta produtividade dos plantios de árvores no país. A China, os Estados Unidos e a Índia possuem a maior parte da área de plantios de árvores do mundo, porém, a produtividade florestal desses países é baixa. O sucesso global da indústria brasileira de base florestal é resultado da alta produtividade das árvores plantadas no país.

Historicamente, as empresas brasileiras do setor priorizam a manutenção de investimentos em pesquisas e desenvolvimento, buscando primordialmente a melhoria da genética dos plantios e das técnicas de manejo florestal. A Figura 2.4 revela o melhor exemplo do sucesso dessa estratégia, o impressionante desenvolvimento da produtividade do eucalipto no Brasil $-5,7 \%$ ao ano no período de 1970 a 2008 - comparativamente aos 2,6\% da América latina, 0,9\% dos países desenvolvidos e 1,9\% para o conjunto de países em desenvolvimento. 


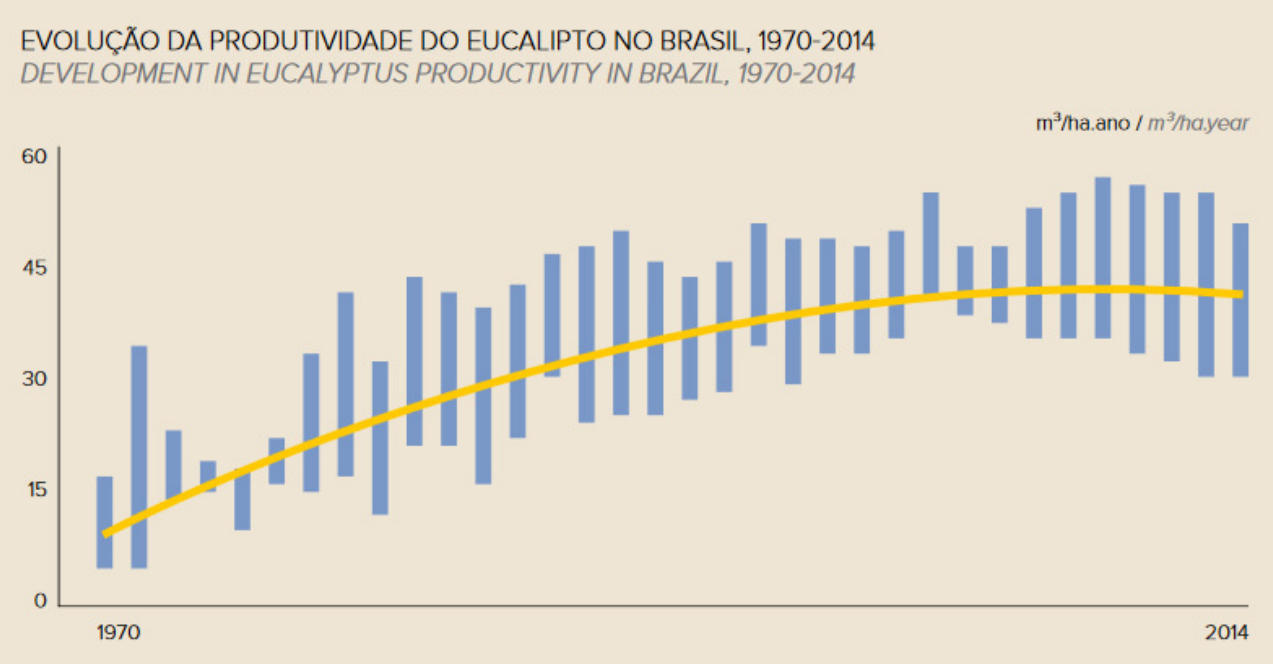

Figura 2.4 - Evolução da produtividade do eucalipto no estado de São Paulo, Brasil.

Fonte: Ibá (2015)

A Figura 2.5 mostra que em 2014, o Brasil manteve mais uma vez sua liderança no ranking global de produtividade florestal. A produtividade média dos plantios brasileiros de eucalipto atingiu $39 \mathrm{~m}$ /ha. ano e a produtividade dos plantios de pinus foi de $31 \mathrm{~m}$ 3/ha.ano. Em decorrência da natural redução dos ganhos incrementais de programas de melhoramento clássico ao longo do tempo, a produtividade do eucalipto no Brasil cresceu por volta de $0,3 \%$ ao ano, entre 2008 e 2014.

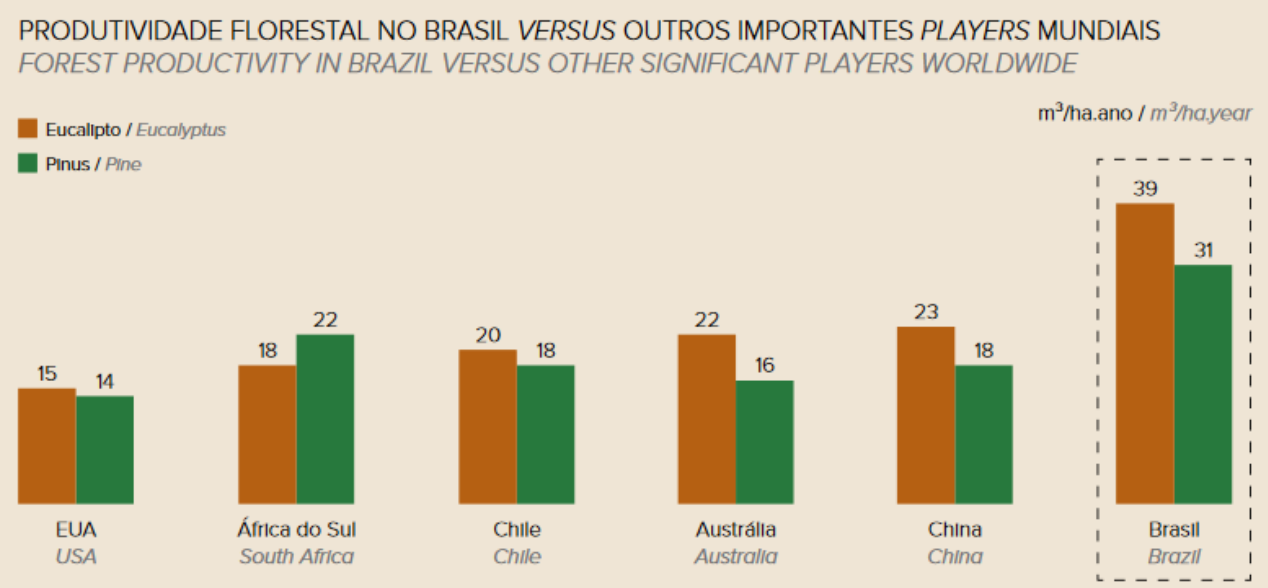
países

Figura 2.5 - Produtividade florestal no Brasil em comparação com outros

Fonte: Ibá (2015)

As árvores plantadas são vistas, cada vez mais, como fonte importante de pesquisa. O uso múltiplo dos plantios de árvores nos próximos anos levará o setor 
a uma nova realidade, na qual a base florestal será fundamental para atender demandas relacionadas ao crescimento populacional mundial. Um bom indicador nesse sentido é o fato de que as árvores já são fontes de mais de cinco mil produtos do dia-a-dia, como móveis, ferramentas, produtos médicos, cosméticos, produtos de limpeza, entre outros itens, sem contar sua aplicação na produção de biocombustíveis, o que torna a base plantada uma alternativa verde como fonte de energia.

Além das condições de solo e clima, outro fator que propiciou o desenvolvimento do setor de árvores plantadas no Brasil foi o grande investimento em tecnologia por parte das empresas e instituições de pesquisa. Em poucas décadas, a pesquisa nacional transformou o país no mais produtivo polo de produção florestal do planeta.

Um significativo avanço que garantiu o aumento da produtividade das árvores plantadas e o ganho de competitividade da indústria foi a adoção do melhoramento genético. O objetivo foi selecionar as árvores com as melhores características florestais e industriais, entre elas, vigor, forma, resistência a doenças e pragas, qualidade da madeira e rendimento industrial. Mas os desafios ainda são muitos e as demandas populacionais cada vez maiores. Os plantios de árvores são uma parte crucial desse futuro, mas, para continuarem a fornecer os bens e serviços do momento atual e do futuro é necessário que se desenvolvam tecnologias cada vez mais avançadas e inovadoras para aumentar a produtividade florestal.

\section{6.}

\section{Modelagem de crescimento de uma floresta}

O crescimento pode ser definido como uma mudança de magnitude de qualquer característica mensurável, como diâmetro, altura, volume, peso, biomassa etc. O crescimento de árvores pode ser entendido como o somatório da divisão, alongamento e engrossamento de suas células. As leis do crescimento biológico exigem uma quantidade variada de atenção crítica e perdem em precisão e significância à medida que o período de tempo sobre o qual elas são aplicadas diminui. 
Encinas, Silva e Pinto (2005) destacam que na vida da árvore se distinguem as diversas performances do crescimento em diâmetro, altura, área basal e volume. Isto se consegue por meio do estudo dos anéis de crescimento em espécies da zona temperada; porém, considera-se, em termos gerais, que todas as árvores seguem a mesma tendência. Nos trópicos, os estudos de crescimento ainda são limitados, muitas vezes porque as árvores nem sempre apresentam anéis de crescimento visíveis e contínuos. Neste caso, tanto para as florestas plantadas como para as florestas nativas, o crescimento das árvores e da floresta como um todo é obtido por meio de medições e remedições em parcelas permanentes.

Os parâmetros de medição do crescimento em diâmetro, altura, área basal e volume de uma árvore, apresentam comportamento semelhantes ao longo do tempo. A Figura 2.9 mostra em forma gráfica como se parece uma curva sigmoidal, em que a primeira fase corresponde a idade juvenil, a segunda a idade madura e a terceira a idade senil (velha). Cada fase mantém um ritmo de crescimento característico da vida total da árvore e juntos eles formam a curva de crescimento.

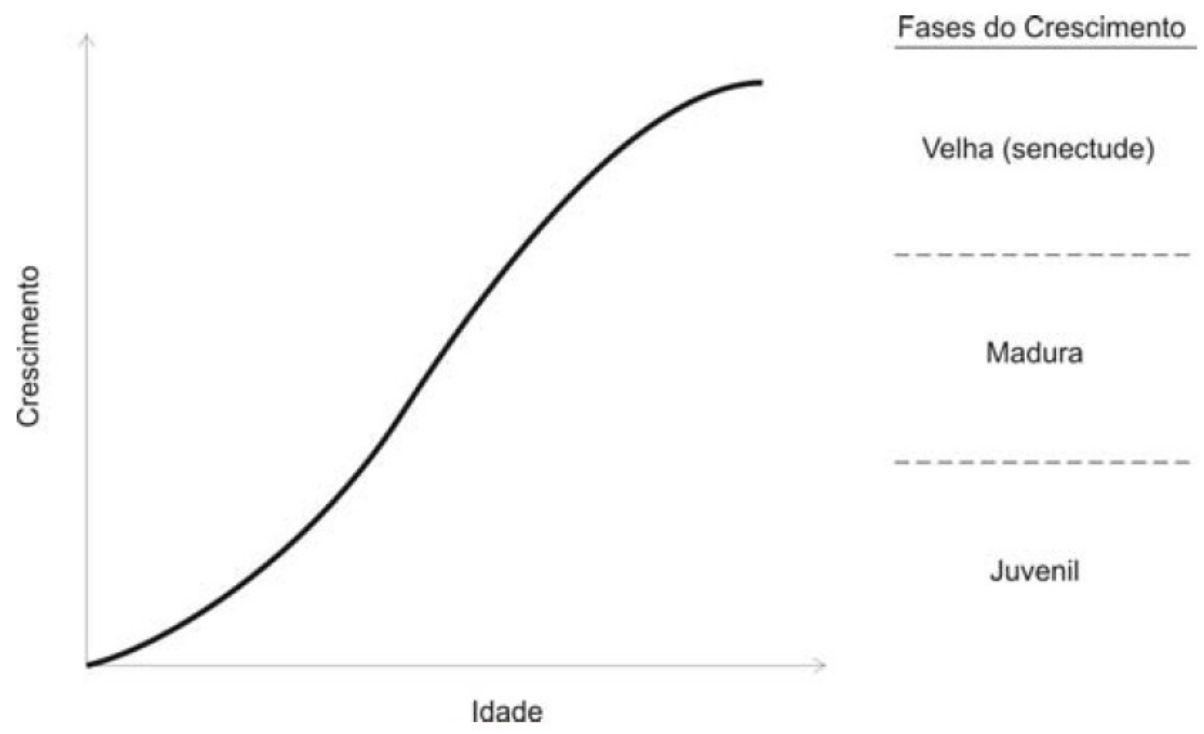

Figura 2.6 - Forma típica da curva de crescimento de uma árvore Fonte: Encinas, Silva e Pinto (2005)

Os autores ainda ressaltam que o crescimento das árvores pode apresentar diferentes variações nas suas dimensões em altura, diâmetro, volume, área basal e peso, em função de diversos fatores que nem sempre podem ser controlados ou monitorados, como os fatores genéticos das espécies e suas interações com o ambiente. Outras fontes de influência direta no crescimento são os fatores climáticos (temperatura, precipitação, vento, insolação etc.), pedológicos 
(características físicas, químicas e biológicas dos solos), topográficos (inclinação, altitude e exposição), biológicos (pragas e doenças) e pela própria competição com outras árvores e outros tipos de vegetação. Outros fatores que também se relacionam são aquelas derivadas de ações antrópicas (desbastes, incêndios etc.).

\subsection{1.}

\section{Crescimento logístico}

Na natureza sabe-se que há fatores que limitam o crescimento populacional. Peroni e Hernández (2011), afirmam que as populações não crescem exponencialmente, salvo raras exceções, tais como um intervalo de tempo em que se acompanha o crescimento populacional de bactérias em laboratório. Isso quer dizer que o tamanho (ou densidade) populacional aumenta até alcançar um limite máximo, relativamente estável, que é conhecido como capacidade de carga, ou capacidade suporte. Esse comportamento pode ser descrito pela equação conhecida como equação de crescimento logístico, representada pela Figura 2.10, na qual o limite máximo é dado pelo fator $\mathrm{K}$.

Quando a população segue esse tipo de comportamento, seu crescimento diminui quando o número de indivíduos tende a zero, assim como quando o número de indivíduos tende à capacidade suporte.

O conceito de capacidade suporte vem da Ecologia de Populações e é definido como a densidade populacional que representa um equilíbrio estável. Ela denota o tamanho de uma população que os recursos do ambiente são capazes de manter, sem a tendência de aumentar ou diminuir, como mostrado na Figura 2.10.

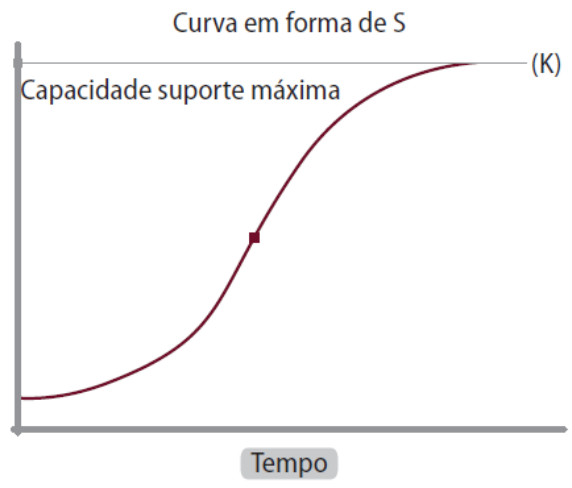

Figura 2.7 - Curva de Crescimento Logístico

Fonte: Peroni e Hernández (2011) 
A Figura 2.11 ilustra esse tipo de comportamento, considerando a parte sombreada que representa a área dentro da qual recaem as formas de crescimento da maioria das populações. Esses modelos são aplicados tanto em trabalhos da área florestal como também em outras áreas que utilizam o crescimento de uma população. Autores que empregam esses modelos de crescimento para o estoque de uma população são citados no capítulo 3 e será feita uma aplicação do comportamento logístico no capítulo 5.

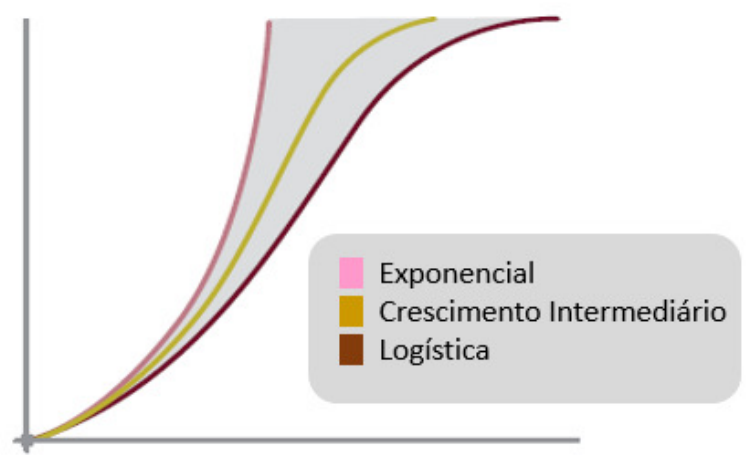

Figura 2.8 - Curva de crescimento exponencial e logístico

Fonte: Adaptado de Peroni e Hernández (2011)

O autor Goes (2012) em sua dissertação faz uma avaliação a respeito de diversos tipos de modelos de crescimento para uma floresta de eucalipto utilizado na produção de papel. O objetivo de seu trabalho é conhecer e caracterizar, numa base anual, a floresta nacional de eucalipto e saber quais as perspectivas da sua evolução no curto e no médio prazo. O autor ainda afirma que para poder simular a evolução dos povoamentos nacionais de eucalipto, abrangendo o maior número possível de situações diferentes, é necessário desenvolver um modelo de crescimento de árvore individual que seja independente da distância, empírico, determinístico e independente da idade. Esta informação, além de fornecer o retrato atual da floresta de eucalipto, permite estimar a disponibilidade futura desta matéria-prima ao se aplicar o modelo de crescimento apropriado.

Tradicionalmente, o propósito habitual de um inventário florestal é a determinação, da forma mais precisa possível, do volume das árvores de uma determinada área de acordo com o tempo e o dinheiro disponíveis (Avery e Burkhart, 2002). Porém, a definição de critérios e indicadores para aferir a qualidade da gestão florestal que é praticada alargou os objetivos do inventário florestal. Atualmente, o cálculo do volume florestal é definido como o conjunto de procedimentos que permite estimar os bens provenientes das áreas florestais de uma 
região, fornecendo dados para estimar a potencialidade produtiva destas áreas e verificar o cumprimento dos princípios de gestão florestal sustentável (Tomé et al., 2005).

Assim, segundo Goes (2012), para prever o possível impacto de várias alternativas de gestão, interessa também simular o comportamento futuro da floresta, de maneira a tomar decisões bem fundamentadas. Com esta finalidade, tenta-se prever o crescimento e produção das florestas, para descrever as alterações na dimensão de um povoamento.

Segundo o autor, o crescimento da generalidade dos organismos vivos segue uma curva sigmoidal, que se caracteriza por uma fase inicial relativamente rápida, do tipo exponencial, convexa, seguida de uma fase retilínea, o que implica que a iguais períodos de tempo correspondem iguais acréscimos da variável, e termina com um período de senescência, caracterizado por um crescimento cada vez mais insignificante, do ponto de vista relativo, apresentando a curva côncava e atingindo, no final, a maior dimensão de forma assintótica.

Segundo Tomé (2011), a seleção de funções para a modelagem do crescimento e produção de árvores e povoamentos, genericamente designadas por funções de crescimento, é uma fase essencial na elaboração de modelos de produção. Os modelos matemáticos para a modelagem do crescimento biológico podem ser lineares ou não lineares. Os primeiros são menos flexíveis e requerem um maior número de parâmetros para descrever os dados, o que poderá originar valores irrealistas, fora do intervalo dos dados de ajustamento, ao passo que os segundos são, geralmente, mais flexíveis, podendo ter bases biológicas e fornecer estimativas razoáveis para lá do intervalo dos dados de ajustamento (Cieszewski e Bella, 1989).

A maneira mais simples é assumir que o crescimento é linear para o período considerado, mas esta assunção é demasiado simplista uma vez que, à medida que o tempo passa, tanto as variáveis do povoamento (altura, densidade e outras) como as da árvore (diâmetro e altura) alteram-se e, como resultado, o crescimento varia anualmente (Cao e Strub, 2008). Segundo Vanclay (1994), os modelos de crescimento auxiliam os investigadores e gestores florestais de diversas maneiras, incluindo a possibilidade de previsão de produções futuras e de exploração de várias opções silvícolas. 
Um modelo de crescimento deverá ser previsto para demonstrar a dinâmica florestal de um povoamento ao longo do tempo sob diversas alternativas de gestão ou sujeito a agentes físicos e bióticos distintos, devendo ter um papel importante na gestão e ordenamento florestal e também, a uma escala mais abrangente, na definição de políticas florestais. Deste modo, os modelos de crescimento devem ser abstrações da realidade. Todos os modelos e os seus componentes têm de ser biologicamente realistas e as estimativas dos seus parâmetros devem estar de acordo com o conhecimento atual dos processos de crescimento, devendo refletir as semelhanças e diferenças nas condições ecológicas dentro da região de interesse (Soares et al., 1995).

Soares et al. (1995) ressaltam que os gestores da produção florestal, quando confrontados com a necessidade de selecionarem um modelo para uma determinada aplicação, devem levar em conta que nenhum é totalmente correto, mas que, face aos objetivos que se pretendem atingir, um pode ser mais útil ou conveniente do que outros. Isto significa que a validade de um modelo não pode estar separada dos objetivos para os quais foi construído, nem dos objetivos dos potenciais utilizadores (Soares et al., 1995).

Segundo Vanclay (1994), a adequada modelagem depende dos dados, meios e conhecimentos disponíveis e o modelo resultante deve ser objetivo, imparcial, bem documentado e disponível.

Segundo Goes (2012) propõe que modelos de crescimento podem ser classificados de acordo com as variáveis que utilizam para simular o processo de crescimento. Uma vez que um inventário florestal recolhe dados de cada árvore presente na unidade de amostragem, o processo de simulação pode incidir sobre (1) o comportamento de cada árvore, ou (2) sobre o comportamento do povoamento, depois de apurados os valores de todas as árvores e extrapolados para uma unidade de área, geralmente, o hectare. Os primeiros são os modelos de árvore e os segundos os modelos de povoamento.

\subsection{2. Modelos de crescimento determinísticos versus modelos estocásticos}

Independentemente do detalhe com que se tenta reproduzir a realidade, um modelo pode ser determinístico ou estocástico. Um modelo determinístico fornece 
uma estimativa do crescimento esperado de um povoamento e, para as mesmas condições iniciais, fornece sempre o mesmo resultado, não comportando nenhuma componente aleatória. De forma contrária, um modelo estocástico incorpora incerteza, tentando simular a variação natural que ocorre no mundo real, fornecendo diferentes predições, associadas a uma probabilidade de ocorrência, para as mesmas condições iniciais. Neste caso, uma estimativa isolada é de pouca utilidade, mas um conjunto de simulações para as mesmas condições iniciais fornece informação, não só sobre o crescimento médio do povoamento, para determinadas condições iniciais, mas também sobre a sua variabilidade.

Os modelos determinísticos e estocásticos são, assim, complementares e a sua utilização em conjunto pode revelar-se útil para a gestão florestal (Vanclay, 1994). De fato, existem modelos estocásticos que incluem efeitos fixos, que contabilizam as relações entre as variáveis dependentes e independentes da população, e efeitos aleatórios, que contabilizam a variação associada à unidade de amostragem. A utilização destes modelos permite que sejam calibrados para diferentes localizações ou períodos de crescimento pela predição de componentes aleatórios a partir de informação do novo povoamento (Lhotka e Loewenstein, 2010). 


\section{3 \\ Teoria das Opções Reais}

A análise de investimentos é um dos tópicos mais importantes no estudo de Finanças. Ao investir em um projeto de ativos reais, os investidores querem saber o quanto realmente vale tal projeto. Dessa forma são tomadas as decisões de investimento a partir da análise econômico-financeira.

A abordagem tradicional por fluxo de caixa descontado usa a metodologia do Valor Presente Líquido (VPL). Primeiramente, calcula-se o valor presente dos fluxos de caixa líquidos esperados ao longo da vida útil do projeto. Em seguida, a decisão de investir é tomada: caso o VPL seja estritamente positivo o investimento será feito; caso seja estritamente negativo, não será feito; e se for igual a zero ele será indiferente entre investir ou não no projeto.

Entretanto, há questões gerenciais que fazem essa metodologia ser considerada uma alternativa limitada para se tomar decisões. A seguir são citadas algumas desvantagens do método VPL:

- fluxo de rendimentos futuros deve ser previsto até um futuro distante e por isso, segue um padrão rígido;

- usa apenas o valor esperado, não explicita as incertezas;

- não considera as flexibilidades das ações gerenciais;

- não considera as mudanças de cenário e o que os gestores e investidores podem fazer caso aconteça algum evento imprevisto;

- assume-se que o risco do projeto será o mesmo ao longo da vida do projeto;

- os tomadores de decisão assumirão o compromisso de seguir uma estratégia operacional estática, não importando os desvios de cenário que possam ocorrer.

A abordagem de opções reais quantifica o valor da flexibilidade gerencial. Como afirma Trigeorgis (1996), essa flexibilidade gerencial pode ser vista como um conjunto de opções sobre ativos reais que agregam valor ao projeto. $\mathrm{O}$ gerente de projeto, que tem o direito de realizar um investimento e com isso receber em troca o fluxo de caixa de um projeto, é visto como detentor de uma opção que lhe dará o direito de exercê-la no momento em que lhe for mais conveniente. 
Assim como nas opções financeiras, essa flexibilidade gerencial aumenta o valor da oportunidade de investimento em um projeto, impactando seu potencial de ganho, bem como limita as perdas relativamente às expectativas iniciais de um gerenciamento passivo.

\section{1.}

Classificação das Opções Reais

Existem diversos tipos de opções reais operacionais, alguns que ocorrem naturalmente nos investimentos (opções de adiar, contrair, fechar e abandonar o investimento) e outros que podem ser planejados e empreendidos a um custo adicional (opções de expansão e troca). A figura abaixo explicita a classificação feita por Dias (2015) dos tipos de opções reais. O autor divide os tipos inicialmente em três grandes classes, na fase de investimento, na fase operacional e na fase de aprendizagem antes de investir. Uma breve descrição de cada subclasse é feita a seguir.

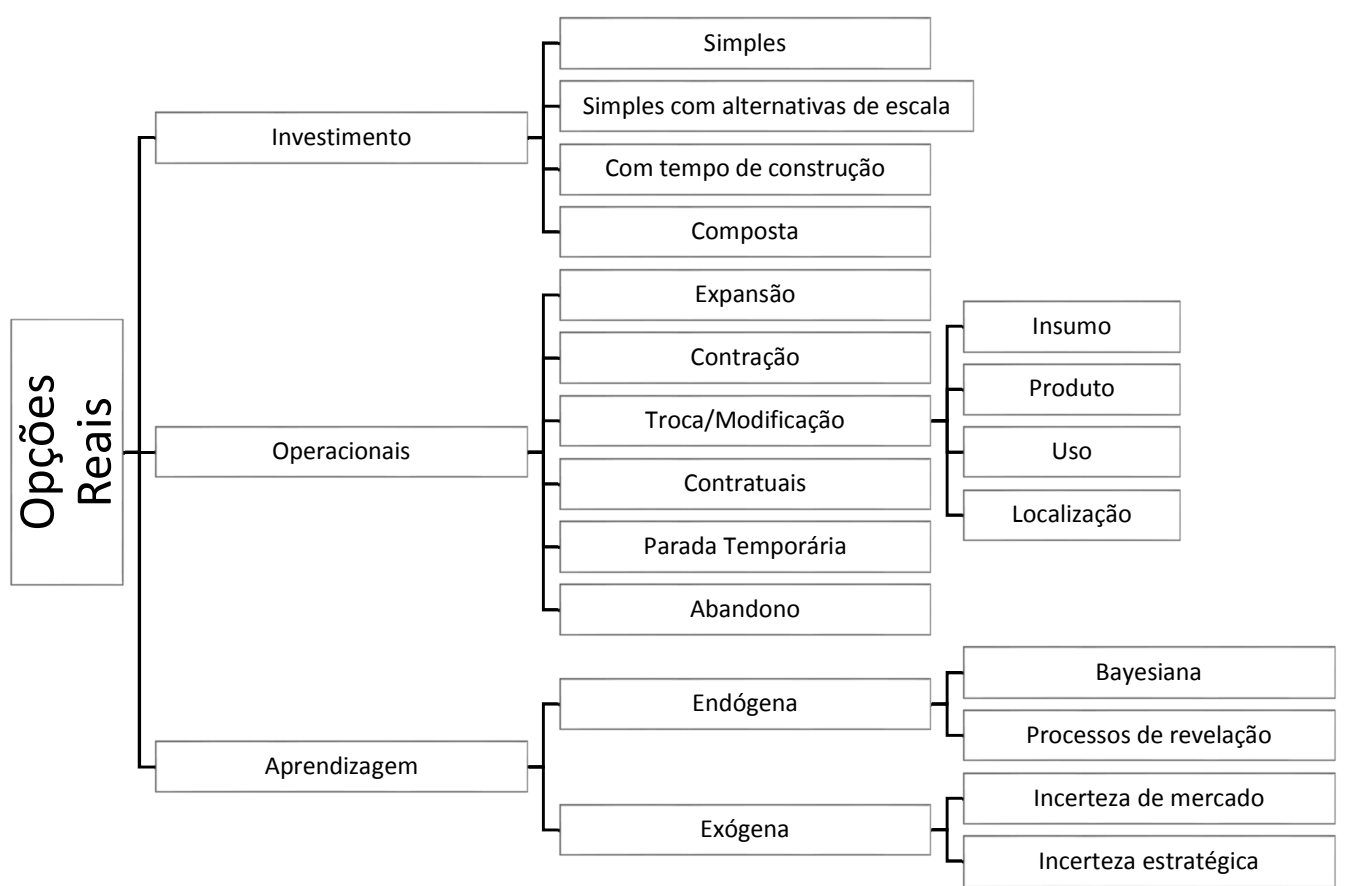

Figura 3.1 - Classificação dos tipos de opções reais

Fonte: Adaptado de Dias (2015)

Para as opções reais de investimento há quatro subgrupos: simples, com alternativa de escala, com tempo de construção e composta, A opção de espera 
significa aguardar melhores condições de mercado. Ela pode ser uma opção de espera simples ou composta que é a opção de espera simples interagindo com outras opções reais.

Para a opção de espera simples, calcula-se o valor de aguardar por novas informações ou condições de mercado mais favoráveis antes de fazer algum investimento. Essa opção em geral surge naturalmente na maioria dos projetos, ou seja, não há custo para manter esse tipo de opção.

Muitas vezes, projetos analisados com base em um determinado fluxo de caixa esperado e uma taxa de desconto possuem VPL negativo. Porém, com o passar do tempo, as incertezas resolvem-se e os fluxos de caixa podem assumir valores diferentes daqueles previstos inicialmente, assim como a taxa de desconto apropriada pode mudar. Desta forma, projetos que não são economicamente viáveis inicialmente podem passar a sê-lo após certo tempo. Projetos cujo investimento possa ser adiado possuem um valor adicional: o valor da opção de adiar o investimento. Uma opção que dê aos gerentes de projeto o direito de adiá-lo por um período para então tomarem sua decisão com base no VPL, se suficientemente positivo, possui as características de uma opção de compra.

Uma opção de espera com escala supõe que uma alternativa de maior VPL hoje pode ter VPL menor do que outra se mudar os preços de mercado e, por isso, há que se considerar a espera na escolha da escala ótima sob incerteza. Também pode ser uma opção de espera com tempo de construção, ou seja, projetos que levam muito tempo para serem construídos em que a opção de interromper temporariamente os investimentos durante a construção pode ser relevante.

Para as opções reais classificadas como operacionais há seis subgrupos: expansão, contração, troca, contratuais, parada temporária e abandono.

As opções de parada temporária e de abandono consideram o caso de um investimento se tornar desvantajoso e não lucrativo. A administração não é obrigada a seguir o planejamento definido previamente caso o cenário se torne desfavorável. A qualquer momento pode-se parar ou abandonar o projeto. Uma das falhas da metodologia tradicional de avaliar investimentos através do VPL estático é devida à suposição de que os fluxos de caixa futuros serão suficientes para garantir a continuidade do projeto ao longo de sua vida útil. Esta premissa revela-se pouco realista. Podem ocorrer situações ou conjunturas de mercado que tornem o projeto deficitário, fazendo com que as receitas não sejam suficientes para cobrir os custos. 
Nesses casos, a gerência pode optar por suspender temporariamente a produção por um certo tempo até que a conjuntura de mercado melhore e a receita seja suficiente para cobrir os custos variáveis de produção. A operação do projeto pode então ser vista como uma opção de comprar suas receitas, pagando para isso os custos variáveis de operação.

Em alguns casos, a gerência tem a alternativa, se a conjuntura de mercado se mostrar desfavorável e o projeto ainda não tiver chegado ao fim de sua vida útil, de abandoná-lo por um determinado valor ou em detrimento de um uso alternativo. $\mathrm{O}$ uso alternativo a ser feito abrange tanto o que será produzido como o insumo usado na produção. Assim, a opção de abandono ou troca de uso comporta-se como uma opção de venda (put), cujo preço de exercício é o valor de revenda do projeto ou seu valor no melhor uso alternativo existente.

Os principais tipos de opções de troca são: troca de insumo, em que o input para a produção de um produto final pode ser trocado dependendo da disponibilidade e do preço do insumo; troca de uso, que é baseada na múltipla aplicabilidade de um ativo ou capacidade de um ativo; troca de produto, em que o produto final pode ser modificado a partir de um mesmo insumo.

A opção de expansão ou de crescimento calcula o valor da flexibilidade de alterar a produção de um projeto levando em conta o seu aspecto estratégico. Uma vez iniciado um projeto, os gerentes podem ter flexibilidade para alterá-lo de diversas formas no decorrer de sua vida útil. Podem, por exemplo, investir em instalações com capacidade maior do que a necessária para ter a possibilidade de aumentar a produção no futuro caso isso se torne necessário. Ou, ainda, alterar a quantidade fabricada de algum produto para atender a demanda e aumentar o lucro.

As opções reais de aprendizagem geralmente ocorrem antes de se fazer investimentos maiores para desenvolver plenamente um novo negócio. Essas opções permitem reduzir a incerteza técnica ou conhecer melhor um negócio antes de se propor um grande investimento para desenvolver em escala industrial esse negócio. Existe o caso em que a aprendizagem endógena, ou seja, a aprendizagem é interna, e é necessário investir em informação para aprender. E aprendizagem exógena, onde se espera por novas informações externas. 


\section{2. \\ Métodos de Avaliação de Ativos}

Quando métodos analíticos não são possíveis ou não são conhecidos, é necessário recorrer aos métodos numéricos usados para se avaliar ativos. Dentre os mais populares em opções financeiras e em opções reais podemos citar o método binomial, o método de Monte Carlo e o método das diferenças finitas (MDF), sendo este último o utilizado no cálculo da opção proposta nesta dissertação

\subsection{1.}

\section{Solução numérica com diferenças finitas}

Quando não há solução analítica ou aproximação analítica é necessário recorrer aos métodos numéricos. Segundo Dias (2015), depois do método binomial e do método de Monte Carlo, o método das diferenças finitas (MDF) é o método numérico mais popular em opções financeiras e em opções reais. Diferenças finitas permite resolver numericamente as equações (e inequações) diferenciais através de equações de diferenças que aproximam as derivadas parciais.

Pode ser usado tanto para equações diferenciais parabólicas, como para equações diferenciais elípticas e hiperbólicas. Ela trabalha bem tanto os casos de saltos (Poisson) como os casos de derivativos com dependência de caminho e com barreiras complexas (Tavella, 2002).

Mitchell e Griffiths (1980) afirmam que a aproximação de derivadas por diferenças finitas é um dos métodos mais simples para resolver equações diferenciais. Resultados teóricos têm sido obtidos durante as últimas cinco décadas a respeito da acurácia, estabilidade e convergência do método de diferenças finitas para equações diferenciais parciais.

O método de diferenças finitas transforma a equação diferencial parcial e suas respectivas condições de contorno em equações diferenciais que podem ser resolvidas numericamente. A respeito dos problemas de fronteira livre definidos por problema de controle estocástico, a forma explícita e a malha de discretização podem facilmente resolver o algoritmo da otimização usado para os casos de tempo de parada ótima, como o estilo de backward induction de programação estocástica dinâmica.

No caso de apreçamento de opções, enquanto o método binomial aproxima o processo estocástico do ativo básico, o MDF aproxima a equação diferencial do 
derivativo. Ambos os métodos sofrem da "maldição da dimensionalidade", já que o tempo computacional cresce exponencialmente com a quantidade de ativos subjacentes (Back, 2005).

No MDF as equações diferenciais são discretizadas com equações de diferenças que geralmente são aproximações. A equação diferencial parcial (EDP) é convertida em um conjunto de equações de diferenças e as mesmas podem ser resolvidas iterativamente. Sendo aproximações, elas geram erros numéricos e podem causar outros problemas numéricos. A EDP do valor do derivativo dado pela função $F(P, t)$, onde $P$ segue um processo estocástico do ativo contingente e $t$ representa o tempo, pode ser discretizada diretamente em $P$ e $t$, ou, ainda, pode ser feita uma transformação funcional como a logarítmica, usada em Brennan e Schwartz (1978), com o objetivo de facilitar a convergência.

Existem algumas versões do MDF. As principais são diferenças finitas explícitas, diferenças finitas implícitas e o método de Crank-Nicholson. Segundo Dias (2015), o MDF explícitas é mais fácil de implementar, menos intensivo numericamente e mais intuitivo que o MDF implícitas; porém, ao contrário deste último, pode apresentar problemas de convergência numérica. No entanto, pode ser aplicada uma condição para evitar esse problema que será explicada ao longo da próxima seção.

O método implícito é mais intensivo numericamente porque no processo backwards de cálculo não se tem uma representação explícita da opção na data $t$ em função de valores conhecidos na data $t+d t$ (como no método explícito), e sim uma representação implícita em termos de sistema de equações com valores desconhecidos em $t$ em função de valores conhecidos em $t+d t$. Assim, a cada passo tempo, é preciso resolver um sistema de equações. Logo, o método implícito é bem mais lento se usar intervalos de tempo pequenos.

Kerr (2008) ressalta que a implementação do método de Crank-Nicholson é semelhante ao método de diferenças finitas totalmente implícitas. A vantagem do método de Crank-Nicholson é que é convergência é mais rápida do que nos outros casos. Wilmott (2000) afirma que, assim como no método implícito, no MDF de Crank-Nicholson não há limitações na malha para o tamanho do intervalo de tempo $\Delta \mathrm{t}$, de modo que se pode utilizar intervalos de tempo maiores e ainda assim obter soluções acuradas. Porém Dias (2015) complementa que apesar de ser superior numericamente quando comparado aos demais métodos, o método de Crank- 
Nicholson é mais difícil de implementar e programar e pode apresentar problemas numéricos em alguns casos.

Em todos os tipos de MDF, são usadas equações de diferenças para aproximar as derivadas. Essas equações de diferenças são deduzidas a partir da expansão de Taylor. Para maior clareza dos conceitos, será desenvolvido o caso de uma função com apenas uma variável estocástica. Seja a função $f(x)$ pelo menos duas vezes diferenciável e seja $h=d x$ um intervalo pequeno de $x$. Em torno de $x(x+h$ e $x-h)$ as expansões de Taylor, truncadas na segunda derivada de $f(x)$, são dadas por

$$
\begin{aligned}
& f(x+h) \cong f(x)+h f^{\prime}(x)+\frac{h^{2}}{2 !} f^{\prime \prime}(x) \\
& f(x-h) \cong f(x)-h f^{\prime}(x)+\frac{h^{2}}{2 !} f^{\prime \prime}(x)
\end{aligned}
$$

O valor da derivada $f^{\prime}(x)$ da equação 3.1 pode ser escrito da seguinte forma, dado pela equação de diferenças para frente (“forward”) de primeira ordem (ou de ordem h)

$f^{\prime}(x) \cong \frac{f(x+h)-f(x)}{h}-\frac{h}{2} f^{\prime \prime}(x)$

onde $\frac{h}{2} f^{\prime \prime}(x)$ são termos desprezíveis com erro de ordem $h$ (erro proporcional a $h$ ). Analogamente, valor da derivada $f^{\prime}(x)$ da equação 3.2 se obtém a partir da equação de diferenças para trás (backward) de primeira ordem (ou de ordem $h$ )

$f^{\prime}(x) \cong \frac{f(x)-f(x-h)}{h}+\frac{h}{2} f^{\prime \prime}(x)$

Se considerar mais um termo na expansão de Taylor, as equações 3.1 e 3.2 podem ser escritas como

$$
\begin{aligned}
& f(x+h) \cong f(x)+h f^{\prime}(x)+\frac{h^{2}}{2 !} f^{\prime \prime}(x)+\frac{h^{3}}{3 !} f^{\prime \prime \prime}(x) \\
& f(x-h) \cong f(x)-h f^{\prime}(x)+\frac{h^{2}}{2 !} f^{\prime \prime}(x)-\frac{h^{3}}{3 !} f^{\prime \prime \prime}(x)
\end{aligned}
$$


Subtraindo a equação 3.5 da equação 3.6, obtém-se a equação de diferenças centrais para a primeira derivada, agora com aproximação de segunda ordem (mais precisa do que a de primeira ordem)

$f^{\prime}(x) \cong \frac{f(x+h)-f(x-h)}{2 h}-O\left(h^{2}\right)$

onde $O\left(h^{2}\right)$ significa que os demais temos da expressão são desprezíveis.

No caso da EDP típica para $F(P, t)$, representando o valor de um derivativo escrito sobre o preço de um ativo estocástico subjacente, como no caso da EDP de Black \& Scholes, pode-se usar essas diferenças tanto para a variável $P$ (ativo básico) como para o tempo. Para melhor entendimento do método esta EDP será utilizada, como exemplo, em uma aplicação para o método de diferenças finitas explícitas na próxima seção.

A diferença central é matematicamente mais precisa por ter erro de ordem $h^{2}$ que, para valores pequenos de $h$, é menor do que os erros de ordem $h$ das outras diferenças. Entretanto, no caso da variável tempo, raramente se usa essa diferença central devido a problemas numéricos de instabilidade.

É necessário também aproximar a segunda derivada da opção. Para tal, considere mais um termo ( $4^{\mathrm{a}}$ derivada) na expansão de Taylor da função $f(x)$ de uma variável apresentada anteriormente.

$$
\begin{aligned}
& f(x+h) \cong f(x)+h f^{\prime}(x)+\frac{h^{2}}{2 !} f^{\prime \prime}(x)+\frac{h^{3}}{3 !} f^{\prime \prime \prime}(x)+\frac{h^{4}}{4 !} f^{\prime \prime \prime \prime}(x) \\
& f(x-h) \cong f(x)-h f^{\prime}(x)+\frac{h^{2}}{2 !} f^{\prime \prime}(x)-\frac{h^{3}}{3 !} f^{\prime \prime \prime}(x)+\frac{h^{4}}{4 !} f^{\prime \prime \prime \prime}(x)
\end{aligned}
$$

Somando as equações anteriores e simplificando, obtém-se a equação de diferenças centrais da segunda derivada, com aproximação de segunda ordem:

$f^{\prime \prime}(x) \cong \frac{f(x+h)-2 f(x)+f(x-h)}{h^{2}}+O\left(h^{2}\right)$ 


\subsection{2.}

\section{Método de diferenças finitas explícitas aplicado a Opções Reais}

Os métodos de diferença finita avaliam um derivativo através da resolução da equação diferencial satisfeita pelo derivativo. A equação diferencial é convertida num conjunto de equações de diferença que são resolvidas iterativamente.

Por meio da EDP clássica de Black-Scholes-Merton $F(P, t)$ mostrada na equação (3.11), pode-se ilustrar como o método de diferenças finitas deve ser aplicado. Dessa forma, a partir deste caso pode-se estender para aplicações mais complexas, como para maior número de variáveis.

$\frac{1}{2} \sigma^{2} P^{2} \frac{\partial^{2} F}{\partial P^{2}}+(r-\delta) P \frac{\partial F}{\partial P}+\frac{\partial F}{\partial t}=r F$

O primeiro passo é o estabelecimento do grid (malha) uniforme em que se discretiza o tempo (do instante atual em $t=0$ até a expiração em $t=T$ ) e o espaço da variável estocástica $P$ (de 0 até um $P_{\text {máx }}$ ). A Figura 3.2 ilustra esse grid de discretização onde cada cruzamento das linhas horizontais da malha e vertical é chamado "nó", sendo que o valor da opção $F(P, t)$ será calculado em cada nó do grid.

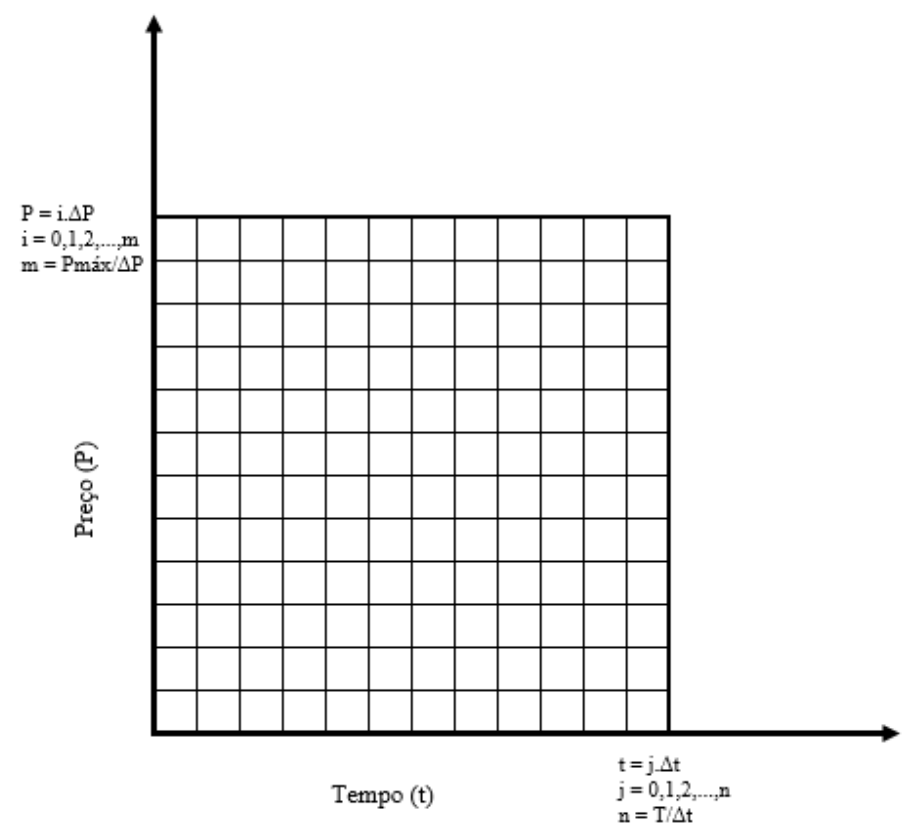

Figura 3.2 - Grid P x t: Discretização do Método das Diferenças Finitas explícitas

Fonte: Elaboração própria. 
Assim, é escolhida uma quantidade de instantes, igualmente espaçados entre o tempo atual, zero, e o vencimento da opção T. O tempo é dividido em $n$ passostempo, $\operatorname{com} n=T / d t$, e o valor do ativo básico é dividido em $m$ passos-espaço, com $m=P_{\text {máx }} / d P$. Em cada nó do $\operatorname{grid}(P, t)=(\mathrm{i} . d P, \mathrm{j} . d t)$ se calcula o valor da opção e é verificado se é ótimo o exercício imediato ou a espera. Quanto maior $m$ e $n$, mais fino é o grid e menor é o erro de discretização. Uma desvantagem do MDF explícitas, a ser vista, é que ele é estável somente se a quantidade de passos-tempo aumenta com o quadrado da quantidade de passos-espaço da variável estocástica (devido à diferença na ordem dos erros). Isso o torna mais lento quando se deseja uma precisão maior na variável estocástica.

Além de discretizar a EDP é necessário colocar condições de contorno no grid. Nesse caso é simples, pois a condição de contorno no tempo se dá na expiração, em $t=T: F(P, T)=0$. Além disso, se coloca a condição trivial em que $F=O$ nos pontos inferiores do grid em que $P=O$. A prática do MDF requer que se estabeleça um valor máximo para $P$ porque não é possível se trabalhar com infinito para $P$ no $g r i d)$, denotado por $P_{\text {máx }}$.

A Figura 3.3 ilustra essas condições de contorno no grid, assim como o objetivo que é calcular o valor da opção para todo $P$ e $t$ do grid, resultando numa matriz de valor da opção $F(P, t)$.

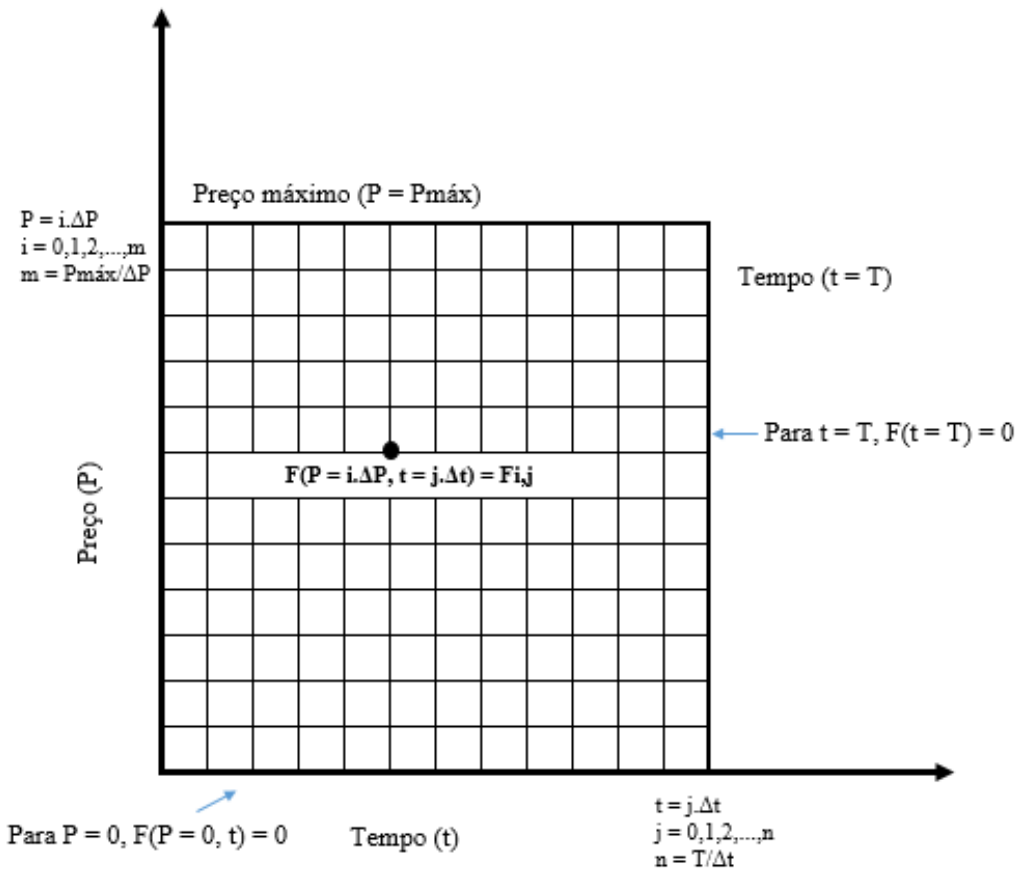

Figura 3.3 - Grid das Diferenças Finitas

Fonte: Adaptado de Dias (2015). 
O valor da opção é obtido a partir da data de expiração, a partir de um processo backwards até a data inicial, de forma que são utilizados os valores no instante $j+1$ para calcular a opção na data $j$.

No método explícito, usa-se a equação de diferenças para frente (forward) no caso da variável tempo. Já para a variável $P$ será usada a mais precisa equação de diferenças central (central difference), assim como para a segunda derivada da opção em relação a $P$.

Assume-se que $F(P, t)$ no ponto $(P, t)$ seja representado por $F_{i, k}$, onde $P=$ $i . d P$ e $i \in(0, m)$ e $t=j . d t$ e $\mathrm{j} \in(0, n)$; e que as seguintes aproximações de derivadas parciais são dadas por

$\frac{\partial F}{\partial t} \cong \frac{F_{i, j+1}-F_{i, j}}{\Delta t}$

$\frac{\partial F}{\partial P} \cong \frac{F_{i+1, j+1}-F_{i-1, j+1}}{2 \Delta P}$

$\frac{\partial^{2} F}{\partial P^{2}} \cong \frac{F_{i+1, j+1}-2 F_{i, j+1}+F_{i-1, j+1}}{\Delta P^{2}}$

onde as derivadas em relação a $P$ são tomadas no instante $j+1$. Substituindo essas aproximações nas equações de diferenças na EDP de Black \& Scholes encontrada anteriormente, obtém-se $F_{i, j}$ em função de $F_{i^{*}, j+1}$, (onde $i^{*}=i, i-1, i+1$ ) dada pela seguinte equação:

$F_{i, j}=\frac{1}{r+\frac{1}{\Delta t}}\left[p_{i}^{+} F_{i+1, j+1}+p_{i}^{-} F_{i-1, j+1}+p^{0} F_{i, j+1}\right]$

onde os valores $p_{i}, p_{j}$ e $p^{0}$ são os pesos atribuídos a cada equação diferencial. Eles dependem do estado $P$ (pois são função de $i$ e $j$ ) e são dados pelas seguintes equações:

$$
\begin{aligned}
& p_{i}^{+}=\frac{\sigma_{P}^{2} i^{2}+(r-\delta) i}{2} \\
& p_{i}^{-}=\frac{\sigma_{P}^{2} i^{2}-(r-\delta) i}{2} \\
& p^{0}=\frac{1}{\Delta t}-\sigma_{P}^{2} i^{2}
\end{aligned}
$$


Segundo Hull (1997) O método de diferenças finitas explícitas é bem semelhante à abordagem da árvore trinomial. Podemos interpretar os termos $p_{i}{ }^{+}, p_{i}{ }^{-}$ ,$p^{0}$ da seguinte forma:

$p_{i}{ }^{+}$: probabilidade do preço da opção aumentar de $i \Delta P$ para $(i+1) \Delta P$ no instante $\Delta t$

$p_{i}{ }^{-}$: probabilidade do preço da opção recuar de $i \Delta P$ para $(i-1) \Delta P$ no instante $\Delta t$

$p^{0}$ : probabilidade do preço da opção permanecer inalterado em $i \Delta P$ no instante $\Delta t$

Os pesos fornecem o aumento esperado para o preço da opção no instante $\Delta t$. Note-se que $p_{i}^{+}, p_{i}^{-}, p^{0}$ somam $1 \mathrm{e}$, por isso, muitas vezes, eles são interpretados como probabilidades, já que, segundo Dias (2015), o critério usual de convergência para o MDF explícitas requer que esses pesos sejam não-negativos.

Logo, o valor desconhecido $F_{i, j}$ é uma função explícita dos valores de $F$ conhecidos na data $j+1$. No instante $j, F_{i, j}$ é o valor presente da média ponderada dos valores da opção em $j+1$.

Para os valores das bordas superiores e inferiores das variáveis $P$ e $t\left(P_{\text {máx }}, P\right.$ $=0$ e $t=T$ ), o valor da opção não é dado pela equação de $F_{i, j}$, e sim pelas condições de contorno.

Para implementar o MDF explícitas, deve-se escolher a discretização de $\Delta P$ e $\Delta t$ para dar um balanço adequado de precisão versus tempo computacional, de forma que não ocorram problemas numéricos e o processo convirja ao valor correto. Deve-se analisar a consistência para se certificar de que o MDF é uma aproximação do problema original. Ao tornar o grid mais fino, as equações de diferenças devem convergir para a verdadeira EDP. Além disso, deve-se garantir a condição de convergência. Com isso, a solução obtida pelas equações de diferenças tem que convergir para a equação real quando $\Delta P$ e $\Delta t$ tendem a zero. Outra condição a ser vista é a estabilidade, pois pode ocorrer instabilidade se os erros de arredondamento do computador forem sendo amplificados a cada passo no grid.

De acordo com Dias (2015), embora atraente pela simplicidade, a desvantagem é que este método possui restrições quanto à estabilidade e, consequentemente, quanto à convergência. É considerado apenas condicionalmente estável, devido à dificuldade de se controlarem os tamanhos do intervalo de tempo e de preço na malha de discretização; por isso, deve-se garantir estabilidade e convergência por meio de uma condição que contorne esse problema 
O MDF explícitas pode apresentar erros de discretização e erros de arredondamento caso não sejam consideradas algumas condições. O primeiro depende de quão fino é o grid usado (quanto menor o $d P$ e $d t$ usados, menor é esse erro), enquanto que o erro de arredondamento é advindo de cada cálculo feito pelo computador (número de casas decimais das contas) que podem se propagar nas iterações. Quanto mais fino é o grid, mais cálculos são feitos no computador. Por isso deve-se assegurar que esses erros se mantêm pequenos e limitados, para que o esquema usado no MDF seja considerado estável.

Para este método a condição crítica para garantir a estabilidade de convergência do problema é assegurar que o peso $\mathrm{p}^{0}$ da equação (3.18) seja não negativo. Dessa forma, chega-se numa relação entre o passo tempo e os demais passos-espaço para que a equação convirja para o resultado correto. Portanto aplicase a condição crítica relativa ao $\mathrm{p}^{0}$, no caso da EDP de Black \& Scholes mencionada anteriormente. Como o maior i é $P_{\max } d d P$ o valor de $\Delta t$ é dado pela equação (3.19).

$\Delta t=\frac{\Delta P^{2}}{\sigma_{P}^{2} P_{\max }^{2}}$

Essa é a condição crítica, pois quando se quer uma boa precisão no valor da opção usando um $d P$ pequeno, se tem o preço de ter de usar um intervalo de tempo $d t$ muito pequeno, o que pode gerar um tempo computacional alto. As outras restrições de pesos não-negativos, em $p_{i}$ e $p_{j}$, na prática são menos restritivas. Elas geram restrições em $d P$, mas só é restritivo para valores da volatilidade muito perto de zero.

\section{3.}

Opções Reais no mercado de recursos renováveis

A avaliação de projetos de recursos renováveis em diversos setores faz uso da Teoria de Opções Reais, tendo em vista características de incerteza e flexibilidade dos projetos. No estudo de investimentos florestais, alguns artigos são referência para pesquisa desta dissertação. Nestes projetos, a incerteza é comumente modelada sobre o preço do produto a ser vendido e sobre o estoque do recurso - no caso a quantidade de árvores. 
Um dos primeiros artigos da área de opções reais no mercado de recursos renováveis foi Pindyck (1984). O autor examina as implicações de incerteza no estoque de um recurso hipotético, ou seja, como a volatilidade desta variável afeta o valor de um ativo e mostra que um aumento na variância das flutuações do estoque reduz a taxa esperada de crescimento do estoque. Um dos resultados apresentados revela que o nível de regulamentação deve depender da medida e velocidade da autocorreção no sistema, ou seja, do recurso biológico e das características da demanda do mercado. Se a recuperação natural do recurso estocado após uma queda acentuada for rápida, e se a demanda for suficientemente elástica para que a taxa de extração caia quando o estoque é menor, menos regulamentação será necessária. A função do estoque utilizada como um processo geral de Itô é a equação (3.20).

$d x=(f(x)-q(t)) d t+\sigma(x) d z$

onde $x$ representa o estoque, $f(x)$ processo de crescimento do estoque, $q(t)$ é a taxa de corte instantanea e $d z$ é o processo de Wiener. Sendo a volatilidade proporcional ao estoque, ou seja, $\sigma(x)=\sigma x$.

$\mathrm{O}$ autor desenvolve soluções para três exemplos de modelos de crescimento do estoque, ilustrando os efeitos da incerteza no aluguel do recurso e na taxa de extração. Ao analisar as aplicações, o autor afirma que a flutuação estocástica afeta a taxa de extração de maneira indeterminada porque a flutuação estocástica aumenta a escassez do recurso, o que reduz a taxa de extração. Em segundo lugar, o aumento contínuo do custo cria um incentivo para os proprietários aumentarem a taxa de extração com o intuito de diminuir o aumento do custo marginal. $\mathrm{O}$ autor aplica uma função logística de crescimento do estoque mostrada na equação 3.21. Um dos resultados relevantes de serem mencionados é que, para este caso, a taxa de extração ou de corte é reduzida. $\mathrm{O}$ autor apresenta duas razões para este resultado: o aumento da volatilidade aumenta a escassez do produto e reduz a taxa de crescimento esperada.

$$
f(x)=r x\left(1-\frac{x}{K}\right)
$$


Brennan e Schwartz (1985) apresentam um modelo para avaliação de uma mina de cobre, cujo preço segue um Movimento Geométrico Browniano (MGB), levando em consideração o controle gerencial sobre a taxa de produção. Além disso, a possibilidade de o projeto ser temporária ou permanentemente abandonado é também considerada. A variação do risco e da taxa de desconto, devido tanto ao esgotamento dos recursos quanto à variação estocástica no preço, são levados em consideração na determinação do modelo de avaliação. No caso do setor florestal, Morck, Schwartz e Stangeland (1989) fazem uma avaliação de recursos florestais em uma concessão ${ }^{2}$ florestal na qual o preço da madeira segue um MGB e o estoque possui uma tendência que varia em função da taxa de crescimento e da taxa de corte.

Um dos objetivos é determinar uma política de produção ótima, $q^{*}(P, I, t)$, maximizando o valor da companhia. Deste modo, determina-se a taxa de corte das toras em função do preço, do estoque atual de madeira e do tempo restante para o término da concessão. As seguintes premissas são adotadas: (i) os parâmetros dos processos estocásticos não mudam com o tempo; (ii) as variações no estoque são descorrelacionadas com o mercado, de modo que o fator de prêmio de risco é zero, (iii) a taxa de conveniência é proporcional ao preço da madeira; (iv) o desvio padrão da taxa de retorno do preço é constante, mas a volatilidade e a tendência do estoque são proporcionais ao nível de estoque; (v) a concessão é pequena em relação à indústria de madeira de tal forma que mudanças no estoque de árvores não afetam o preço de mercado da madeira; e (vi) a função de custo é dada por uma equação quadrática.

Como o custo é quadrático, a função para a política de produção ótima apresenta um ponto máximo na quantidade a ser produzida. Esse ponto ótimo é calculado impondo-se as seguintes restrições: (i) a produção deve ser não negativa; e (ii) poderá ser suspensa e posteriormente reaberta sem custo adicional. Os autores calculam o valor de uma floresta no Canadá e é conduzida uma análise de sensibilidade em relação a algumas variáveis do problema. As equações 3.22, 3.23

\footnotetext{
${ }^{2}$ Segundo o Serviço Florestal Brasileiro - SFB, concessão florestal é o direito que o governo concede - mediante licitação - para uma empresa ou comunidade manejar uma determinada área pública, usando produtos e serviços florestais de forma sustentável e respeitando o Plano de Manejo Florestal - PMF, aprovado pelo governo. A vigência do contrato é por tempo determinado de 40 anos. Portanto, a empresa ou comunidade que se habilite a concessão é obrigada a fazer a devolução da unidade de manejo ao Estado nas condições previstas no contrato assinado entre as partes.
} 
e 3.24 mostram como são calculados o fluxo de caixa após os impostos, a função de custo e a política de produção ótima, respectivamente.

$f(t)=\left(1-\tau_{C}\right)\left[\left(1-\tau_{R}\right) P q(P, I, t)-A(q, t)\right]-\lambda V(P, I, t)(3.22)$

onde $\tau_{C}:$ taxa de imposto corporativa

$\tau_{R}$ : taxa de imposto sobre a venda de madeira

$A(q, t):$ custos de operação da quantidade de corte $\mathrm{q}$

$\lambda$ : taxa de imposto da propriedade, proporcional ao valor da companhia

$V(P, I, t)$ : valor da concessão florestal

A função $A(q, t)$ é dada por

$A(q, t)=\left\{\begin{array}{r}a_{0}+a_{1} q+\frac{a_{2} \times q^{2}}{2}, \text { se } f(t)>0 \\ 0, \text { se } f(t) \leq 0\end{array}\right.$

onde $a_{0}$ é o custo fixo, $a_{1}$ é o custo variável, $a_{2}$ é o termo quadrático que reflete o aumento do custo marginal. Deste modo, a função de custo reflete a suposição que a produção pode ser parada ou reaberta sem custo. Segundo o autor, ela é escolhida apenas pela sua simplicidade algébrica. A política de produção ótima é dada pela condição de primeira ordem, ou seja, a derivada da EDP em relação à taxa de corte igualada a zero, respeitando a condição de que a taxa de corte é não negativa e que a produção pode parar e reabrir sem custos adicionais.

$q^{*}(P, I, t)=\left\{\begin{array}{r}\max \left[0, \frac{-V_{I}}{\left(1-\tau_{c}\right) a_{2}}+\frac{\left(1-\tau_{R}\right) P-a_{1}}{a_{2}}\right], \\ 0, \text { se } f(t)>0 \\ 0(t) \leq 0\end{array}\right.$

Para uma floresta concedida por um período fixo de tempo, o valor da floresta e a taxa de corte ótima são função do preço, do estoque de árvores e do tempo restante para a maturidade. Dentre os resultados obtidos, destaca-se que, ao se aproximar o término da concessão, a taxa de corte ótima decresce conforme o estoque diminui. Quanto maior a taxa de crescimento do estoque, menor será a taxa 
de corte, de modo que o corte será realizado por mais períodos até o término do estoque. Por outro lado, quanto maior o preço inicial, maior é o incentivo para cortar mais cedo. Finalmente, quanto maior a volatilidade do preço, maior será o valor da opção da floresta, de forma que é melhor adiar o exercício de cortar para obter um lucro maior.

Com o objetivo de estender a pesquisa de Morck, Schwartz e Stangeland (1989), Levi (1996) apresenta uma aplicação de opções reais a projetos de exploração de uma floresta de eucalipto visando à produção de celulose. As dinâmicas de crescimento dos preços e do estoque são as mesmas do estudo de referência, mas a função de custo é suposta linear na quantidade, ao invés da função de custo quadrática original. Segundo o autor, uma vez que a tal função é linear, o problema de controle ótimo estocástico terá uma solução do tipo "produzir a máxima capacidade ou não produzir", o que simplifica a solução numérica do problema. Além disso, outra diferença é que o autor considera vários tipos de custos ao longo do período de concessão. Utilizando simulação de Monte Carlo, o valor da concessão é calculado e as análises de sensibilidade realizadas.

Levi (1996) considera o processo químico-industrial para a fabricação de celulose, que determina o tempo ótimo de corte em função da relação entre fibra e lignina. Neste modelo, as variáveis que mais influenciam a decisão de investir num projeto de exploração de eucalipto são o custo de transporte, a taxa de desconto e a volatilidade na dinâmica dos preços.

Sob outra perspectiva, Conrad (1997) utiliza a abordagem de valor da opção para analisar a decisão de preservar uma floresta centenária em um parque nacional dos Estados Unidos. O autor considera o volume de madeira e seu valor comercial como sendo conhecidos e constantes, enquanto os valores futuros dos benefícios (ou amenidades) da manutenção do parque, como visitação e habitat para a fauna local são incertos e seguem um MGB. Considerando o fluxo de amenidades como sendo proporcional ao fluxo de visitação do parque, o autor calcula os parâmetros de tendência e volatilidade do MGB. Com isso, são derivadas soluções analíticas para o valor da amenidade que justifica a preservação da floresta em detrimento da sua derrubada para comercialização. Os resultados mostram que valor o lucro com visitação deve exceder \$5,008 milhões por ano para justificar a preservação.

Forsyth (2000) aplica o mesmo conceito de Conrad para avaliar uma área selvagem. Em ambos os artigos a abordagem valor da opção é usada para 
determinar se deve ou não colher uma floresta ou preservá-la para uso recreativo. A preservação gera um fluxo anual para os usuários; presume-se que estes benefícios aumentam proporcionalmente com o número de visitantes, e que este segue um processo estocástico conhecido. Diferentemente do trabalho de Conrad (1997), o processo estocástico da amenidade - A, utilizado por Forsyth (2000) segue um processo logístico conforme a seguinte equação

$d A=r A\left(1-\frac{A}{A^{\text {máx }}}\right) d t+A \sigma d z$

Nesse processo, a tendência depende de quão próximo A está do nível de saturação máximo de $\mathrm{A}$ ( $\left.\mathrm{A}^{\text {máx }}\right)$. $\mathrm{O}$ valor esperado de $\mathrm{A}$ cresce pela taxa de $\mathrm{r}$ para um valor pequeno de $\mathrm{A}$, e posteriormente o crescimento é reduzido gradualmente até chegar a zero à medida que $\mathrm{A}$ se aproxima do limite superior. O valor da opção mostrou-se sensível em relação à volatilidade de maneiras diferentes para os dois autores. O resultado de Forsyth (2000), que usa a função de crescimento logístico, revela que o valor de amenidade crítica diminuiu à medida que a volatilidade aumenta. Segundo a autora o impacto da volatilidade depende do sinal da segunda derivada do valor da opção com relação ao valor de amenidade. No caso de Conrad (1997), o resultado é inverso ao descrito, conforme a volatilidade aumenta maior é o valor de preservação.

Moreira et al (2000) avaliam o valor de uma concessão florestal no Brasil, que depende de incertezas na estimação do volume de madeira comercial na área de concessão, bem como do preço futuro da tora, além de restrições legais impostas à concessão, como técnicas de manejo sustentado, limite mínimo preservado de estoque de madeira por hectare e taxa máxima de extração. Os autores propõem uma metodologia para valorar concessões florestais baseada na Teoria das Opções Reais. Combinando hipóteses a respeito de incertezas relativas a volume e preço da madeira na concessão com um modelo de maximização estocástica intertemporal de receitas, a distribuição do volume é especificada como função de características geográficas da área (solo, vegetação, clima, distância do mar, altitude etc.) e de sua respectiva vizinhança. Os resultados mostram que o valor da concessão obtido pela técnica tradicional de valoração, usando o valor presente líquido (VPL), é o menor do que o resultado pela aplicação da TOR; o valor da concessão não é proporcional 
aos preços e estoques correntes, sendo mais sensível à incerteza dos preços do que à dos estoques. Assim, a primeira deve ser medida com mais cuidado. Além disso, o valor da concessão decresce ao supor desconhecimento do nível inicial de estoque, de forma que quanto maior a incerteza em relação à quantidade inicial de madeira na região, menor o valor obtido para a concessão.

Rocha et al. (2004) aplicam o modelo similar ao de Morck, Schwartz e Stangeland (1989) a uma concessão na Amazônia. Dois processos estocásticos são propostos para o preço: MGB e Movimento de Reversão à Média (MRM). O resultado do teste estatístico de raiz unitária de Dickey-Fuller não rejeita a hipótese do MGB para o preço. O estoque segue um processo que segundo os autores é a equação diferencial estocástica padrão para a literatura de população ecológica, dada por 3.26, sendo esta um caso particular da equação 3.20.

$d I=(\mu I-q(P, I, t)) d t+\sigma I d z$

Assim como no trabalho de Levi (1996), o custo é dado como uma função linear da taxa de corte, de modo que a taxa de corte é sempre o valor máximo ou nulo. Aplicando a metodologia de diferenças finitas explícitas para o cálculo do valor da concessão, os autores analisam a sensibilidade do valor da opção em relação a algumas variáveis do problema para os dois processos estocásticos do preço.

Para os parâmetros do caso base, o valor da opção da concessão florestal calculado quando o preço segue MGB é pelo menos 1,5 vezes maior do que o calculado quando a suposição é de reversão à media, e 8 vezes maior quando comparado com o valor dado pelo método tradicional do VPL. Além disso, a sensibilidade do valor da opção em relação ao tempo de concessão diminui quanto maior for o prazo para expiração. Conforme se aumenta a volatilidade do preço, o valor da concessão aumenta; porém, o oposto ocorre com o estoque, de modo que conforme sua volatilidade é aumentada, o valor da concessão diminui.

Insley (2002) avalia um investimento florestal também utilizando opções reais e modela a decisão ótima de colheita. $\mathrm{O}$ valor da opção de cortar é estimado usando a abordagem de programação dinâmica, usando um MGB para o processo estocástico do preço. O processo de crescimento determinístico para o volume de árvores é dado pela seguinte equação 
$d X(t)=g(t) d t \quad(3.27)$

onde $\mathrm{g}(\mathrm{t})$ é a curva de crescimento para a madeira.

De acordo com Insley (2002), a relação entre o valor da opção e a volatilidade pode ser entendida examinando a solução do problema, que descreve como a opção varia com o tempo. Para um tempo maior até a expiração (ou seja, movendo-se backwards no tempo), o valor da opção é maior para maiores valores de volatilidade do ativo base se a segunda derivada da EDP em relação ao ativo base for positiva. Este resultado faz sentido intuitivamente, pois uma maior volatilidade significa que as chances de se obter um preço excepcionalmente alto ao longo do projeto são maiores. No entanto, com suposições diferentes a respeito da natureza da opção, a segunda derivada poderia ser negativa ou mudar de sinal. Por exemplo, para Forsyth (2000), o ativo base de uma floresta é suposto como o apresentado pela equação (3.25) com uma taxa de drift que é logística. Isso significa que o ativo cresce inicialmente a uma determinada taxa $r$ quando o valor do ativo é baixo, mas a taxa de crescimento vai se aproximando de zero à medida que o valor do ativo atinge um determinado nível máximo. Nesse caso, a segunda derivada muda de sinal dependendo do nível da taxa de crescimento inicial. Com uma taxa $r$ que seja suficientemente grande, aumentando a volatilidade, o valor da opção na verdade irá diminuir.

Kerr (2008) aplica a metodologia de Insley (2002) a um projeto de reflorestamento, de forma que a decisão ótima de colheita é modelada como uma opção real americana. As inequações diferenciais do problema são resolvidas pelo método das diferenças finitas implícitas e o sistema linear de equações simultâneas é resolvido. O crescimento da floresta é dado pela mesma equação (3.27), e comparações são realizadas para dois processos de difusão de preços: MGB e MRM. Segundo o autor a hipótese de que os preços de madeira no Brasil seguem um MGB não pode ser rejeitada.

Além disso, o autor verifica a sensibilidade do valor da opção e da regra de corte ótima em relação à volatilidade de preço da madeira e à taxa de juros livre de risco. Em ambos os casos, estas variáveis mostram ter influência significativa sobre o valor da opção e sobre a regra ótima de corte. Especificamente para o processo de difusão do MGB para o preço, a influência dos custos de colheita sobre o valor da 
opção e sobre a regra ótima de corte da floresta é examinada. Esta variável também influencia de forma significativa o valor da opção e a regra ótima de corte.

Brobouski (2004) aplica a Teoria das Opções Reais na área de reflorestamento propondo um contrato de parceria florestal entre as empresas e o produtor rural. Para estimar o volume da madeira, foi utilizado um simulador de crescimento e produção, conhecido como Sispinus ${ }^{3}$. Através de árvores binomiais, o autor compara o investimento florestal atrelado a um contrato de preço mínimo com contratos de arrendamento fixo, arrendamento variável (com participação na produção) e contratos de parceria, concluindo que tal contrato minimiza os riscos para o produtor, sendo uma alternativa viável de incentivo para a produção. A ideia deste contrato de parceria entre o pequeno produtor rural e as madeireiras da região é estabelecer um preço mínimo para a compra da madeira, tornando possível avaliar a opção de abandono, com a incerteza do preço futuro.

No referido trabalho, o autor mostra que o cultivo de pinus apresenta expectativa de retorno superior ao mercado financeiro, possibilitando uma boa alternativa de renda para o produtor. Tendo em vista que pode ser cultivado em áreas impróprias às culturas rurais, o projeto proposto auxilia no combate a falta de madeira, fornecendo suprimento à empresa, diminuindo o risco ao produtor em relação a mudanças nos preços e aumentando o valor do projeto, devido à flexibilidade. No caso de um projeto de reflorestamento, pode-se adiar o investimento, desistir do projeto, ou abandonar o mesmo durante a execução. Caso haja uma queda significativa no preço, o produtor tem a flexibilidade de optar pela venda da floresta por um preço mínimo, conforme o estipulado no contrato de parceria. Dadas estas flexibilidades, a análise a partir da Teoria das Opções Reais é mais adequada e observa-se que vale a pena do ponto de vista do produtor a venda da madeira por um preço mínimo a partir do oitavo ano do projeto. Observa-se ainda que a decisão é mais apropriada a partir do décimo sexto ano, quando a madeira admite uma maior utilidade.

Baran (2005) assume uma função de crescimento segundo o modelo de Schumacher (1939) - determinístico e dependente da idade da árvore - apresentado a seguir, e considera que o preço da madeira segue um MGB.

\footnotetext{
${ }^{3}$ Simulador de Crescimento e Produção de Pinus elliottii e Pinus taeda, conhecido que foi desenvolvido por Oliveira (1995).
} 
$\mathrm{V}=751,336 e^{-6,0777 / \text { Idade }}$

Com isso o autor avalia, através de opções reais, a possibilidade de manter a floresta ao invés de extraí-la para o produtor florestal se beneficiar de créditos de carbono $^{4}$. O sequestro de gás carbono gera um fluxo de dividendos que se transforma em uma fonte adicional de receita. Diante de um preço de mercado incerto o autor trabalha com três opções: derrubar a floresta, esperar ou abandonar. Baran (2005) mostra que, mesmo se o mercado de madeira estiver passando por uma conjuntura desfavorável, a atividade florestal torna-se mais rentável ao se levar em conta o pagamento de dividendos como recompensa pela absorção de gás carbônico podendo até levar a um aumento da área cultivada.

Gastaldi e Minardi (2012) avaliam o valor referente à possibilidade de antecipação ou postergação da colheita de uma floresta de eucalipto frente a incertezas acerca do preço da madeira, tomando como base o corte realizado no sétimo ano. A avaliação concentra-se na comparação entre o uso do tradicional fluxo de caixa descontado com a avaliação por opções reais. Utiliza-se para isso o modelo binomial e comparam-se os resultados obtidos para quando o preço segue o movimento browniano geométrico e o processo de reversão à média. Os resultados apresentados pelo modelo são bastante intuitivos, sugerindo que a melhor opção é cortar florestas mais jovens quando os preços estão altos.

A Tabela 3.1 apresenta de forma consolidada os artigos pesquisados para facilitar a comparação. Tendo em vista o levantamento dos estudos das aplicações da teoria de opções reais no contexto florestal, o objetivo da presente pesquisa é estender o modelo de Morck, Schwartz e Stangeland (1989) considerando um processo diferente para evolução do crescimento do estoque de árvores em um projeto de investimento florestal hipotético. A base para a escolha do processo desta dissertação é aproximar o modelo para o crescimento real de uma floresta ao invés de considerar um drift constante e limitar o crescimento com uma barreira como em alguns artigos aqui mencionados (Morck, Schwartz e Stangeland, 1989; Levi, 1996; Moreira et al, 2000; Rocha et al, 2004). Além disso, com base no trabalho de Rocha

${ }^{4}$ A criação de um mercado internacional para reduções de emissões de gases de efeito estufa firmados no Protocolo de Quioto deu origem a um novo ativo a ser levado em consideração: a absorção do $\mathrm{CO}_{2}$ pela atmosfera. O que, no caso de investimentos florestais, possibilita a valorização do empreendimento e propicia uma receita adicional para a entidade administradora. 
et al (2004), que aplicam também um modelo similar ao de Morck, Schwartz e Stangeland (1989), a solução será analisada a partir do método de diferenças finitas

explícitas. Em ambos os trabalhos citados, é calculada uma taxa de corte ótima de árvores a cada instante de tempo. 
Tabela 3.1 - Principais referências de opções reais da área de recursos renováveis

\begin{tabular}{|c|c|c|c|c|c|c|}
\hline Ano & Autor(es) & $\begin{array}{l}\text { Variáveis } \\
\text { Modeladas }\end{array}$ & $\begin{array}{l}\text { Processos } \\
\text { correspondentes }\end{array}$ & Tipo de opção & Decisão & Resultados Relevantes \\
\hline 1984 & Pindyck & Estoque & $\begin{array}{l}\text { Modelo estocástico } \\
\text { clássico com função de } \\
\text { crescimento geral }\end{array}$ & Espera simples & $\begin{array}{l}\text { corta a uma taxa } \\
q \text { ou não corta }\end{array}$ & $\begin{array}{l}\text { Para aplicação de uma } \\
\text { função logística de } \\
\text { crescimento do estoque a } \\
\text { taxa de corte é reduzida. }\end{array}$ \\
\hline 1985 & $\begin{array}{l}\text { Brennan e } \\
\text { Schwartz }\end{array}$ & $\begin{array}{l}\text { Preço e } \\
\text { Produção }\end{array}$ & $\begin{array}{l}\text { MGB e modelo } \\
\text { determinístico }\end{array}$ & $\begin{array}{l}\text { Parada } \\
\text { temporária e } \\
\text { Abandono }\end{array}$ & $\begin{array}{l}\text { tempo de } \\
\text { exercício ótimo }\end{array}$ & $\begin{array}{l}\text { Quanto maior o estoque na } \\
\text { mina maior é o incentivo para } \\
\text { extrair o cobre e menor é o } \\
\text { preço sob o qual a mina é } \\
\text { aberta, fechada ou } \\
\text { abandonada. }\end{array}$ \\
\hline 1989 & $\begin{array}{l}\text { Morck, } \\
\text { Schwartz e } \\
\text { Stangeland }\end{array}$ & $\begin{array}{l}\text { Preço e } \\
\text { Estoque }\end{array}$ & $\begin{array}{l}\text { MGB e modelo } \\
\text { estocástico clássico }\end{array}$ & Expansão & $\begin{array}{l}\text { taxa de corte } \\
\text { ótimo }\end{array}$ & $\begin{array}{l}\text { A taxa de corte ótima } \\
\text { decresce conforme o estoque } \\
\text { diminui. Quanto maior a taxa } \\
\text { de crescimento do estoque, } \\
\text { menor será a taxa de corte. }\end{array}$ \\
\hline 1996 & Levi & $\begin{array}{l}\text { Preço e } \\
\text { Estoque }\end{array}$ & $\begin{array}{l}\text { MGB e modelo } \\
\text { estocástico clássico }\end{array}$ & Espera simples & $\begin{array}{l}\text { corta uma taxa } q \\
\text { ou não corta }\end{array}$ & $\begin{array}{l}\text { O custo de transporte é o } \\
\text { principal diferencial para se } \\
\text { aceitar ao rejeitar um projeto. }\end{array}$ \\
\hline 1997 & Conrad & Amenidade & MGB & Espera simples & $\begin{array}{l}\text { preservar uma } \\
\text { floresta ou não }\end{array}$ & $\begin{array}{l}\text { Conforme a volatilidade do } \\
\text { estoque aumenta maior é o } \\
\text { valor de preservação. }\end{array}$ \\
\hline 2000 & Moreira et al & $\begin{array}{l}\text { Preço e } \\
\text { Estoque }\end{array}$ & $\begin{array}{l}\text { MGB e modelo } \\
\text { estocástico clássico }\end{array}$ & Espera simples & $\begin{array}{l}\text { corta uma taxa } q \\
\text { ou não corta }\end{array}$ & $\begin{array}{l}\text { Quanto maior a incerteza em } \\
\text { relação ao estoque, menor o } \\
\text { valor para a concessão. }\end{array}$ \\
\hline 2000 & Forsyth & Amenidade & $\begin{array}{l}\text { processo de crescimento } \\
\text { logístico estocástico }\end{array}$ & Espera simples & $\begin{array}{l}\text { preservar uma } \\
\text { floresta ou não }\end{array}$ & $\begin{array}{l}\text { O valor de amenidade crítica } \\
\text { diminui à medida que a } \\
\text { volatilidade aumenta. }\end{array}$ \\
\hline 2002 & Insley & $\begin{array}{l}\text { Preço e } \\
\text { Estoque }\end{array}$ & $\begin{array}{l}\text { MGB/MRM e modelo } \\
\text { determinístico de Rollins } \\
\& \text { Forsyth (1995) }\end{array}$ & Espera simples & $\begin{array}{l}\text { corta a floresta } \\
\text { ou não corta }\end{array}$ & $\begin{array}{l}\text { O valor da opção é maior } \\
\text { para maiores valores de } \\
\text { volatilidade da amenidade }\end{array}$ \\
\hline 2005 & Baran & $\begin{array}{l}\text { Preço e } \\
\text { Estoque }\end{array}$ & $\begin{array}{l}\text { MGB e modelo } \\
\text { determinístico de } \\
\text { Schumacher (1939) }\end{array}$ & Espera simples & $\begin{array}{l}\text { preservar uma } \\
\text { floresta ou não }\end{array}$ & $\begin{array}{l}\text { A atividade florestal torna-se } \\
\text { mais rentável ao se levar em } \\
\text { conta a recompensa pela } \\
\text { absorção de gás carbônico. }\end{array}$ \\
\hline 2004 & Rocha et al & $\begin{array}{l}\text { Preço e } \\
\text { Estoque }\end{array}$ & $\begin{array}{l}\text { MGB/MRM e modelo } \\
\text { estocástico clássico }\end{array}$ & Espera simples & $\begin{array}{l}\text { corta uma taxa q } \\
\text { ou não corta }\end{array}$ & $\begin{array}{l}\text { Quanto maior a volatilidade } \\
\text { do preço, o valor da } \\
\text { concessão aumenta; porém, o } \\
\text { oposto ocorre com o estoque, } \\
\text { quando a volatilidade é } \\
\text { aumentada, o valor da } \\
\text { concessão diminui. }\end{array}$ \\
\hline 2008 & Kerr & $\begin{array}{l}\text { Preço e } \\
\text { Estoque }\end{array}$ & $\begin{array}{l}\text { MGB/MRM e modelo } \\
\text { determinístico de } \\
\text { Schumacher (1939) }\end{array}$ & Espera simples & $\begin{array}{l}\text { corta a floresta } \\
\text { ou não corta }\end{array}$ & $\begin{array}{l}\text { O custo de colheita influencia } \\
\text { de forma significativa o valor } \\
\text { da opção e a regra ótima de } \\
\text { corte. }\end{array}$ \\
\hline 2012 & $\begin{array}{l}\text { Gastaldi e } \\
\text { Minardi }\end{array}$ & Preço & MGB/MRM & Espera simples & $\begin{array}{l}\text { corta a floresta } \\
\text { ou não corta }\end{array}$ & $\begin{array}{l}\text { A avaliação do projeto } \\
\text { considerando uma única } \\
\text { rotação de } 7 \text { anos aufere um } \\
\text { valor muito superior ao ativo. }\end{array}$ \\
\hline
\end{tabular}

Fonte: Elaboração própria 


\section{4 Modelo com estoque dado pela equação logística}

A metodologia descrita neste trabalho é aplicável para o estudo de oportunidades de investimentos em projetos de concessão de recursos naturais renováveis sob condições de incerteza.

Sendo um trabalho metodológico, um dos objetivos é calcular o valor de mercado de uma concessão florestal com propósito comercial. Esse valor irá depender de alguns parâmetros selecionados de modo a refletir uma gama de perspectivas sobre a produtividade ou a evolução do mercado. Os resultados serão as melhores estimativas para o valor de mercado da concessão condicionado ao conjunto de parâmetros adotados.

O objetivo desse capítulo é indicar o instrumental utilizado para determinar o valor de um projeto de concessão florestal. É importante ressaltar que o valor da concessão é calculado considerando que a firma agirá otimamente no corte de árvores. A característica principal deste trabalho é implementar o crescimento do estoque utilizando um modelo de reversão à média. Segundo Dias (2015), a tendência é que, sem cortes, a população de árvores poderá crescer até um limite máximo, a partir do qual tende a se estabilizar. Dessa forma, o crescimento do estoque de árvores será em função do crescimento natural e do corte de árvores.

\section{1.}

Premissas

Para avaliação do valor do projeto florestal, considera-se o preço de venda da madeira como uma fonte de incerteza.

A hipótese subjacente a este trabalho é que o preço de madeira é uma variável estocástica e segue um MGB e o estoque de madeira varia em função do crescimento logístico e da taxa de corte de árvores. Esta última depende do preço, do estoque e do tempo, de modo que uma taxa de corte ótima é escolhida a cada instante de tempo para estimar o valor da opção. 
Assume-se que a empresa em questão é pequena comparada à indústria como um todo; assim, diferenças de apenas de um projeto florestal não afetam os preços de mercado. Esta hipótese também chamada hipótese da firma tomadora de preço, implica em considerar o preço de mercado como um dado externo ao problema (Rocha et al, 2004).

\section{2. \\ Modelagem da opção de cortar árvores}

A Teoria de Opções Reais permite quantificar adequadamente a flexibilidade gerencial na avaliação de um projeto de investimento de capital sob incerteza e produz melhores resultados na modelagem da decisão ótima de corte de um lote de árvores para comercialização do que as técnicas tradicionais de avaliação.

A cada instante $t$, determina-se se é valioso ou não realizar o corte de árvores para produção de madeira, e à qual taxa este corte deve ser realizado. Para incorporar um elemento realístico ao problema florestal, leva-se em conta a redução da taxa de crescimento das árvores com o passar do tempo até um nível de saturação máximo, onde ainda há crescimento, porém a uma taxa menor. O valor do investimento florestal considerando a opção de cortar árvores em um período de tempo é a variável dependente neste trabalho. A empresa que possui a concessão suspostamente irá escolher a taxa de corte de uma forma que maximize o seu valor de mercado.

Considerando que a firma agirá otimamente no corte de árvores, as variáveis que influenciam no valor do projeto de investimento são o preço, o estoque, o tempo e a taxa de corte, da seguinte forma

- Preço da madeira $P$ - quanto maior o preço, maior o incentivo para cortar a uma taxa alta.

- Estoque de madeira $E$ - quanto menos madeira estiver disponível, menor o incentivo para cortar, pois, se houver pouca madeira em determinada data, pode ser melhor esperar as árvores crescerem mais antes de cortar.

- Tempo $t$ - quanto mais se aproximar do final do período de concessão, maior o incentivo para cortar. 
- Taxa de corte - caso seja ótimo cortar uma taxa $q^{*}(P, E, t)$, a opção será exercida; caso contrário, a decisão ótima será esperar.

Neste trabalho, o preço e o estoque serão modelados, de forma que sua evolução temporal é dada por processos conforme descritos a seguir. A primeira contribuição deste trabalho é a modelagem do estoque de uma forma diferente da comumente utilizada na literatura de opções reais.

\subsection{1.}

Modelagem do Preço

A série histórica dos preços à vista de eucalipto foi obtida através do setor florestal do Centro de Estudos Avançados em Economia Aplicada (CEPEA). Os dados foram coletados mensalmente para a região de Sorocaba em São Paulo em reais por estéreo ( $\mathrm{R} \$ / \mathrm{st}$ ), que é a medida de volume de madeira em toras empilhadas. Foi realizada a conversão para reais por metro cúbico $\left(\mathrm{R} \$ / \mathrm{m}^{3}\right)^{5}$. A Figura 4.1 mostra a série que possui 204 observações com frequência mensal, com início em junho/1998 a abril/2015 totalizando aproximadamente 18 anos de série histórica.

A série de preços foi deflacionada e convertida em reais constantes pelo Índice Geral de Preços-Disponibilidade Interna (IGP-DI), calculado pelo Instituto Brasileiro de Economia (IBRE) e publicado pela Fundação Getúlio Vargas (FGV), para isto foi utilizado como base abril de 2015. A representação gráfica da deflação da série histórica dos preços da madeira pode ser observada na Figura 4.2.

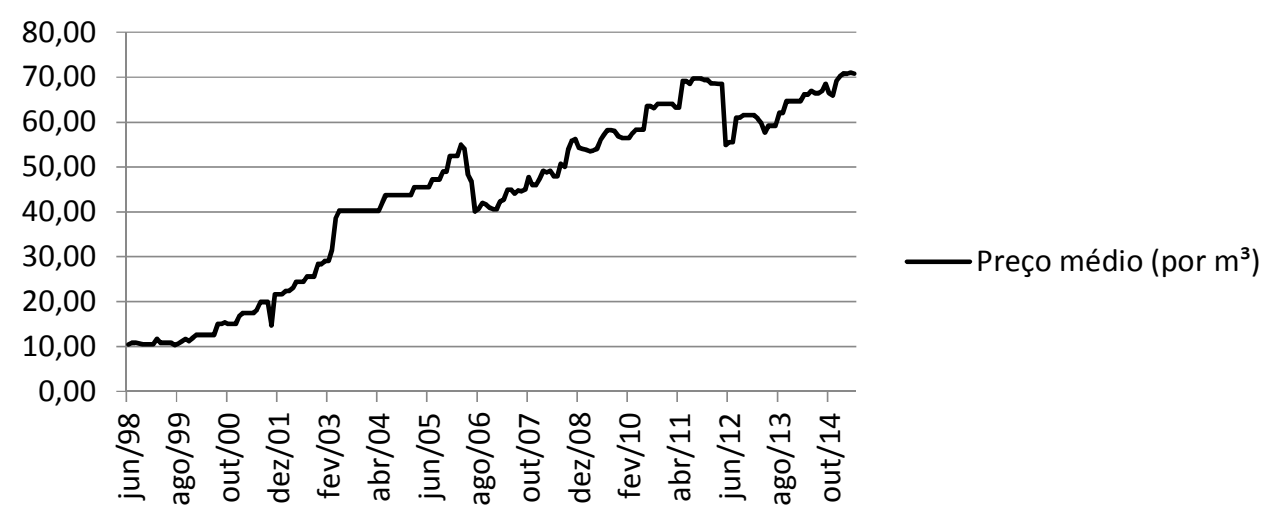

Figura 4.1 - Série histórica de preços médios de eucaliptos no Brasil Fonte: CEPEA

\footnotetext{
${ }^{5}$ Segundo a tabela padrão de conversão em estéreis para metro cúbico $\left(\mathrm{m}^{3}\right)$ divulgada pela Florestar Estatístico (2004), 1 st de eucalipto com casca (empilhado) corresponde a 0,7 $\mathrm{m}^{3}$ de madeira sólida, com isso foi realizada a conversão dos preços para $\mathrm{R} \$ / \mathrm{m}^{3}$.
} 


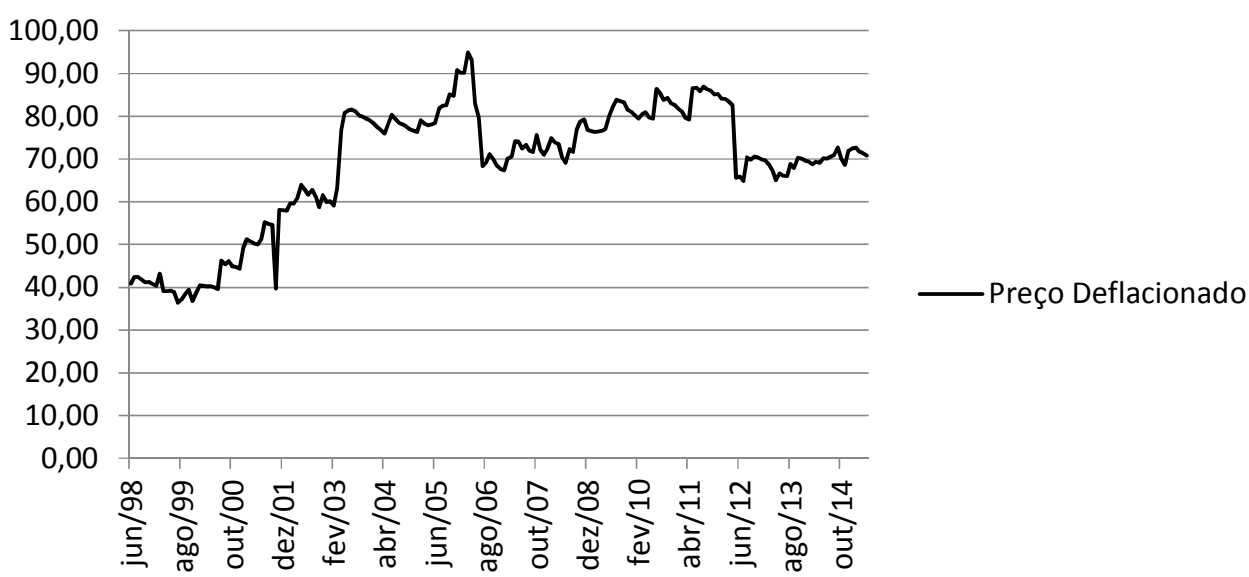

Figura 4.2 - Série histórica de preços deflacionados de eucaliptos no Brasil Fonte: CEPEA

Um dos principais testes de verificação da existência de estacionaridade em uma série de tempo é o teste da raiz unitária conhecido como teste Dickey-Fuller Aumentado (ADF), podendo ser realizados para verificar se o MGB pode ser rejeitado ou não para uma série de preços. Esse teste infere existência de raiz unitária, onde a hipótese nula (H0) de que existe raiz unitária na série, ou seja, b=1, através de regressão linear por mínimos quadrados. Caso não seja possível rejeitar H0, a série apresenta raiz unitária e segue um processo de difusão aleatória. Caso contrário, há indícios de que a série seja um processo estacionário, no qual a média e variância são constantes ao longo do tempo, caracterizando uma reversão à média.

Em sequencia, foi utilizado o software EViews para realizar o teste DickeyFuller aumentado (ADF) nas séries deflacionadas em base logaritmo neperiano de preços deflacionados de Eucalipto por $\mathrm{m}^{3}$. A Tabela 4.1 mostra que a estatística-t (= -2.17) para a série de preço não permite rejeição da hipótese nula de raiz unitária (ao nível de significância de 1\%), indicando que a hipótese de que os preços seguem um MGB não pode ser rejeitada. Portanto o MGB é um processo adequado para representar a série de preços. 
Tabela 4.1 - Resultado do teste Dickey-Fuller

Null Hypothesis: LNPRECO has a unit root

Exogenous: Constant

Lag Length: 0 (Automatic - based on SIC, maxlag=0)

\begin{tabular}{llrr}
\hline \hline & & t-Statistic & Prob. $^{*}$ \\
\hline \hline Augmented Dickey-Fuller test statistic & $-2,17076$ & 0,2177 \\
\hline Test critical values: & 1\% level & $-3,462574$ & \\
& $5 \%$ level & $-2,875608$ & \\
& $10 \%$ level & $-2,574346$ & \\
\hline \hline
\end{tabular}

*MacKinnon (1996) one-sided p-values.

Augmented Dickey-Fuller Test Equation

Dependent Variable: D(LNPRECO)

Method: Least Squares

Date: 07/18/16 Time: 15:16

Sample (adjusted): 2204

Included observations: 203 after adjustments

\begin{tabular}{lrlll}
\multicolumn{1}{c}{ Variable } & Coefficient & Std. Error & t-Statistic & Prob. \\
\hline \hline \multicolumn{1}{c}{ LNPRECO(-1) } & $-0,03197$ & 0,014727 & $-2,17076$ & 0,0311 \\
\multicolumn{1}{c}{ C } & 0,13697 & 0,061958 & 2,210741 & 0,0282 \\
\hline \hline & & & \\
R-squared & 0,02291 & Mean dependent var & 0,00271 \\
Adjusted R-squared & 0,01805 & S.D. dependent var & 0,05211 \\
S.E. of regression & 0,05164 & Akaike info criterion & $-3,07931$ \\
Sum squared resid & 0,53597 & Schwarz criterion & $-3,04667$ \\
Log likelihood & 314,55 & Hannan-Quinn criter. & $-3,06611$ \\
F-statistic & 4,7122 & Durbin-Watson stat & 2,35873 \\
Prob(F-statistic) & 0,03112 & & \\
\hline
\end{tabular}

Fonte: Elaboração Própria

Apesar de o MRM usualmente ser utilizado para a modelagem dos preços de commodities em geral, na literatura do setor florestal o MGB é usando como processo de difusão do preço na maioria dos casos. Como exemplo, podemos citar Morck, Schwartz, Stangeland (1989), Thompson (1992), Levi (1996), Cortazar (1998), Schwartz e Salinas (1998), Moreira et al (2000) e Baran (2005).

Dado que o preço da madeira, $\mathrm{P}\left(\mathrm{R} \$ / \mathrm{m}^{3}\right)$, segue um $\mathrm{MGB}$, para cálculo do valor da opção o MGB sob medida neutra ao risco pode ser escrito como mostra a equação (4.1). 
$\frac{d P^{Q}}{P}=(r-\delta) d t+\sigma d z^{Q}$

onde:

P é o preço da madeira no instante $\mathrm{t}$; $(r-\delta)$ é a tendência neutra ao risco;

r é a taxa de retorno livre de risco;

$\delta$ é a taxa de conveniência para a madeira;

$\sigma$ é a volatilidade dos preços de madeira;

$d z$ o incremento de um processo de Wiener, isto é: $d z=\varepsilon \sqrt{\mathrm{t}}$, onde $\varepsilon \sim N(0,1)$;

$Q$ caracteriza que os processos são de medida neutra ao risco.

Considerando $\mathrm{P}_{0}$ como o preço corrente da madeira, o processo possui as seguintes propriedades estatísticas para média e variância:

$$
\begin{aligned}
& \mathrm{E}^{\mathrm{Q}}[\mathrm{P}(\mathrm{t})]=\mathrm{P}_{0} \mathrm{e}^{(\mathrm{r}-\delta) \mathrm{t}} \\
& \operatorname{Var}[\mathrm{P}(\mathrm{t})]=\mathrm{P}_{0}{ }^{2} \mathrm{e}^{2(\mathrm{r}-\delta) \mathrm{t}}\left(\mathrm{e}^{\sigma^{2} \mathrm{t}}-1\right)
\end{aligned}
$$

Com o valor esperado e a variância, se os preços seguem um MGB, os parâmetros de tendência e volatilidade podem ser estimados com uma regressão linear como mostra as equações 4.4 e 4.5 .

$$
\begin{aligned}
& \alpha=E[\operatorname{Ln}[P(t)]-\operatorname{Ln}[P(t-1)]]+\sigma^{2} / 2 \\
& \sigma^{2}=\operatorname{Var}[\operatorname{Ln}[P(t)]-\operatorname{Ln}[P(t-1)]]
\end{aligned}
$$

Os parâmetros $\alpha$ e $\sigma$ normalmente são reportados em unidades anuais (\% a.a.), mas os dados muitas vezes são diários, semanais ou mensais. Seja $\mathrm{N}$ o número de períodos por ano da observação dos dados - no caso mensal $\mathrm{N}=12$ - então os parâmetros do MGB são estimados com as equações:

$$
\begin{aligned}
& \alpha=N\left\{\operatorname{Ln}[P(t) / P(t-1)]+\frac{\sigma^{2}}{2 N}\right\} \\
& \sigma^{2}=N \operatorname{Var}[\operatorname{Ln}[P(t) / P(t-1)]]
\end{aligned}
$$


Como os dados empregados na aplicação do Capítulo 5 são mensais a estimativa de tendência e volatilidade foi feita com base nas equações 4.6 e 4.7 por meio da série histórica de preços de madeira. Os demais parâmetros do modelo do preço foram obtidos em trabalhos de opções reais aplicados à área florestal.

\subsection{2.}

\section{Modelagem do Estoque}

Os trabalhos clássicos de opções reais da área florestal propõem um crescimento para o estoque florestal cuja tendência é dada por uma taxa de crescimento constante, porém limitada pelo corte e por uma condição de contorno adicional, para que o estoque não cresça ilimitadamente. A princípio, neste trabalho será proposto um modelo logístico, utilizado por ser um modelo mais simples e que consegue representar o crescimento de uma floresta, no qual a tendência de crescimento é dada por uma equação logística de crescimento. Esta é uma contribuição de avaliação nesta área uma vez que a modelagem é diferente da comumente observada nos artigos e acrescenta-se um grau realístico ao problema, já que este tratamento é recomendado em livros e trabalhos da área florestal para mostrar a variação do estoque no caso de biomassa. (Encinas, Silva e Pinto, 2005; Goes, 2012). Para este modelo, não é necessária condição de contorno para limitar o estoque, pois já está embutida no processo do estoque. Os trabalhos comumente tratam o processo do estoque como estocástico; por isso, serão feitas comparações entre os resultados gerados pelo modelo proposto e o caso estocástico na aplicação de um estudo hipotético.

Seja $E(t)$ a variável que representa o estoque de madeira no tempo $t$. Considerando que a floresta possua inicialmente $E_{0}$ metros cúbicos de madeira, para fins deste trabalho a variação do estoque é determinada pela seguinte função

$$
d E=[\eta[\bar{E}-E(t)] E(t)] d t-q(E, P, t) d t
$$

Logo, quando $q=0$, ou seja, para um processo sem cortes, a dinâmica do estoque seguirá a seguinte equação logística de crescimento

$d E=[\eta[\bar{E}-E(t)] E(t)] d t$ 
onde:

$\eta[\bar{E}-E(t)]$ é o coeficiente de $d r i f t$, que representa a taxa de crescimento do estoque

$\eta$ é a velocidade de reversão a média para o estoque de madeira

$\bar{E}$ representa o nível de saturação do estoque

$t$ representa o tempo

$d E$ é a variação do estoque em um intervalo de tempo $d t$ e representa o crescimento de uma população enquanto $E(t)<\bar{E}$, deixando de crescer no nível de saturação $\bar{E}$

A solução do caso determinístico é obtida integrando a equação (4.9):

$E(t)=\frac{\bar{E} E_{0} \operatorname{Exp}[\eta \bar{E} t]}{\bar{E}+E_{0}[\operatorname{Exp}[\eta \bar{E} t]-1]}$

Para o caso sem corte, a equação logística de crescimento considera um nível de saturação $\bar{E}$. Dessa forma, numa determinada área, o estoque de madeira cresce inicialmente a taxas elevadas, mas depois vai crescendo a taxas menores até um nível de saturação em que praticamente não cresce.

A taxa de crescimento $d E / d t$ é zero para $E=0$, que representa o nível de extinção, e para $E=\bar{E}$, que representa o nível de saturação. Além disso, $d E / d t$ atinge um máximo em $\bar{E} / 2$, de forma que essa taxa cresce entre 0 e $\bar{E} / 2$ e decresce de $\bar{E} / 2$ até $\bar{E}$.

Além do modelo original descrito, são feitas considerações adicionais para comparação entre diferentes modelos. As duas outras alternativas pressupõem o mesmo modelo considerando que a decisão de produção é, para cada período, cortar ou não a uma taxa de corte fixa, bem um modelo estocástico, no qual a equação do estoque passa a ser a seguinte

$d E=[\eta[\bar{E}-E(t)] E(t)] d t-q(E, P, t) d t+\sigma_{E} E(t) d z$

onde, $\sigma_{E}$ é a volatilidade do estoque e reflete a incerteza em relação ao volume de madeira. 


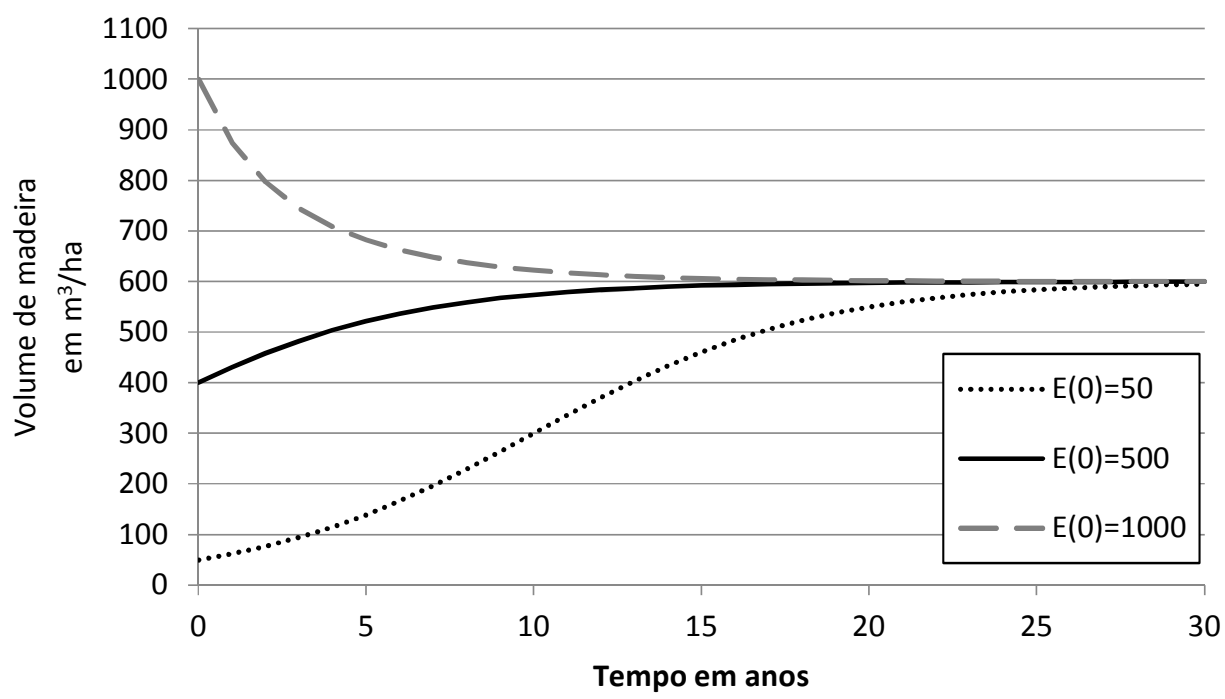

Figura 4.3 - Crescimento Logístico para diferentes valores iniciais para o estoque $\mathrm{E}(0)$.

Fonte: Elaboração própria.

A Figura 4.3 ilustra o comportamento do estoque no caso determinístico do crescimento logístico, para $\bar{E}=600 \mathrm{~m}^{3}$ e a velocidade de reversão à media $\eta=$ 0,0004, obtida a partir dos dados de entrada, para três casos de valor inicial do estoque: $E_{0}<\frac{\bar{E}}{2}, \frac{\bar{E}}{2}<\mathrm{E}_{0}<\bar{E}$ e $\mathrm{E}_{0}>\bar{E} .{ }^{6}$ Com essa análise pode ser verificado que, após 30 anos, a taxa de crescimento diminui a um valor muito próximo de zero. Observa-se que em todos os casos, com o passar do tempo, a população irá convergir para o nível de saturação $\bar{E}$. O primeiro caso, em que o estoque inicial é menor que a metade do nível de saturação, será utilizado como base na análise dos resultados porque é o que representa melhor o crescimento de uma população em que a abundância de recursos promove um crescimento acelerado por certo tempo e depois um crescimento lento devido à perda de recursos naturais provenientes do solo. Essa curva reflete melhor o crescimento de uma população florestal, pois inicialmente o volume de madeira irá aumentar de maneira exponencial pelo excesso de nutrientes no solo; porém, com o passar do tempo esses elementos e minerais vão se tornando escassos, seja por erosão, escoamento, queimadas, ou pela própria colheita de árvores, fazendo com que o crescimento seja mais lento e gerando uma inflexão na curva.

${ }^{6}$ Para os parâmetros selecionados aplicou-se a equação (4.10), dessa forma foi obtida a Figura 4.3 e a velocidade de reversão que mais se adequou ao modelo. 


\section{3.}

\section{Cálculo do valor de um investimento florestal}

Nesta dissertação, iremos supor que o fluxo de caixa de uma empresa sobre a produção de madeira é determinado por

$f(t)=(1-\tau) \times(P \times q-C(t))$

onde $\tau$ equivale à taxa de imposto sobre o lucro da produção.

Para o cálculo do custo, ao invés de uma função linear (Levi, 1996; Rocha et al, 2004), adotou-se uma função quadrática de custo da empresa madeireira (Morck, Schwartz e Stangeland, 1989). Segundo Levi (1996) se a função de custo é linear em relação à taxa de corte, o problema de controle ótimo estocástico terá uma solução do tipo "produzir a máxima capacidade ou não produzir", simplificando a solução numérica do problema. Quando a função de custo é quadrática, a política de corte ótima não assume necessariamente apenas os valores zero ou máximo, mas valores entre um intervalo. Pela falta de disponibilidade dos parâmetros em relação aos custos aplicados na avaliação realizada no Capítulo 5 a respeito de uma floresta de eucalipto foram considerados apenas custos variáveis. A função considera que há custo variável e um custo quadrático que reflete o aumento do custo marginal e pode ser representada da seguinte forma

$C(t)=\left\{\begin{array}{r}c_{1} \times q+\frac{c_{2} \times q^{2}}{2}, \text { se } f(t)>0 \\ 0, \text { se } f(t) \leq 0\end{array}\right.$

Para calcular o valor de um projeto de investimento florestal $F(E, P, t)$ a partir da Teoria de Opções Reais, é necessário determinar a equação diferencial parcial (EDP) e suas condições de contorno.

Dada as equações 4.1 e 4.8 para variação do preço $\mathrm{P}(\mathrm{t})$ e do estoque $\mathrm{E}(\mathrm{t})$, segundo a equação de Itô-Doeblin para duas variáveis estocásticas, a EDP do valor da floresta é dada por:

$d F=F_{t} d t+F_{P} d P+\frac{1}{2} F_{P P}(d P)^{2}+F_{E} d E+\frac{1}{2} F_{E E}(d E)^{2}+F_{P E}(d E . d P)$ 
Os termos de ordem maior que 1 para $d t$ são considerados desprezíveis. Como, nesse caso, o estoque é tratado de forma determinística e $d z_{P}=\varepsilon_{P} \sqrt{d t}$ então $(d E)^{2} \cong 0$ e $(d E \cdot d P) \cong 0$ são termos desprezíveis na EDP.

Desta forma, a EDP sem os termos anteriormente mencionados é a seguinte

$d F=F_{t} d t+F_{P} d P+\frac{1}{2} F_{P P}(d P)^{2}+F_{E} d E$

Pelo método dos ativos contingentes, monta-se um portfólio sem risco considerando que apenas a variável preço é estocástica

$\phi=F-n P$

Em seguida iguala-se o retorno do portfólio sem risco com os retornos dos componentes do portfólio

$r \phi d t=r[F-n P] d t=d F+f(t) \cdot d t-n\left(d P+\delta_{P} P d t\right)$

onde $f(t)$ é o fluxo de caixa do período, gerado pelo corte de árvores.

Para eliminar o termo estocástico $d P$, escolhe-se $n=F_{P}$ e cancelando $d t$ temse a seguinte EDP

$r F=F_{t}+\frac{1}{2} F_{P P} \sigma^{2} P^{2}+F_{E}\{[\eta[\bar{E}-E(t)]] E(t)-q(t)\}+\left(r-\delta_{P}\right) F_{P} P+f(t)$

Aplicando o Lema de Itô, pode ser demonstrado que o valor de mercado da concessão florestal, $F(P, E, t)$, é um ativo contingente do preço e estoque subjacente e cresce de acordo com a equação diferencial parcial (4.18).

Para este problema, aplicam-se as seguintes condições de contorno

$$
\begin{aligned}
& F(P, E, T)=0, \\
& F(0, E, t)=0, \\
& F(P, 0, t)=0,
\end{aligned}
$$


$\lim _{P \rightarrow P_{\text {máx }}} F_{P}=E-E_{\text {min }}$,

A equação 4.19 garante que o valor da concessão é zero ao final do prazo. As equações 4.20 e 4.21 garantem que o valor da concessão é zero quando os preços da madeira ou do estoque caem para zero e se o preço da madeira aumentar muito. Finalmente, de acordo com a equação 4.22, mudanças no valor de mercado devido a mudanças no preço são linearmente proporcionais ao estoque disponível para produção porque quando o preço tende para infinito, tenta-se explorar toda a reserva disponível imediatamente. Neste caso, o valor do projeto é função apenas da variação do estoque. Esta última condição pode ser questionada porque mesmo que o preço da madeira tenda a infinito ainda existem as limitações técnicas que impediriam a exploração instantânea de toda a reserva. No entanto, deve-se ressaltar que, como a resolução é numérica, todas estas condições de contorno envolvem conceitos empregados para tentar simplificar o desenvolvimento do problema.

A cada período de tempo, de preço e de estoque, é calculada a taxa ótima de corte $q^{*}$ para cálculo do valor da opção, conforme proposto por Morck, Schwartz e Stangeland (1989) e Rocha et al (2004). No caso de Morck, Schwartz e Stangeland (1989) o custo é quadrático, gerando uma decisão ótima para cada preço, estoque e tempo; porém, em Rocha et al (2004), assim como Levi (1996), o custo é linear, de modo que a opção é cortar ou não cortar a uma taxa fixa. Seguindo a mesma abordagem utilizada por Morck, Schwartz e Stangeland (1989), a taxa de corte é escolhida de forma a maximizar o valor do projeto. Para encontrar essa política de produção ótima, toma-se a derivada parcial de 4.18 em relação à quantidade $q$ :

$$
(1-\tau) \times\left(P-c_{1}-q *(P, E, t) \times c_{2}\right)-F_{E}=0
$$

Impondo as restrições que (i) a produção deve ser não negativa e (ii) a produção pode ser suspensa ou reiniciada sem custos adicionais, a equação (4.23) pode ser resolvida para uma política de produção ótima dada por:

$q^{*}(P, E, t)=\left\{\begin{array}{r}\max \left[0, \frac{-F_{E}}{(1-\tau) \times c_{2}}+\frac{P-c_{1}}{c_{2}}\right], \text { se } f(t)>0 \\ 0, \text { se } f(t) \leq 0\end{array}\right.$ 
Para solução do valor da opção, a EDP dada pela equação 4.18, juntamente com as condições de contorno nas equações 4.19 a 4.22 e as restrições de $q *(P, E, t)$ em 4.24, deve ser resolvida numericamente.

\section{4.}

\section{Aplicação do Método de Diferenças Finitas}

O problema de apreçamento do projeto de investimento desta dissertação não pode ser resolvido analiticamente, tornando-se então necessário recorrer às soluções numéricas, sendo aplicado, portanto, o método de diferenças finitas (MDF) explícitas. Como o problema será resolvido recursivamente de forma backwards, isto é do vencimento para trás, então o fato de cinco valores conhecidos determinarem um valor a ser conhecido, leva a um problema de fácil solução, com uma equação e uma incógnita.

O MDF na sua forma explícita transforma a equação diferencial parcial e suas respectivas condições de contorno em uma equação que pode ser resolvida numericamente. Segundo Rocha et al (2004), usando uma discretização específica para o tempo, preço e estoque, a forma explícita converge para a solução da EDP, e é mais fácil e rápida comparada às técnicas da forma implícita e da simulação de Monte Carlo associadas com procedimentos de otimização. A respeito dos problemas de fronteira livre definidos por um problema de controle estocástico, a forma explícita e a discretização podem facilmente lidar com o algoritmo de otimização usado para resolver esses problemas de parada ótima. A forma implícita, no entanto, tem que lidar com ambos: equações de sistemas simultâneos e procedimentos de otimização.

O primeiro passo é o estabelecimento do grid ou malha uniforme onde serão discretizados o tempo, o preço e o estoque. Como nesta dissertação a opção $F(P, E, t)$ é função de três variáveis, representa-se um grid de três dimensões. Para esse tipo de modelagem, é necessário que haja um limite para cada variável, e, portanto, define-se um cubo maior com as extremidades nos limites de preço, estoque e tempo. Na construção, é como se este cubo contivesse pequenos cubos, de forma que o valor da opção $F(P, E, t)$ é calculado em cada um dos vértices dos cubos, ou seja, nos cruzamentos das linhas de comprimento, largura e altura. 
As Figuras 4.4 e 4.5 ilustram os cortes transversais do cubo descrito e as condições de contorno no grid. O objetivo é calcular o valor da opção para todo $P$, $E$ e $t$ do $g r i d$, resultando numa matriz de valor da opção $F(P, E, t)$.

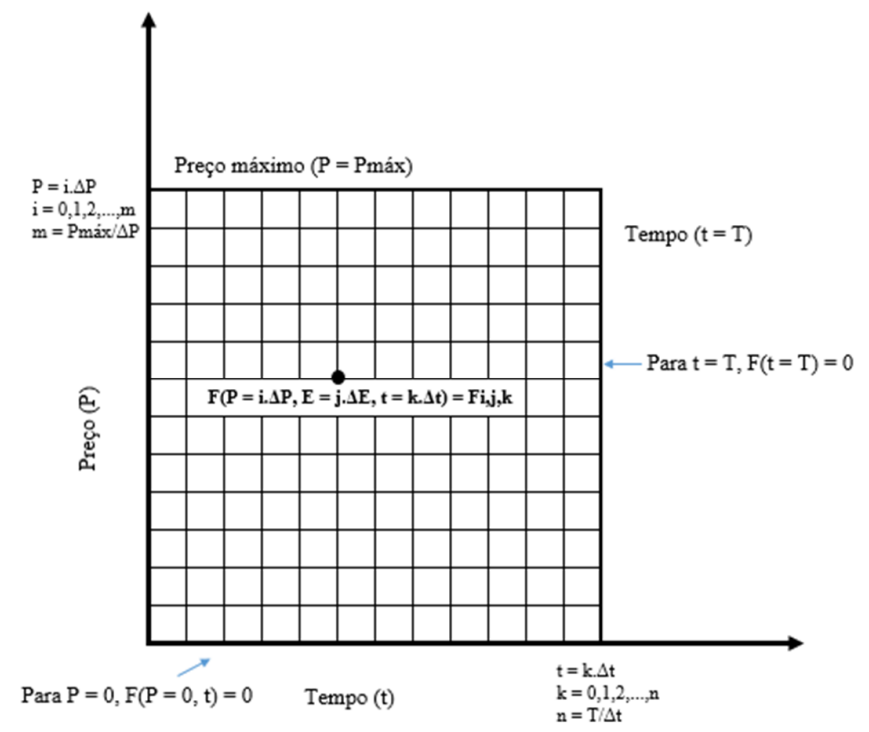

Figura 4.4 - Grid das Diferenças Finitas - Preço vs. Tempo

Fonte: Adaptado de Dias (2015).

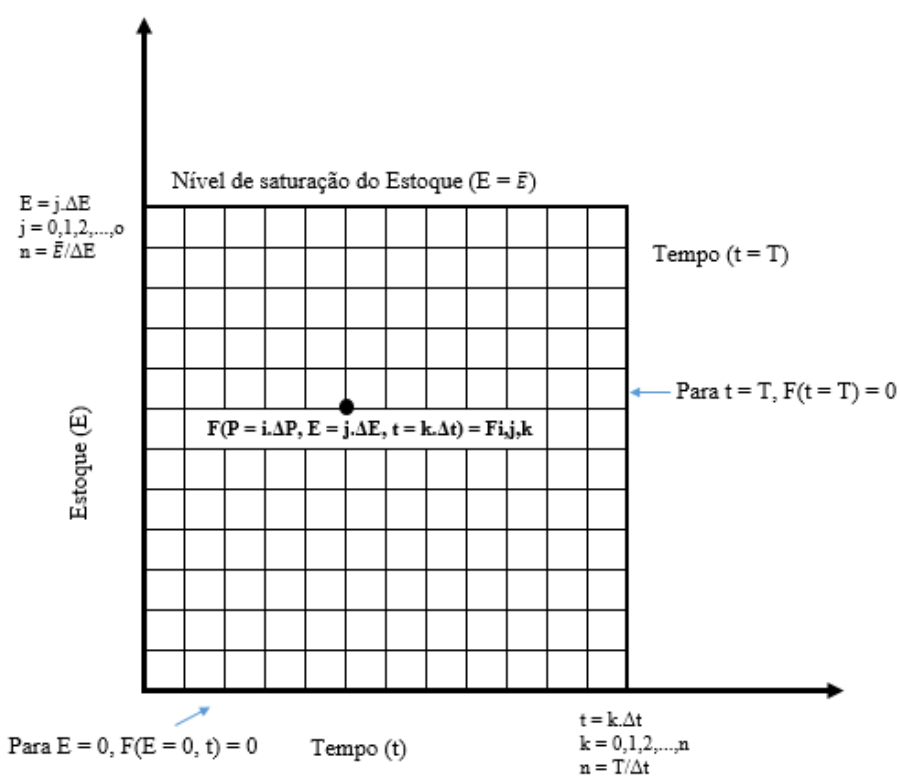

Figura 4.5 - Grid das Diferenças Finitas - Estoque vs. Tempo

Fonte: Adaptado de Dias (2015).

O valor da opção será obtido a partir da data de expiração, a partir de um processo backwards até a data inicial, de forma que são utilizados os valores no instante $k+1$ para calcular a opção na data $k$. 
Foi aplicado o método de diferenças finitas explícitas descrito na seção 3.2.2 iniciando pelo estabelecimento do grid (ou malha) no qual são discretizadas as variáveis tempo, preço e estoque. Como se trata de três variáveis de estado, representa-se um grid de três dimensões. Para construir a malha, o tempo foi dividido em $o$ passos-tempo, com $o=T / d t$; o preço em $m$ passos-espaço, com $m=$ $P_{\text {máx }} / d P$; e o estoque em $n$ passos-espaço, $\operatorname{com} n=\frac{\bar{E}}{d E}$. Em cada nó do $\operatorname{grid}(m, n, o)$ $=(i . \Delta P, j . \Delta E, o . \Delta t)$, é calculado o valor da opção e determinada a taxa de corte ótima. Sendo $P_{\text {máx }}$ o preço máximo da madeira, $T$, a expiração e $\bar{E}$ o nível de saturação.

Após determinar o grid, pode ser estabelecido um valor máximo para o preço, denotado por $P_{m a ́ x}$, uma vez que não é viável trabalhar com um preço infinito no grid. Do mesmo modo, deve-se estimar um estoque máximo para estabelecer o grid. Além disso, como o tempo de expiração é considerado finito, $T$ é o valor máximo para o tempo.

O valor da opção é obtido inicialmente na data de expiração, e trabalha-se no cálculo em cada nó por um processo backwards até a data inicial, de forma que são utilizados os valores no instante $k+1$ para calcular a opção na data $k$.

Assumindo que $F(P, E, t)$ no ponto $(P, E, t)$ seja representado por $F_{i, j, k}$, onde $P=i . d P$ e $i \in(0, m), E=j . d E$ e $j \in(0, n)$ e $t=k . d t$ e $k \in(0, o)$; e as seguintes aproximações de derivadas parciais

$$
\begin{aligned}
& \frac{\partial F}{\partial t} \cong \frac{F_{i, j, k+1}-F_{i, j, k}}{\Delta t} \\
& \frac{\partial F}{\partial P} \cong \frac{F_{i+1, j, k+1}-F_{i-1, j, k+1}}{2 \Delta P} \\
& \frac{\partial^{2} F}{\partial P^{2}} \cong \frac{F_{i+1, j, k+1}-2 F_{i, j, k+1}+F_{i-1, j, k+1}}{\Delta P^{2}} \\
& \frac{\partial F}{\partial E} \cong \frac{F_{i, j+1, k+1}-F_{i, j-1, k+1}}{2 \Delta E} \\
& \frac{\partial^{2} F}{\partial E^{2}} \cong \frac{F_{i, j+1, k+1}-2 F_{i, j, k+1}+F_{i, j-1, k+1}}{\Delta E^{2}}
\end{aligned}
$$

Substituindo essas aproximações nas equações de diferenças na EDP 4.18, obtém-se $F_{i, j, k}$ em função de $F_{i^{*}, j^{*}, k+1}$, (onde $i^{*}=i, i-1, i+1$ e $\left.j^{*}=j, j-1, j+1\right)$ dada pela seguinte equação: 


$$
\begin{aligned}
& F_{i, j, k}=\frac{1}{r+\frac{1}{\Delta t}}\left[p_{i}^{+} F_{i+1, j, k+1}+p_{i}^{-} F_{i-1, j, k+1}+p^{0} F_{i, j, k+1}+p_{j}^{+} F_{i, j+1, k+1}+\right. \\
& \left.p_{j}^{-} F_{i, j-1, k+1}+f(t)\right](4.30)
\end{aligned}
$$

onde os valores $p_{i}, p_{j}$ e $p^{0}$ dependem do estado $P$ e $E$ (pois são função de $i$ e $j$ ) e são dados por

$$
\begin{aligned}
& p_{i}^{+}=\frac{\sigma_{P}^{2} i^{2}+(r-\delta) i}{2} \\
& p_{i}^{-}=\frac{\sigma_{P}^{2} i^{2}-(r-\delta) i}{2} \\
& p^{0}=\frac{1}{\Delta t}-\sigma_{P}^{2} i^{2} \\
& p_{j}^{+}=\frac{[\eta[\bar{E}-j \Delta E]](j \Delta E)-q}{2 \Delta E} \\
& p_{j}^{-}=\frac{q-[\eta[\bar{E}-j \Delta E]](j \Delta E)}{2 \Delta E}
\end{aligned}
$$

Logo, o valor desconhecido $F_{i, j, k}$ é uma função explícita dos valores de $\mathrm{F}$ conhecidos na data $k+1$. Para os valores das bordas superiores e inferiores das variáveis $P$ e $T\left(P_{\text {máx }}, P=0\right.$ e $\left.t=T\right)$, o valor da opção não é dado pela equação de $F_{i, j, k}$, e sim pelas condições de contorno, 4.19 a 4.22 . As três primeiras zeram o valor da opção; já a última altera a forma de calculá-lo e está demonstrada a seguir.

Cálculo de $\mathrm{F}\left(\mathrm{P}_{\max }, \mathrm{E}, \mathrm{t}\right)$ :

$\lim _{P \rightarrow P_{\text {máx }}} F_{P}=E-E_{\text {min }}$,

$F_{i, j, k}=\frac{1}{r+\frac{1}{\Delta t}}\left[\left(r-\delta_{P}\right)\left(E-E_{\text {min }}\right) i . \Delta P+F_{i, j, k+1}+p_{j}^{+} F_{i, j+1, k+1}+p_{j}^{-} F_{i, j-1, k+1}+\right.$ $f(t)](4.37)$

Em seguida, escolhe-se a discretização de $d P, d E$ e $d t$ para dar um balanço adequado de precisão versus tempo computacional, de forma que não ocorram problemas numéricos e o processo convirja ao valor correto.

Neste trabalho, para calcular $d P$ e $d E$, é utilizada a mesma abordagem de Dias (2015). Os valores de entrada não são os passos-espaço ( $m$ e $n$ ) e nem o passo tempo (o), mas o erro esperado $\varepsilon$. Os passos em $P$ e $E$ foram definidos como percentuais de acurácia de seus respectivos valores correntes. Desta forma, sendo $\varepsilon$ o erro esperado, a discretização é calculada da seguinte maneira 


$$
\begin{aligned}
\Delta P & =P_{0} \times \varepsilon \\
\Delta E & =E_{0} \times \varepsilon
\end{aligned}
$$

Como visto na seção 3.2.2, para que o MDF explícitas seja estável a quantidade de passos-tempo deve considerar a condição crítica relativa ao $p^{0}$, e, portanto, o valor de $\Delta t$ é dado pela equação (4.40).

$$
\Delta t=\frac{\Delta P^{2}}{\sigma_{P}^{2} P_{\max }^{2}}
$$

No caso em que o estoque possui a componente estocástica, ou seja , para o modelo logístico estocástico, a EDP possui uma derivada parcial de segunda ordem em relação ao estoque, conforma mostra a equação 4.41. Este termo adicional consequentemente, gera modificações no método. Os pesos devem ser modificados conforme as equações $4.42,4.43$ e 4.44 ; os demais relacionados ao preço permanecem os mesmos.

$$
\begin{aligned}
& r F=F_{t}+\frac{1}{2} F_{P P} \sigma^{2} P^{2}+F_{E}\{[\eta[\bar{E}-E(t)]] E(t)-q(t)\}+\frac{1}{2} F_{E E} \sigma_{E}^{2} E^{2}+(r- \\
& \left.\delta_{P}\right) F_{P} P+f(t) \\
& p^{0}=\frac{1}{\Delta t}-\sigma_{P}^{2} i^{2}-\sigma_{E}^{2} j^{2} \\
& p_{j}^{+}=\frac{\sigma_{E}^{2}}{2}+\frac{[\eta[\bar{E}-j \Delta E]](j \Delta E)-q}{2 \Delta E}(4.43) \\
& p_{j}^{-}=\frac{\sigma_{E}^{2}}{2}-\frac{[\eta[\bar{E}-j \Delta E]](j \Delta E)-q}{2 \Delta E}(4.44)
\end{aligned}
$$

Além disso, como $p^{0}$ é diferente, o cálculo da condição de estabilidade do problema que depende de $d t$ é diferente para o caso estocástico. Logo, a equação do espaço-tempo será determinada conforme mostrado a seguir.

$$
\Delta t=\frac{1}{\frac{\sigma_{P}^{2} \max ^{2}}{\Delta P^{2}}+\frac{\sigma_{E}^{2} \bar{E}^{2}}{\Delta E^{2}}}
$$

Após aplicar os modelos supracitados, foi aplicada a metodologia do Valor Presente Líquido (VPL). Dessa forma, compara-se o valor de mercado dado pela 
metodologia de opções reais com a abordagem de avaliação tradicional. A abordagem tradicional não é capaz de quantificar o valor intrínseco em relação à flexibilidade de poder suspender a produção temporariamente e é dada pelo fluxo de caixa esperado descontado pela taxa ajustada ao risco do projeto como mostrado abaixo

$$
\begin{aligned}
& \sum_{t=0}^{T} \frac{F C\left(P_{0}, q, t\right)}{(1+\mu)^{t}}=\sum_{t=0}^{T} \frac{(1-\tau)\left[\left(P_{0} q\right)-(\text { custo })\right]}{(1+\mu)^{t}} \\
& \text { custo }=c_{1} q+\frac{c_{2} q^{2}}{2}
\end{aligned}
$$

Neste trabalho, são realizadas duas aplicações para este modelo. Primeiramente, foi considerada a taxa de corte $q$ como sendo fixa e realizada a cada período. Em seguida foi feita uma aplicação levando em conta a maximização do fluxo de caixa de modo a obter uma taxa de corte ótima $-q^{*}$, que varia em função do preço e dos custos. Além disso, considera-se a variação do estoque conforme o corte é efetuado. Maiores detalhes sobre esta aplicação estão descritos no próximo capítulo. 


\section{5}

\section{Aplicação}

\section{1.}

\section{Estudo hipotético de um investimento florestal}

Tendo em vista a modelagem proposta no Capítulo 4, o presente trabalho apresenta a aplicação em um projeto hipotético de investimento florestal ${ }^{7}$. No primeiro modelo, chamado aqui de modelo logístico, evoluções do preço e do estoque são dadas pelas equações 5.1 e 5.2, repetidas a seguir para facilitar a leitura. O preço segue um Movimento Geométrico Browniano (MGB) e o estoque, para esta análise inicial, segue a equação logística apresentada a seguir. Posteriormente, são feitas aplicações com o estoque seguindo um processo equivalente com termo estocástico, bem como o caso com a escolha da taxa de corte mais simplificada.

$\frac{d P^{Q}}{P}=(r-\delta) d t+\sigma d z^{Q}$

$d E=[\eta[\bar{E}-E(t)] E(t)] d t-q(E, P, t) d t$

O projeto é considerado como tendo um período total de 10 anos. Os parâmetros utilizados nesta análise são mostrados na Tabela 5.1.

\footnotetext{
${ }^{7}$ Os dados obtidos pelo CEPEA referem-se à uma floresta de eucalipto destinada à serraria $\mathrm{e}$ localizada na cidade de Sorocaba - São Paulo.
} 
Tabela 5.1 - Parâmetros utilizados para análise dos resultados do modelo.

Parâmetros

\begin{tabular}{lll}
\hline \hline Taxa de retorno livre de risco & $\mathrm{r}$ & $5 \%$ a.a. \\
Preço atual da madeira & $\mathrm{P}_{0}$ & $\mathrm{R} \$ 50 / \mathrm{m}^{3}$ \\
Preço máximo & $\mathrm{P}_{\max }$ & $\mathrm{R} \$ 500 / \mathrm{m}^{3}$ \\
Volatilidade do Preço & $\sigma$ & $18 \%$ a.a \\
Taxa de Conveniência & $\delta$ & $4,6 \%$ a.a. \\
Estoque corrente & $\mathrm{E}_{0}(\mathrm{mil})$ & $100 \mathrm{~m}^{3} / \mathrm{ha}$ \\
Estoque mínimo & $\mathrm{E}_{\min }(\mathrm{mil})$ & $30 \mathrm{~m}^{3} / \mathrm{ha}$ \\
Nível de saturação do estoque & $\bar{E}(\mathrm{mil})$ & $600 \mathrm{~m}^{3} / \mathrm{ha}$ \\
Velocidade de Reversão a média & $\eta$ & 0.0004 \\
Expiração & $\mathrm{T}$ & 10 anos \\
Alíquota de Imposto* & $\tau$ & $15 \%$ a.a. \\
Custo Variável Linear & $\mathrm{c}_{1}$ & $\mathrm{R} \$ 10 / \mathrm{m}^{3}$ \\
Custo Variável Quadrático & $\mathrm{c}_{2}$ & $\mathrm{R} \$ 5 / \mathrm{m}^{3}$ \\
\hline
\end{tabular}

Fonte: Elaboração própria.

*Alíquota de imposto de renda - IR obtida segundo a Lei No 9.393 (Brasil, 1996) para uma floresta com área total de 500 a 1000 hectares e um grau de utilização da terra de pelo menos $80 \%$. Apenas o IR foi considerado como imposto sobre o lucro. Qualquer outro imposto que incida sobre o lucro pode ser adicionado sem que comprometa os resultados.

Os dados da população de eucalipto para o nível de saturação e estoque mínimo foram considerados os mesmos do trabalho de Rodriguez, Bueno, Rodrigues (1997), que utilizam uma curva de crescimento tradicional para o meio florestal pelo modelo de Schumacher (1939) ajustado para um conjunto de dados contendo informações provenientes de alguns eucaliptais paulistas. Segundo este modelo, o nível de saturação do estoque é $600 \mathrm{mil} \mathrm{m}$ 3/ha e o estoque mínimo, a ser

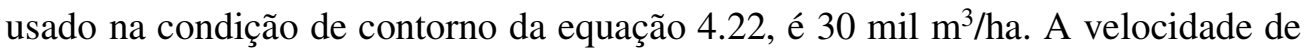
reversão à média utilizada foi $\eta=0,0004$ mencionada na Seção 4.2.2, que mostra como o modelo que usa a equação logística deve se comportar.

Para a análise, utilizou-se a base de dados dos preços médios de eucalipto, proveniente da Região de Sorocaba. As informações foram disponibilizadas pelo Centro de Estudos Avançados em Economia Aplicada - CEPEA, para o período entre junho de 1998 até maio de 2015. A unidade do preço divulgado é dada em estéreo, de modo que para prosseguir o desenvolvimento realiza-se a conversão de para metros cúbicos $\left(\mathrm{m}^{3}\right)$. Em seguida os preços são deflacionados, tendo abril de 2015 como mês base. Ao obter os preços reais mensais para $\mathrm{o}^{3}$ de eucalipto, estimam-se os parâmetros de volatilidade e taxa de conveniência. Com base na série histórica de preços de madeira e nas estimativa mostrada nas equações 4.6 e 4.7 
foram obtidos os valores aplicados para a tendência ( $\alpha=4,8 \%$ a.a.) e volatilidade ( $\sigma=18 \%$ a.a.). A taxa de retorno livre de risco, assim como a taxa de conveniência foram as mesmas empregadas por Moreira et al. (2000). O preço máximo, considerado como sendo o preço no limite tendendo a infinito, é R $\$ 500 / \mathrm{m}^{3}$, já que a série não supera o valor de $\mathrm{R} \$ 95,00$ no período analisado.

Além dos parâmetros do preço, os custos variáveis linear e quadrático considerados são, respectivamente, $R \$ 10 / \mathrm{m}^{3}$ e $\mathrm{R} \$ 5 / \mathrm{m}^{3}$, mas para ambos serão feitas análises de sensibilidade. O custo variável linear é o mais utilizado na literatura de opções reais e incorpora o custo de implementação e manutenção. Já o custo variável quadrático, utilizado na literatura por Morck, Schwartz e Stangeland (1989), possui uma importância econômica para o problema porque incorpora possíveis custos adicionais, como taxas extraordinárias, custos adicionais de estocagem e deslocamento, dentre outros.

Para aplicação do Método de Diferenças Finitas explícitas (MDF explícitas) apresentado no Capítulo 4, a partir das equações discretizadas correspondentes ao modelo proposto, foi desenvolvido um software escrito em linguagem Java. O Apêndice ao final da dissertação apresenta a interface do programa.

Ao invés de se supor um grid fixo, foi considerado um grid dependente do erro esperado $\varepsilon$, que é um dado de entrada. Este erro determina o grau de discretização do preço e do estoque, pois o valor é empregado no passo-espaço do estoque e do preço, mencionado no Capítulo 4. Desta forma, considera-se um valor mais eficiente do ponto de vista da relação custo / beneficio em relação ao tempo de processamento do programa e, ao mesmo tempo, tal que gera resultados satisfatórios e confiáveis. Assim, para todas as análises, o erro esperado adequado foi a tolerância $\varepsilon=5 \%$, pois para valores maiores o tempo de processamento aumenta consideravelmente.

Para explorar a política de corte ótimo, deve-se fazer suposições a respeito do preço futuro e do nível de estoque. Se assumirmos que essas variáveis crescem pelas suas taxas históricas, uma política de corte ótimo em relação ao tempo pode ser obtida, como apresentado nas figuras subsequentes. As taxas de corte ótimo são baseadas em duas suposições: (i) o preço inicial de madeira (no caso base R $\$ 50$ ) cresce pela taxa neutra ao risco, (ii) o estoque é calculado com base na equação 4.10, que é o valor do estoque levando em consideração o crescimento logístico. Além disso, do valor do estoque ao longo do tempo E(t), é deduzido o corte efetuado 
no período anterior. Dessa forma, os gráficos mostram como a taxa de corte varia com o passar do tempo tendo em vista a variação do preço e estoque.

\section{2.}

\section{Resultados para o modelo logístico}

Inicialmente, devem-se assumir suposições a respeito do preço e do nível de estoque, que, como descrito na seção anterior, seguem as equações 5.1 e 5.2, respectivamente.

Para o caso base, em que o preço inicial é $\mathrm{R} \$ 50,00$ e o estoque inicial é 100 mil $\mathrm{m}^{3}$, e considerando uma taxa de desconto ajustada ao risco do projeto de $9 \%$ a.a., o resultado obtido pela metodologia tradicional para o VPL em que o corte é fixo $\left(q=15 \mathrm{~m}^{3} /\right.$ ano $)$ e efetuado em todos os períodos é $\mathrm{R} \$ 236$ mil. Ao considerar a otimização da taxa de corte o resultado para o VPL tradicional é R\$ 1.009 mil. Já o resultado obtido pela Teoria das Opções Reais (TOR), em que se calcula a taxa de corte ótima, é R\$ 1.411 mil. Logo a avaliação do projeto pela TOR é mais do que duas vezes maior comparada à encontrada pelo VPL no primeiro caso e aproximadamente $40 \%$ maior que o VPL no segundo modelo.

Algumas análises relativas à política de corte são realizadas a partir das Figuras 5.1 a 5.3. Para obter os gráficos relacionados com a taxa de corte, assumese que o preço inicial da madeira cresce de acordo com a sua taxa esperada e que o estoque é recalculado para cada período diminuindo o corte efetuado no período anterior. Várias similaridades são observadas em relação ao trabalho de Morck, Schwartz e Stangeland (1989). Na Figura 5.1, é apresentada a taxa de corte ao longo do tempo para diferentes valores de estoque inicial e observa-se que a maior parte do estoque é cortada durante a primeira metade do período de investimento. Além disso, quanto maior o estoque inicial, maior o período de corte. Esse resultado é similar ao encontrado por Morck, Schwartz e Stangeland (1989), pois, a taxa de corte diminui ao longo do tempo e à medida que o estoque aumenta, o tempo de corte é ampliado. Deste modo, a política ótima de corte deve seguir este comportamento. 


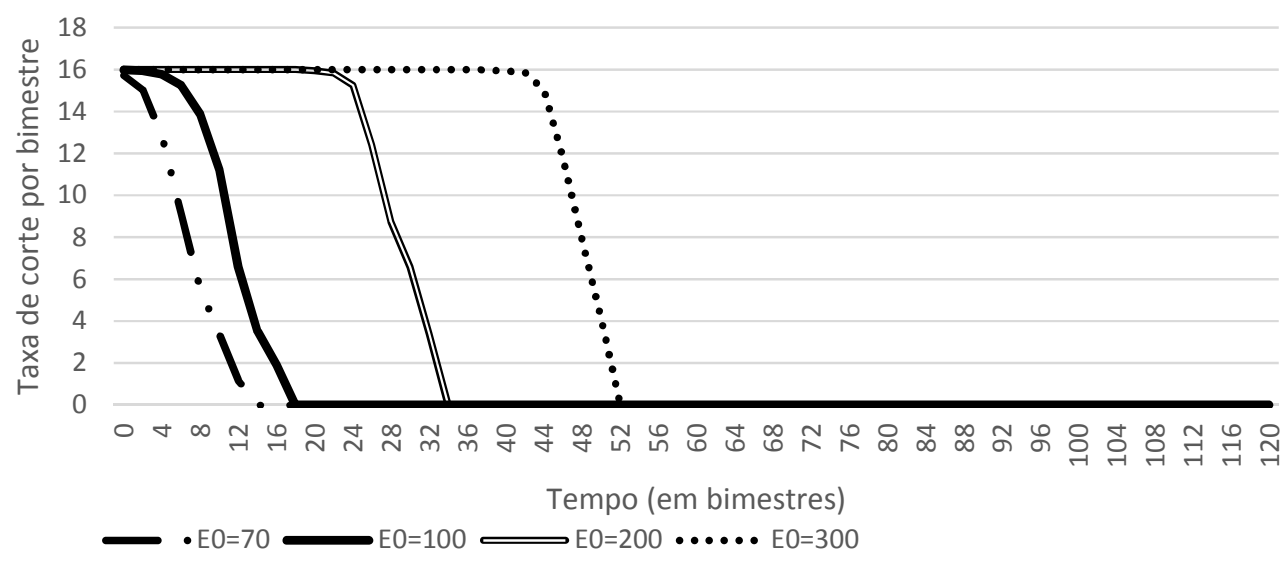
iniciais

Figura 5.1 - Taxa de corte vs. Tempo para diferentes níveis de estoques

Fonte: Elaboração própria

A Figura 5.2 apresenta as taxas de corte ao longo do tempo considerando diferentes preços iniciais. Como esperado, observa-se que, quanto maior o preço inicial, maior é o incentivo para cortar a floresta mais rapidamente nos primeiros períodos, assim como o resultado mostrado no trabalho de Morck, Schwartz e Stangeland (1989). A diferença é que no presente trabalho o corte é efetuado mais rapidamente e num menor período de tempo a floresta é cortada, provavelmente pela escolha dos parâmetros.

A Figura 5.3 mostra a sensibilidade da taxa de corte para a volatilidade dos preços. Uma volatilidade maior implica num valor de opção maior e postergar o exercício pode ser consequentemente melhor do que cortar imediatamente. Observa-se a formação de picos à medida que a volatilidade aumenta, sendo uma possível explicação para este comportamento o fato de estar se usando uma discretização maior, ou seja, um grid mais fino e um período bimestral para a análise. 


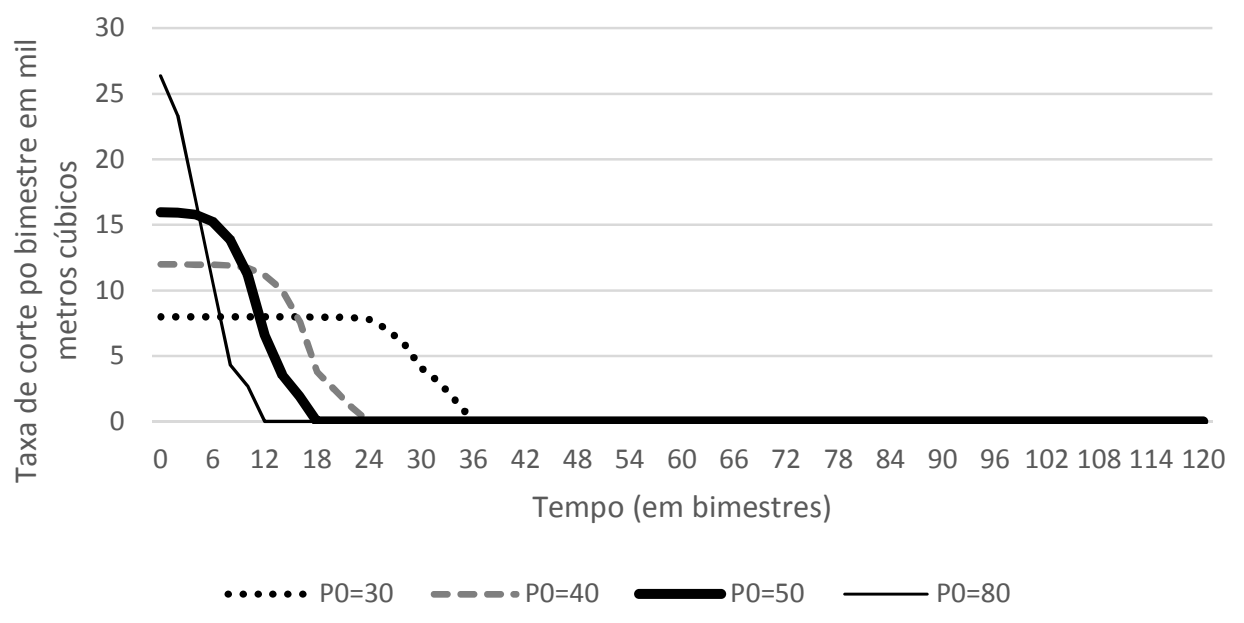

Figura 5.2 - Taxa de corte vs. Tempo para diferentes níveis de preços iniciais Fonte: Elaboração própria

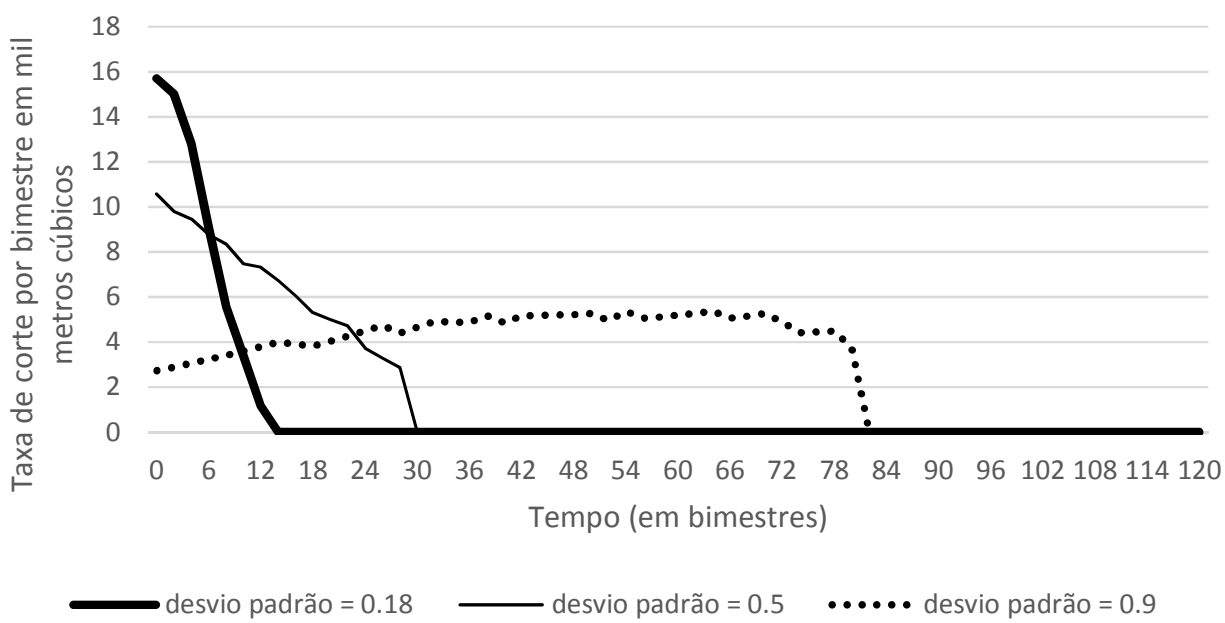

Figura 5.3 - Taxa de corte vs. Tempo para diferentes níveis de volatilidade Fonte: Elaboração própria

Considerando o valor do investimento dada a opção de cortar as árvores em diferentes momentos do período considerado, as Figuras de 5.4 a 5.9 ilustram a sensibilidade do valor da empresa florestal no inicio do projeto, para diferentes níveis de estoque iniciais, preço inicial, velocidade de reversão, volatilidade, tempos para a expiração, taxa livre de risco e custo quadrático.

Na Figura 5.4, pode-se verificar que o valor da floresta em relação ao preço inicial é uma função crescente dos níveis de estoque, ou seja, quanto maior o estoque, maior será o valor da opção. Essa mesma análise foi feita por Morck, Schwartz e Stangeland (1989), e os autores obtiveram resultado análogo. Porém, aqui se pode observar também que a diferença entre o valor da opção para diferentes 
estoques iniciais só é realmente relevante quando os preços iniciais são maiores. Além disso, quanto maior o nível de estoque, menor a diferença entre os valores da opção.

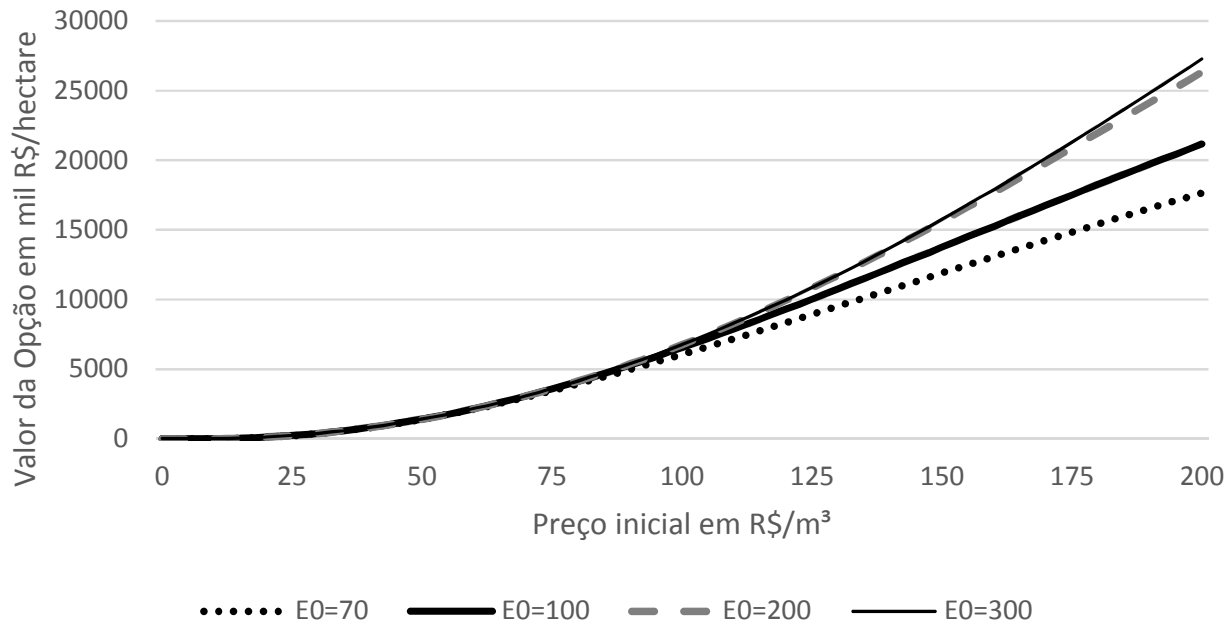

Figura 5.4 - Valor da Opção em mil R\$ por hectare vs. Preço para diferentes estoques iniciais

Fonte: Elaboração própria

A Figura 5.5 mostra que o valor da floresta em relação ao preço inicial aumenta mais rápido para maiores níveis da velocidade de reversão à média. Tendo em vista que o aumento da velocidade de reversão aumenta a taxa de crescimento da floresta, o valor da opção é diretamente afetado.

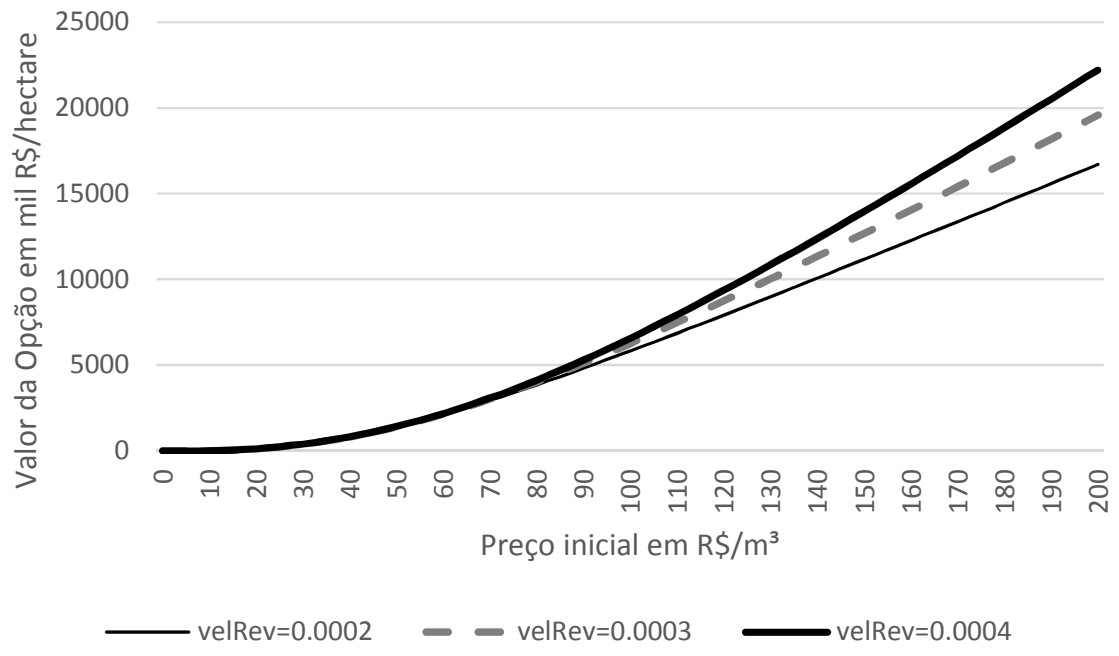

Figura 5.5 - Valor da Opção em mil R \$ por hectare vs. Preço para diferentes velocidades de reversão à média

Fonte: Elaboração própria 


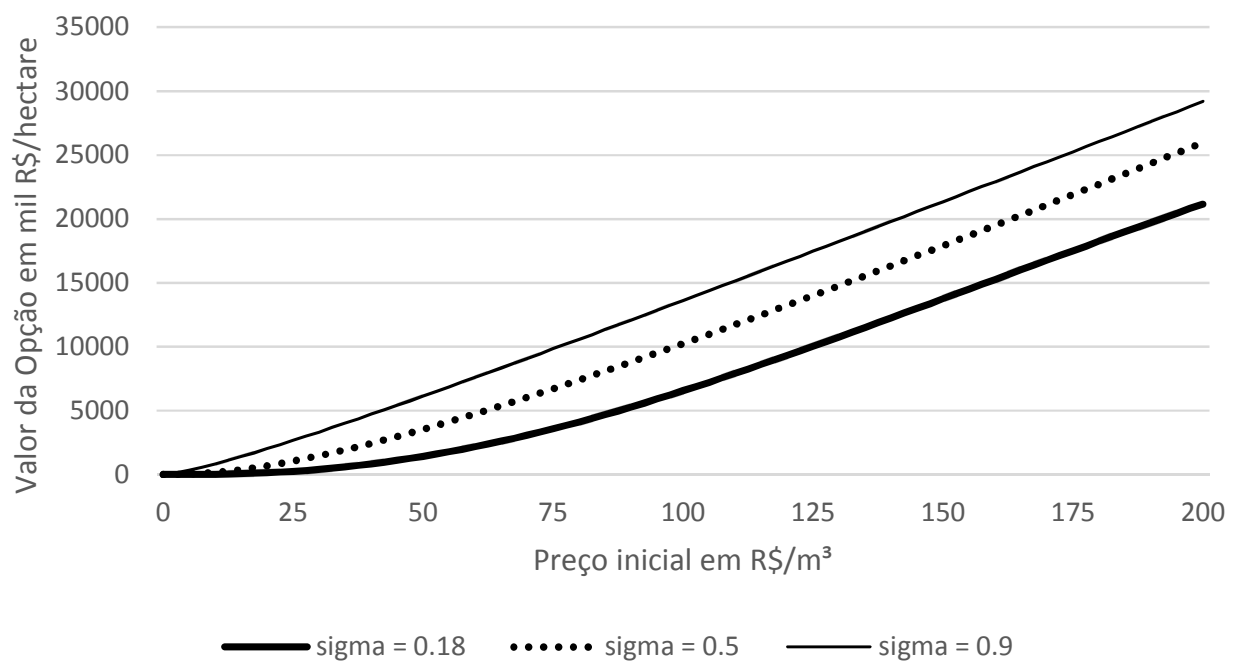

Figura 5.6 - Valor da Opção em mil R\$ por hectare vs. Preço para diferentes volatilidade do preço

Fonte: Elaboração própria

A Figura 5.6 apresenta o valor da opção em função do preço inicial para diferentes níveis de desvio-padrão do processo estocástico do preço. Esse resultado apresenta similaridades com o apresentado por Insley (2002), Rocha et al (2004) e Moreira et al (2000) porque, quanto maior a incerteza, maior o valor do projeto. Porém, ao otimizar a quantidade de madeira a ser cortada e utilizando a equação logística de crescimento para o estoque, o valor da opção se torna menos sensível a uma variação na volatilidade do preço. Logo, quando o preço inicial chega a um determinado patamar, ele não influencia mais na variação do valor da opção, mesmo com uma volatilidade mais alta.

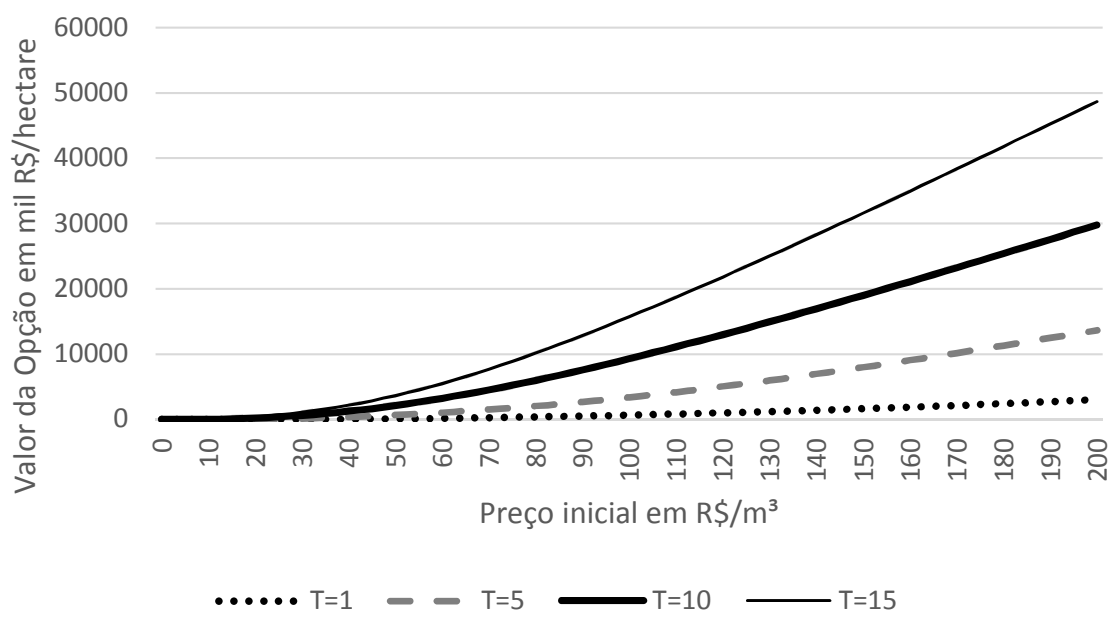

Figura 5.7 - Valor da Opção em mil R\$ por hectare vs. Preço para diferentes tempos de expiração

Fonte: Elaboração própria 
Como esperado, a Figura 5.7 ilustra que o valor da floresta em relação ao preço inicial é maior para os casos em que tempo para a expiração é maior, assim como observado por Rocha et al (2004). A diferença é que, conforme apresentado pelos autores citados, no caso de prazos mais longos para a expiração, ou seja, para um tempo de expiração maior, o valor da opção vai se tornando mais sensível a variação no preço inicial.

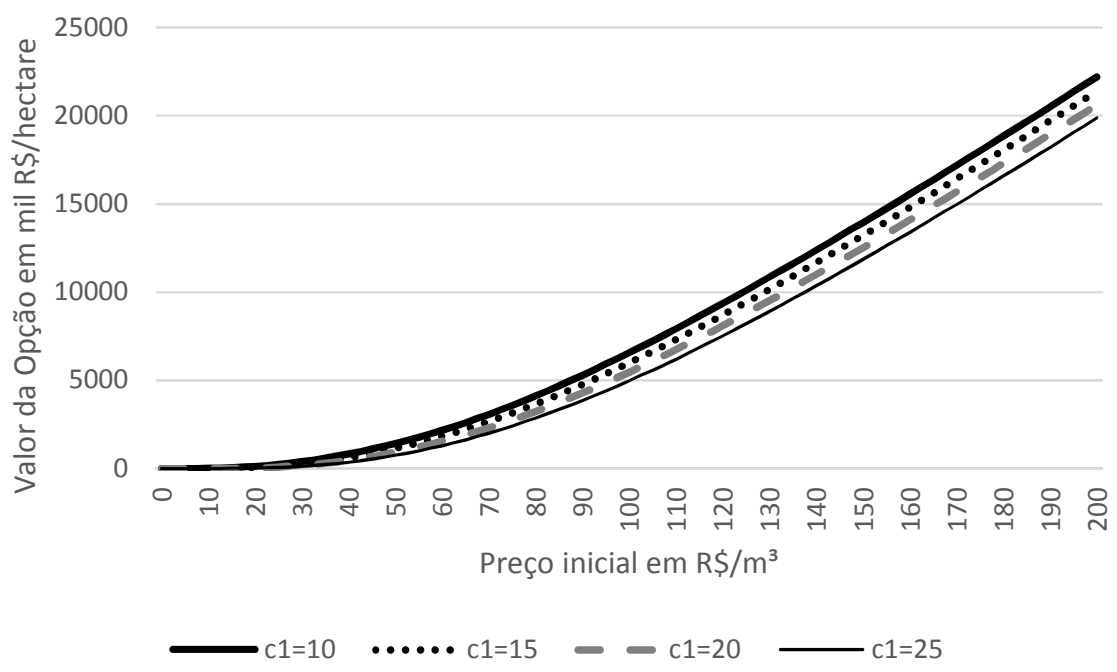

Figura 5.8 - Valor da Opção em mil R \$ por hectare vs. Preço para diferentes custos variáveis lineares

Fonte: Elaboração própria

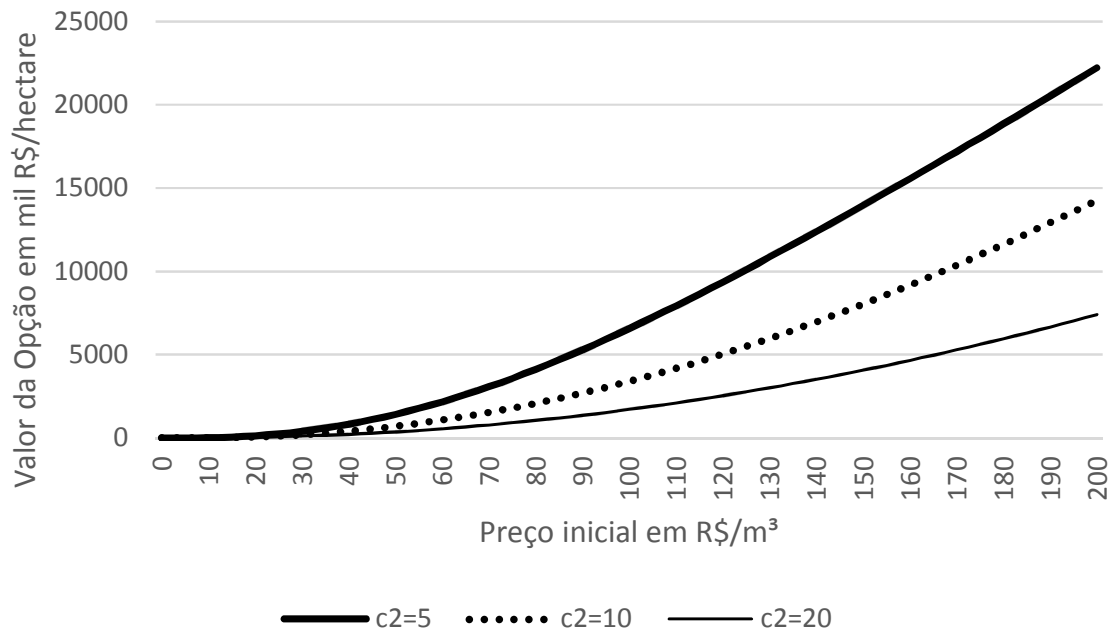

Figura 5.9 - Valor da Opção em mil R\$ por hectare vs. Preço para diferentes custos variáveis quadráticos

Fonte: Elaboração própria

As Figuras 5.8 e 5.9 ilustram que o valor da floresta em relação ao preço inicial é menor para maiores níveis dos custos variáveis, tanto linear quanto 
quadrático. Observa-se que a opção possui maior sensibilidade em relação ao custo quadrático comparativamente ao custo linear.

\section{3.}

\section{Resultados para o modelo logístico com componente estocástica}

Neste segundo modelo analisado, as evoluções do preço e do estoque são dadas pelas equações 5.3 e 5.4, aqui repetidas para facilitar a leitura

$$
\begin{aligned}
& \frac{d P^{Q}}{P}=(r-\delta) d t+\sigma d z^{Q} \\
& d E=[\eta[\bar{E}-E(t)] E(t)] d t-q(E, P, t) d t+\sigma_{E} d z
\end{aligned}
$$

A metodologia utilizada é equivalente à do caso acima com a suposição adicional de incerteza em relação ao estoque. No caso base, é considerada uma volatilidade de $10 \%$ a.a. para o volume de madeira. O resultado para o valor da opção para este caso é $\mathrm{R} \$ 1.410$ mil.

As Figuras 5.10, 5.11 e 5.12 apresentam os resultados análogos aos encontrados para o modelo anterior para a política ótima de corte ao longo do tempo, considerando diferentes valores de estoque inicial, preço inicial e volatilidade. Observa-se que os resultados apresentam similaridade com os encontrados para o modelo anterior.

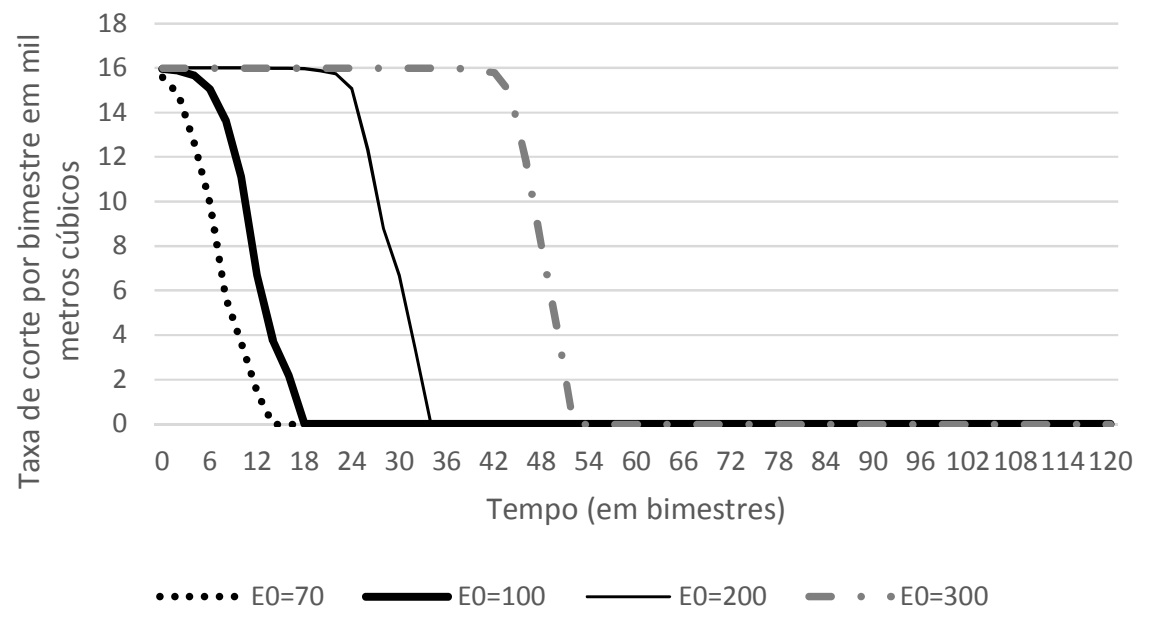

Figura 5.10 - Taxa de corte vs. Tempo para diferentes níveis de estoques iniciais

Fonte: Elaboração própria 


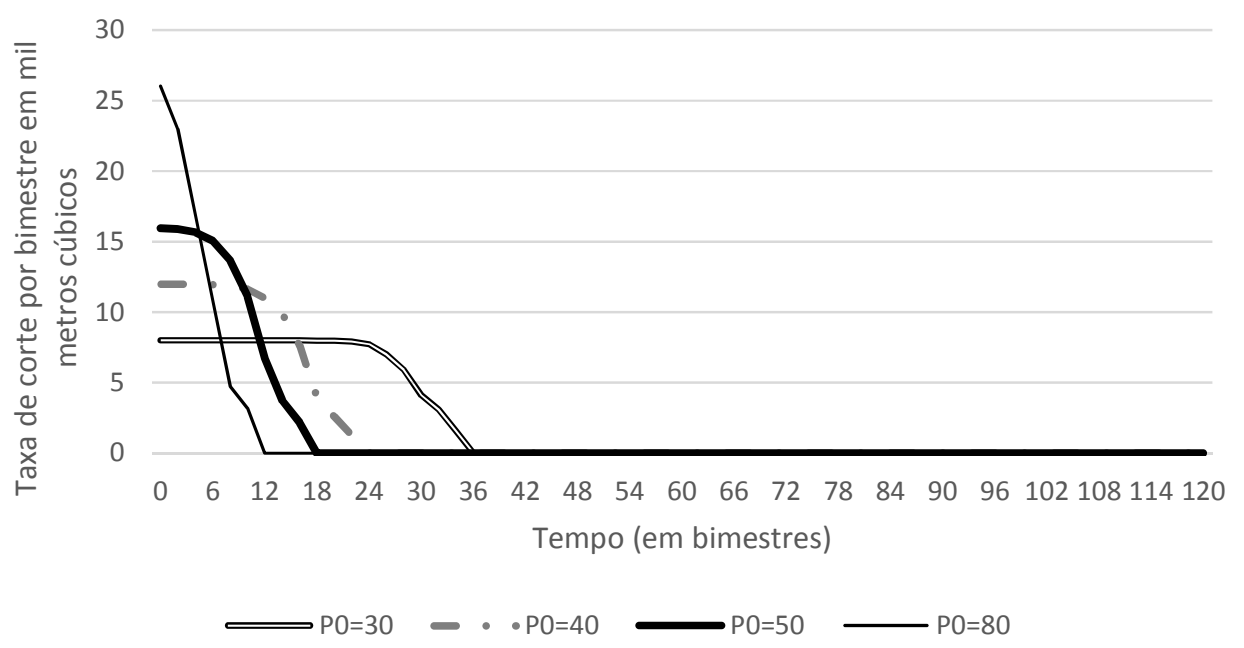

Figura 5.11 - Taxa de corte vs. Tempo para diferentes níveis de preço iniciais Fonte: Elaboração própria
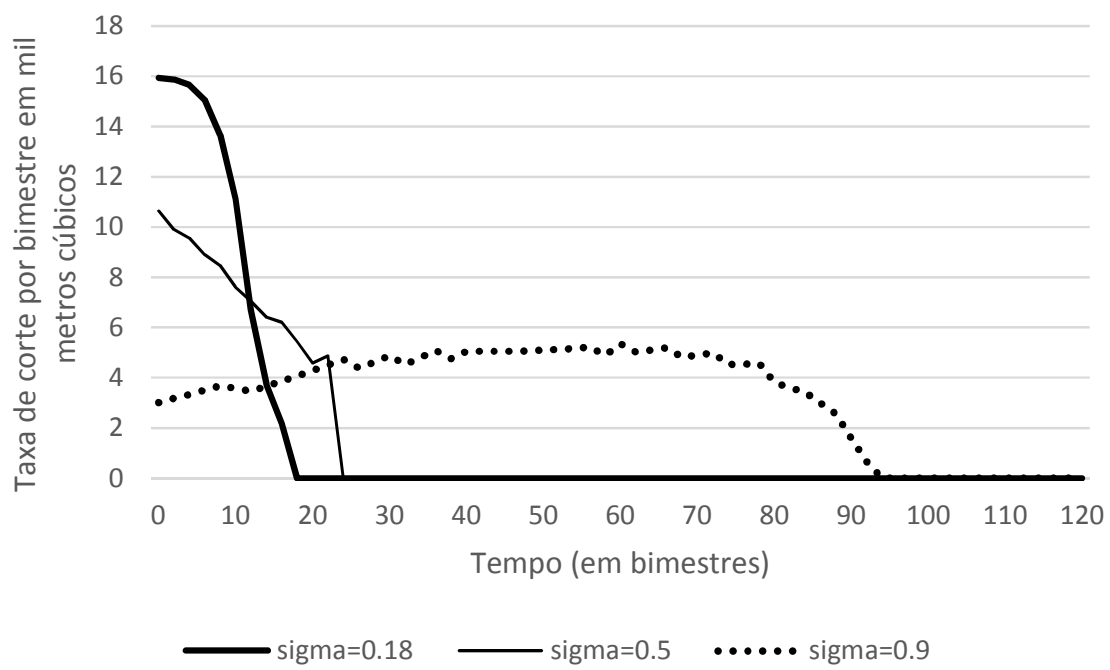

Figura 5.12 - Taxa de corte vs. Tempo para diferentes níveis de volatilidade do preço

Fonte: Elaboração própria

Nas Figuras 5.13 e 5.14 é mostrado como a taxa de corte varia com o passar do tempo para diferentes valores de custo variáveis - linear e quadrático. Verificase que, com o aumento do custo tanto linear quanto quadrático, a taxa de corte diminui e o corte propriamente dito é realizado por um período mais prolongado. Pode-se notar que a sensibilidade da taxa de corte em relação ao custo variável quadrático é maior do que o linear. Ou seja, custos adicionais ao longo do projeto podem acarretar num efeito negativo no valor final do investimento. Tal 
constatação indica que se deve fazer uma avaliação detalhada dessa variável para que o projeto seja mais corretamente avaliado.

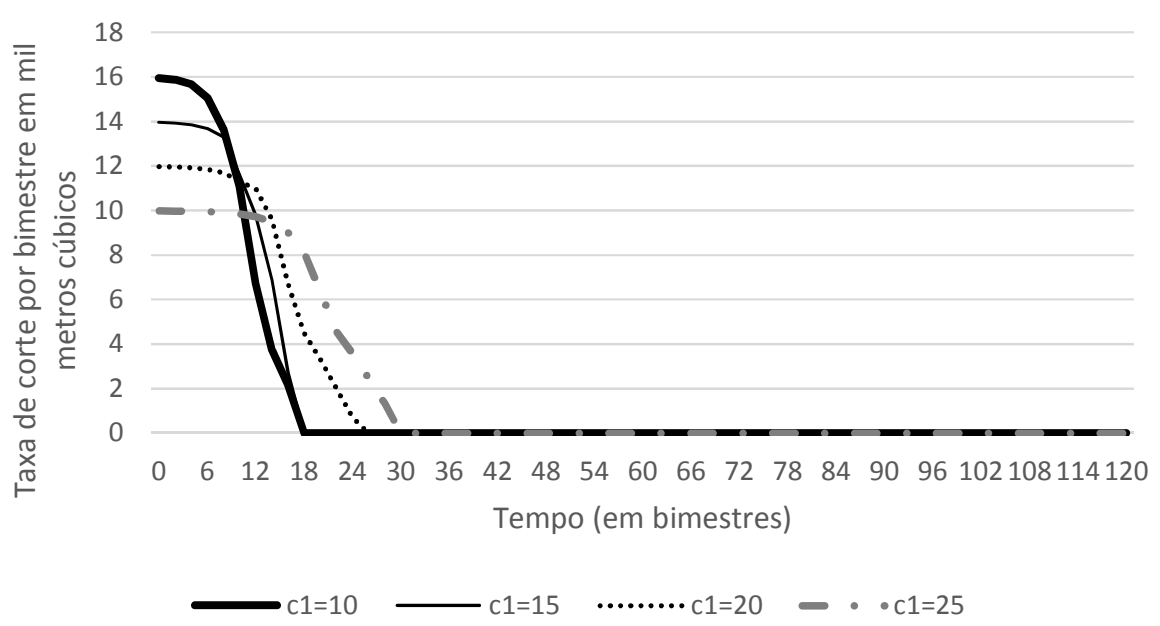

Figura 5.13 - Taxa de corte vs. Tempo para diferentes níveis de custos variáveis lineares

Fonte: Elaboração própria

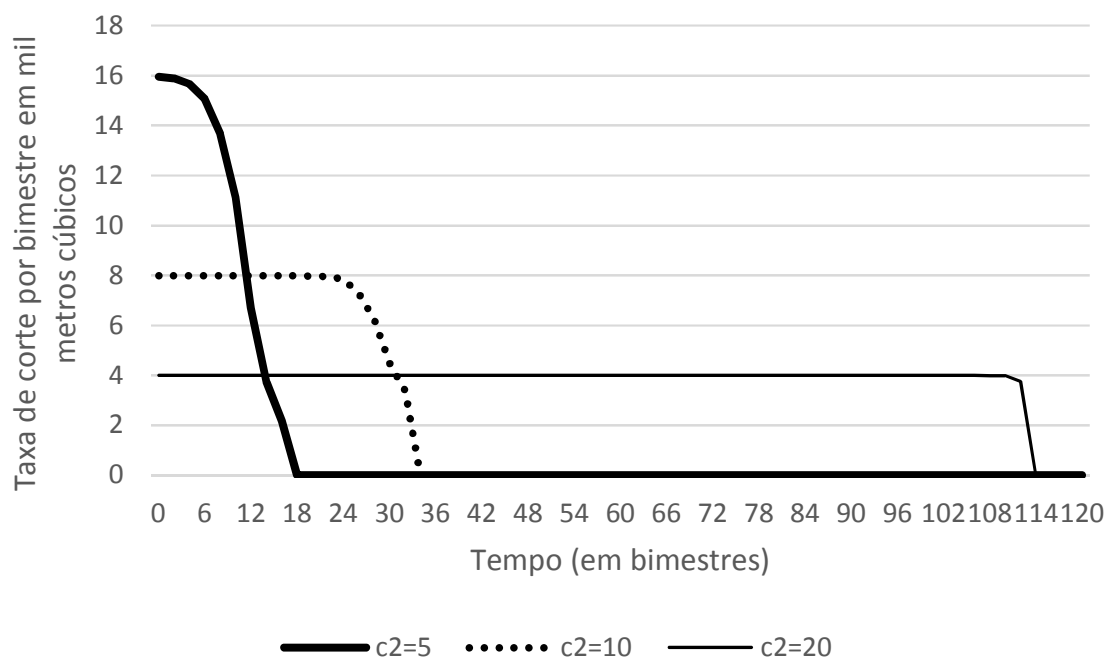

Figura 5.14 - Taxa de corte vs. Tempo para diferentes níveis de custos variáveis quadráticos

Fonte: Elaboração própria 


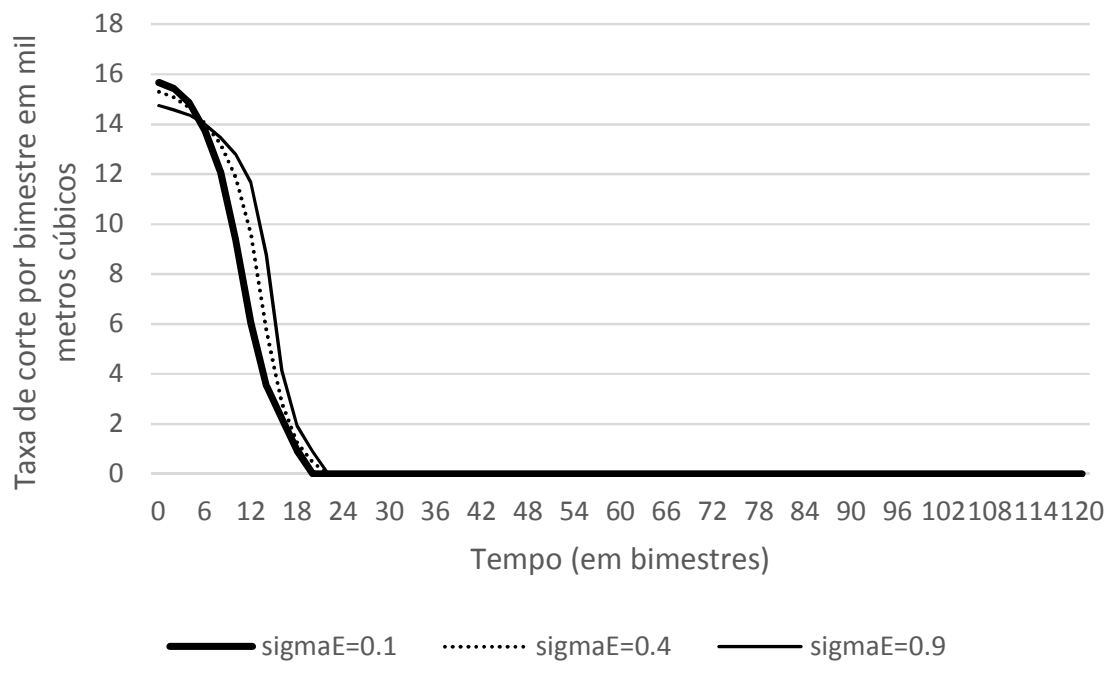

Figura 5.15 - Taxa de corte vs. Tempo para diferentes níveis de volatilidade do estoque

Fonte: Elaboração própria

A Figura 5.15 mostra a variação da taxa de corte com o passar do tempo para diferentes valores de volatilidade para o estoque. Verifica-se que o efeito do aumento da volatilidade na taxa de corte é indefinido, assim como no modelo apresentado por Pindyck (1984). Inicialmente maiores volatilidades geram uma taxa de corte menor, porém esse efeito é inverso a partir de um determinado momento. $\mathrm{O}$ aumento da incerteza do estoque faz com que a taxa de corte perdure por um tempo maior. Porém esta variação mostra-se menos sensível do que no caso da incerteza do preço.

As Figuras 5.16 a 5.18 mostram o valor da opção em relação ao preço inicial, para diferentes níveis de parâmetros dos processos estocásticos de evolução do preço e para o estoque para este segundo modelo.

A Figura 5.16 mostra que quanto maior o estoque inicial, maior será o valor da opção, o que é mostrado também na Figura 5.4 para o modelo logístico anterior. Esse resultado é também similar ao apresentado por Morck, Schwartz e Stangeland (1989). 


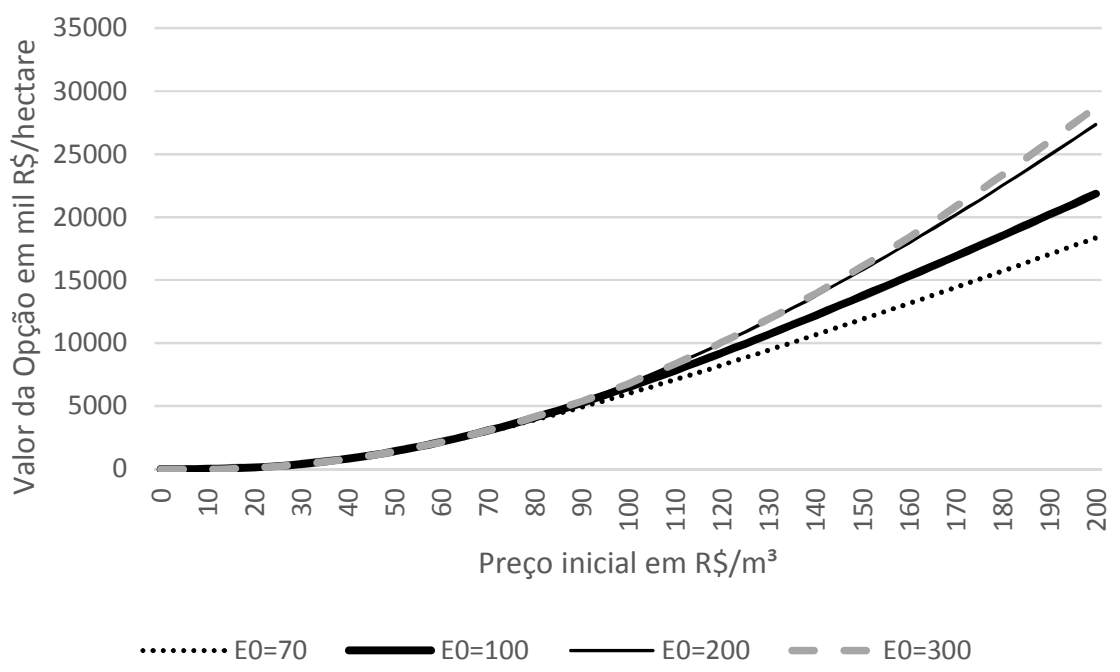

Figura 5.16 - Valor da Opção em mil R\$ por hectare vs. Preço para diferentes Estoques iniciais

Fonte: Elaboração própria

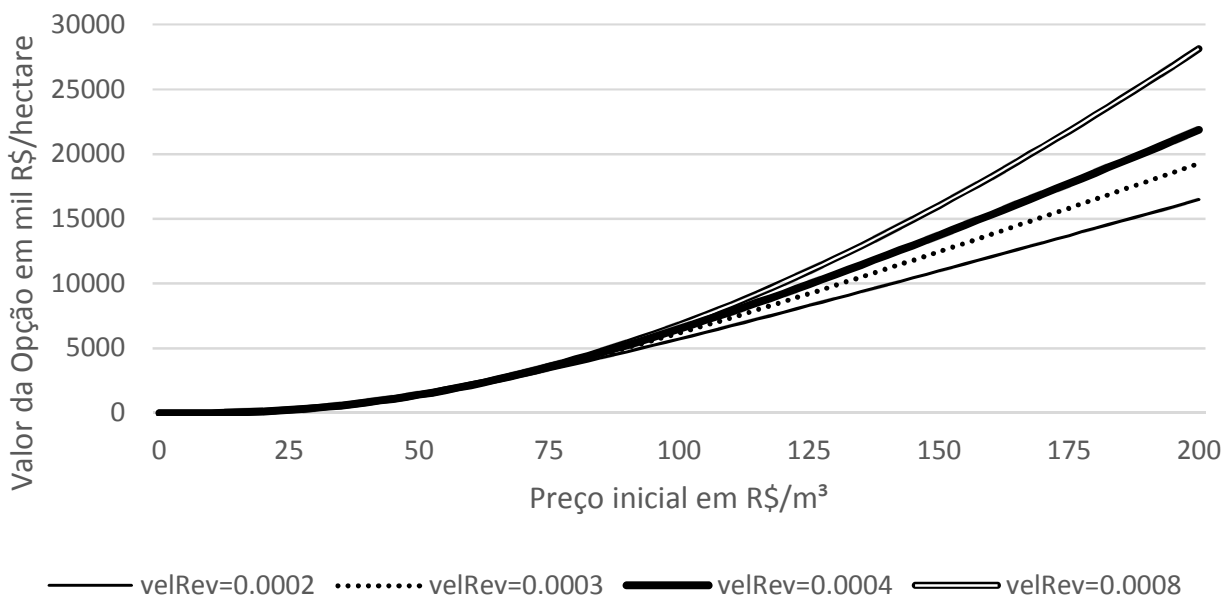

Figura 5.17 - Valor da Opção em mil R\$ por hectare vs. Preço para diferentes velocidades de reversão à média

Fonte: Elaboração própria

A Figura 5.17 mostra que quanto maior a velocidade de reversão à média do estoque, maior o valor da opção com o aumento do preço, pois a velocidade de reversão à média maior acarreta numa maior taxa de crescimento do volume de árvores, valorizando assim o investimento.

A Figura 5.18 mostra que a taxa de conveniência do preço possui uma relação inversa com o valor da opção, pois, quanto maior a taxa de conveniência, menor é o valor da opção com o aumento do preço. Esse resultado pode ser examinado matematicamente porque este é um fator que diminui a tendência neutra ao risco de crescimento dos preços. Além disso, a taxa de conveniência pode também ser 
chamada de taxa de retorno da escassez (Dias, 2015), de forma que, quando os estoques de um produto estão elevados, a probabilidade de ocorrer interrupção do suprimento é baixa, fazendo a taxa de conveniência ser baixa. Portanto, pode-se perceber que, consequentemente, quanto menor a taxa de conveniência, maior o valor da opção.

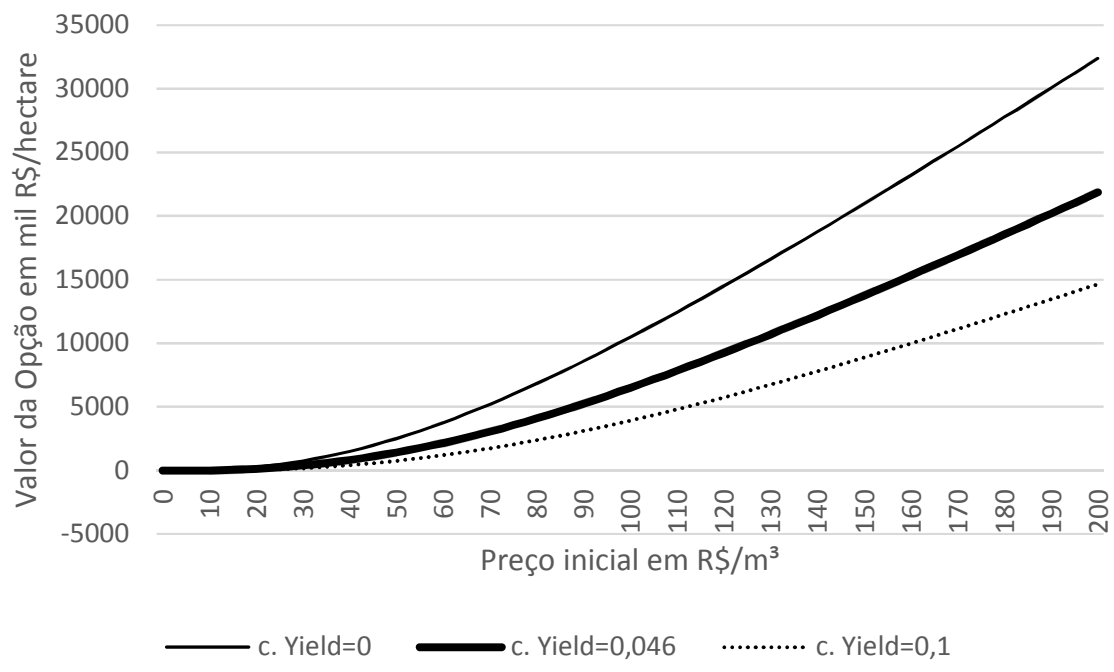

Figura 5.18 - Valor da Opção em mil R \$ por hectare vs. Preço para diferentes taxas de conveniência

Fonte: Elaboração própria

A Figura 5.19 mostra a variação do valor da opção em relação ao estoque inicial para diferentes volatilidades do volume de árvores. O resultado mostra que o aumento da incerteza em relação ao estoque diminui o valor da opção. Como justificado por Moreira et al (2000), o sinal negativo na EDP dada pela equação 4.41 pode ser inspecionado para verificar este fato. Portanto, o resultado é similar ao apresentado pelos referidos autores. 


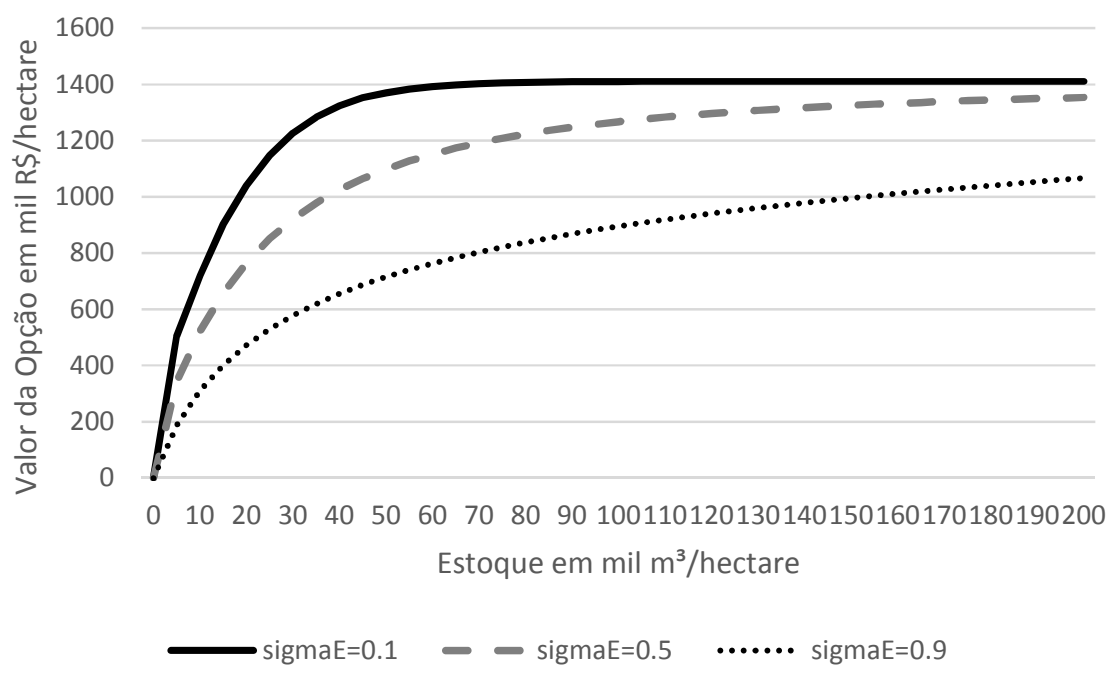

Figura 5.19 - Valor da Opção em mil R \$ por hectare vs. Estoque inicial para diferentes volatilidades do estoque

Fonte: Elaboração própria

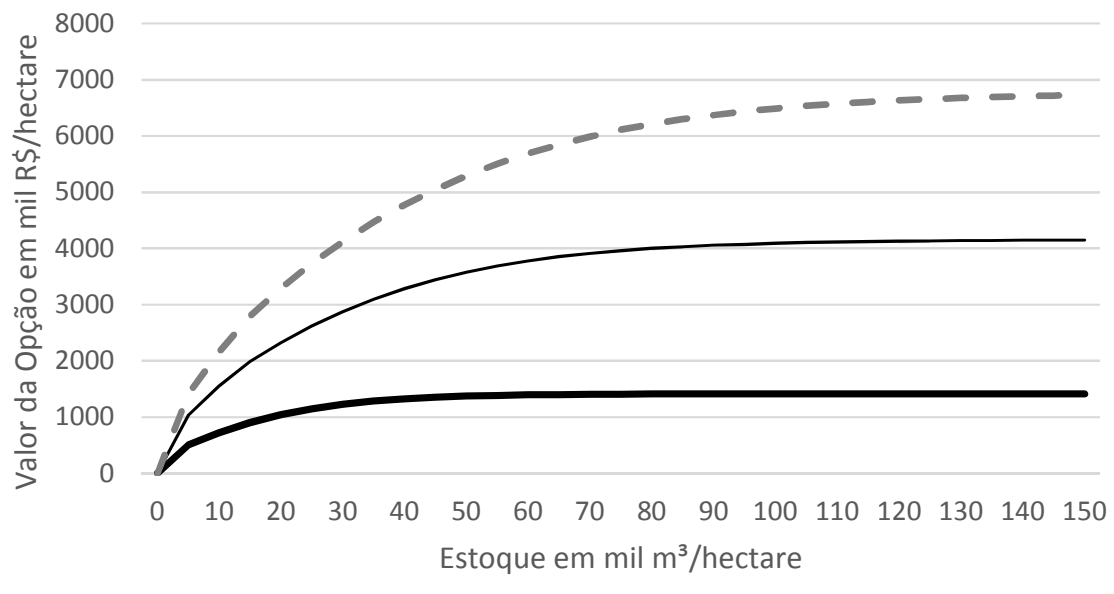

$\longrightarrow \mathrm{PO}=50 \longrightarrow \mathrm{P} 0=80-\mathrm{P} 0=100$

Figura 5.20 - Valor da Opção em mil R\$ por hectare vs. Estoque inicial para diferentes preços inicias

Fonte: Elaboração própria

A Figura 5.20 mostra a variação do valor da opção em relação ao estoque para diferentes preços iniciais. Assim como no modelo logístico anterior, o valor da opção tende para uma constante, e da mesma forma, esse resultado corrobora os obtidos por Morck, Schwartz e Stangeland (1989) e Levi (1996) que utilizam outra modelagem para o crescimento. 


\section{4.}

\section{Análise Comparativa dos modelos}

Pela a Teoria das Opções Reais, são propostos nessa análise comparativa três modelos para analisar os resultados, sendo a principal diferença entre eles a forma de variação do estoque: (i) logístico, (ii) logístico com componente estocástica e (iii) logístico "corta ou não corta". O modelo (i) é o caso principal avaliado nesse trabalho. No modelo (iii), assim como no modelo (i), o estoque apresenta um crescimento segundo a equação logística, sendo a diferença dada pelo fato de que no caso (iii) a escolha é cortar ou não cortar a uma determinada taxa de corte máxima ( $\mathrm{q}_{\text {máx }}$ ). Já no caso (ii) estocástico, o estoque segue o modelo geométrico de Ornstein-Unlenbeck e a taxa de corte é otimizada, assim como no modelo (i).

Aplicando o método de diferenças finitas com os parâmetros dados na Tabela 5.1, o valor de uma empresa madeireira, ou seja, o valor da opção de investimento, é mostrado na Tabela 5.2. A tabela mostra o valor do projeto para as três abordagens diferentes, considerando diferentes valores iniciais para o nível dos preços.

Tabela 5.2 - Valor de Mercado em milhares de reais para diferentes Preços iniciais

\begin{tabular}{|c|c|c|c|c|c|}
\hline & Logístico & $\begin{array}{l}\text { Logístico } \\
\text { Estocástico }\end{array}$ & $\begin{array}{l}\text { Logístico "corta } \\
\text { ou não corta"** }\end{array}$ & $\begin{array}{l}\text { VPL } \\
q=15\end{array}$ & VPL q* \\
\hline$P 0=40$ & 818 & 818 & 366 & -709 & 567 \\
\hline $\begin{array}{c}\mathbf{P} 0=50 \\
\text { (Caso Base) }\end{array}$ & 1.411 & 1.410 & 890 & 236 & 1.009 \\
\hline$P 0=100$ & 6.561 & 6.495 & 5.495 & 4.965 & 5.107 \\
\hline$P 0=200$ & 22.225 & 21.866 & 15.808 & 14.423 & 20.052 \\
\hline$P 0=300$ & 40.020 & 39.330 & 27.034 & 23.880 & 30.307 \\
\hline
\end{tabular}

Fonte: Elaboração própria

**Neste modelo, foi considerado um valor para qmax $=15 \mathrm{~m}^{3} / \mathrm{ano}$

$\mathrm{Na}$ Tabela 5.2, há cinco resultados diferentes para cada preço inicial. Além dos casos em que se usa a teoria das opções reais, foi feita uma comparação com o método tradicional do Valor Presente Líquido, para o caso em que a taxa de corte é $\mathrm{q}_{\text {máx }}=15 \mathrm{~m}$ 3/ano e outra para o caso em que a taxa de corte é otimizada. Como esperado, o critério do Valor Presente Líquido subestima o valor da opção em todos os casos comparado à metodologia de Opções Reais. Considerando os diferentes modelos para avaliação do valor da opção, no caso logístico “corta ou não corta”, o valor da opção representa aproximadamente $60 \%$ do valor da opção gerado pelo modelo em que a taxa de corte é otimizada (logístico), assumindo que se pode cortar qualquer valor. 
O caso em que se considera a componente estocástica fornece um valor menor para a opção em relação ao modelo originalmente proposto, o que pode ser verificado pelo sinal do termo $F_{I I}$ - segunda derivada em relação ao estoque - que é negativo, como pode ser visto pela derivada parcial da equação 4.41. Nesse caso, quanto maior a volatilidade do estoque, menor será o valor da opção. Essas conclusões corroboram os encontrados por Rocha et al. (2004). Os autores concluem que, acima de um determinado estoque mínimo, o aumento da volatilidade desvaloriza a opção.

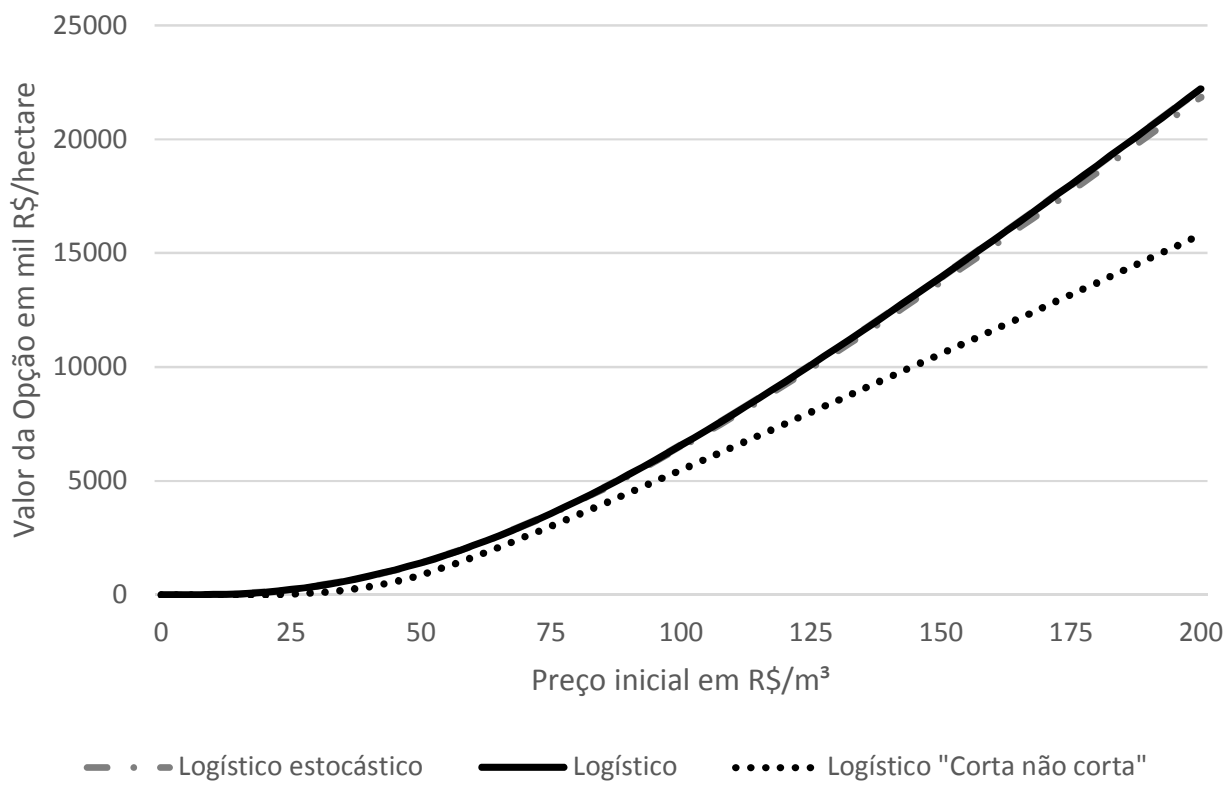

Figura 5.21 - Valor da Opção em mil R\$ por hectare vs. Preço inicial para diferentes modelos

Fonte: Elaboração própria

Na Figura 5.21 verifica-se que o valor da opção é maior para o modelo logístico. Porém a variação entre o resultado obtido pelo modelo logístico estocástico para o modelo logístico é pequena. Conforme já visto pela análise das Figuras 5.4 e 5.16, para os modelos logístico e logístico estocástico, respectivamente, com estoques iniciais menores que $150 \mathrm{~m}^{3}$, a sensibilidade do valor da opção em relação ao preço é muito pequena. Como para o caso base considera-se um estoque inicial de $100 \mathrm{~m}^{3}$, esta diferença é pouco sensível na análise gráfica mostrada. 
De forma geral, a metodologia de apreçamento de opções pode ser útil para auxiliar investidores a determinar o valor mínimo para um ativo, para quantificar o benefício econômico do investimento e a viabilidade do gerenciamento florestal. 


\section{6 Conclusão}

Este estudo propõe uma extensão do modelo de Morck, Schwartz e Stangeland (1989) e utiliza a teoria de opções reais (TOR) para estimar o valor de uma concessão florestal para produção de madeiras destinadas a serraria. O método proposto é superior à abordagem tradicional do valor presente líquido (VPL), que tende a subestimar o valor potencial do projeto. Isso porque a TOR permite avaliar os ganhos advindos da flexibilidade das decisões para cenários de incerteza. No caso base considerado, o valor do projeto obtido pela TOR é mais do que duas vezes maior comparada à encontrada pelo VPL com a taxa de corte fixa e aproximadamente $40 \%$ maior que o VPL com a taxa de corte otimizada.

O objetivo principal do trabalho, caracterizado pela avaliação de um projeto florestal com a opção de se cortar árvores a uma taxa ótima quantificando a flexibilidade gerencial pela abordagem de opções reais, foi atingido. Os objetivos específicos também foram alcançados. Foi mostrada a base de literatura florestal que emprega modelo de crescimento logístico para um estoque de árvores. Foi realizada uma profunda revisão bibliográfica de trabalhos que aplicam a Teoria das Opções Reais na área florestal. Além disso, o ferramental necessário para aplicar a Teoria das Opções Reais em um caso prático foi apresentado, de forma a obter o valor de um povoamento de árvores em um projeto de investimento florestal e a política ótima de corte das árvores. A decisão ótima de colheita obtida para diferentes modelos de crescimento do estoque e para um caso em que a decisão é apenas cortar ou não a uma taxa fixa, foram comparadas. Por fim, foram realizadas as análises de sensibilidade para diferentes parâmetros do modelo e foram observados os movimentos ocorridos na taxa de corte e no valor da opção.

Uma importante contribuição deste estudo é considerar um modelo utilizado na literatura da área florestal que possui a hipótese mais realista de crescimento do estoque de madeira. Para os modelos logístico e logístico estocástico, os resultados mostram que, com o aumento de preço inicial, a taxa de corte aumenta e é realizada em menor tempo. Por outro lado, para maiores níveis de estoque inicial, a taxa de corte 
é também realizada por mais tempo, sendo necessário um intervalo de tempo mais extenso quando quantidade de árvores inicial é maior.

Além disso, os modelos que aplicam a otimização da taxa de corte mostram que uma volatilidade do preço maior implica num valor de opção maior e postergar o exercício pode ser consequentemente melhor do que cortar imediatamente.

Com relação ao valor da opção, observa-se que quanto maior o estoque, maior será o valor da opção. Um fato importante para a análise pode ser observado na diferença entre o valor da opção para diferentes estoques iniciais que só é realmente relevante quando os preços iniciais são maiores.

O valor opção em função do preço inicial para diferentes níveis de desviopadrão do processo estocástico do preço corrobora os resultados apresentados na literatura. Verifica-se que com o aumento da volatilidade o efeito gerado pela taxa de corte é indefinido. Este resultado pode ser comprovado pela análise feita por Pindyck (1984).

Foi verificado que a taxa de conveniência do preço possui uma relação inversa com o valor da opção, pois, quanto maior a taxa de conveniência, maior é o valor da opção com o aumento do preço. Dada a variação do valor da opção em relação ao estoque inicial para diferentes volatilidades do volume de árvores, o resultado mostra que o aumento da incerteza em relação ao estoque diminui o valor da opção.

Além dos casos em que se usa a teoria das opções reais, foi feita uma comparação com o método tradicional do Valor Presente Líquido, para o caso em que a taxa de corte é fixa. Como esperado, o critério do Valor Presente Líquido subestima o valor da opção em todos os casos comparado à metodologia de Opções Reais. Considerando os diferentes modelos para avaliação do valor da opção, no caso logístico "corta ou não corta", o valor da opção representa aproximadamente $60 \%$ do valor da opção gerado pelo modelo em que a taxa de corte é otimizada (logístico), assumindo que se pode cortar qualquer valor.

Outro resultado relevante da análise foi que o valor da opção é maior para o modelo logístico. Os resultados mostram que, assim como para os autores Moreira et al (2000), o valor de um projeto de investimento florestal é mais sensível à incerteza dos preços do que à dos estoques, de modo que a estimação da primeira deve ser ainda mais importante.

Considerando a falta de disponibilidade dos dados utilizados e a precariedade de dados específicos de projetos reais os resultados obtidos são apenas indicativos do 
valor do projeto. Porém, acredita-se que esses resultados sejam sugestivos e reveladores o suficiente para impulsionar a aplicação da metodologia proposta com um conjunto de parâmetros que seja considerado mais realista.

Portanto é possível determinar a taxa de corte de madeira em concessões florestais, no contexto de uma política de controle ótimo, de modo similar a Morck, Schwartz e Stangelang (1989). Esta política de controle ótimo, determinaria o padrão de corte das árvores, em função do preço da madeira, da quantidade de madeira na reserva florestal e do tempo corrente. Porém, não foi considerado o fato de que o tempo ótimo para o corte de árvores é determinado tecnicamente. Não considerar que a taxa de corte, e a idade ideal para o corte de árvores, sejam determinados tecnicamente, pode levar a resultados que não representam a realidade do mercado florestal. Uma análise técnica e econômica, considerando desde a plantação até o processo industrial, seria uma ferramenta importante para o gerenciamento porque as duas atividades são correlacionadas. Esta aplicação, assim como a análise de uma concessão florestal onde exista maior flexibilidade quanto à época apropriada para o corte, são sugeridos como temas de pesquisa para o futuro.

Observa-se que a análise dessa pesquisa pode ser estendida para diferentes abordagens e pode interessar tanto a empresas do setor florestal quanto a governos na tomada de decisão sobre políticas públicas, seja para precificar melhor as concessões seja para incluir informações socioambientais na análise. Como sugestão de trabalhos futuros podem ser aplicados outros métodos numéricos para avaliar a opção. Ou ainda podem ser simulados outros processos estocásticos para o preço, como o processo de reversão à média. Também seria interessante estender o problema por um horizonte de tempo maior para considerar um projeto mais longo e realizar uma análise do preço em que se começaria a cortar para um determinado estoque inicial para cada período.

De fato, ao focar na política ótima para um investimento, foram desconsideradas outras questões que envolvem problemas sociais e regulamentares, que também é um tema motivador para o emprego da abordagem aqui apresentada. Também poderiam ser feitas estimações dos parâmetros que envolvem a variável estoque. Além disso, com uma pesquisa mais aprofundada a respeito dos custos em trabalhos do mercado florestal, poderia considerar-se o custo fixo de manutenção da produção florestal e terse uma aproximação mais assertiva a respeito dos custos variáveis. Como se trata de 
uma metodologia aplicada a um recurso natural, outros tipos de recursos poderiam ser considerados.

A expectativa é que a aplicação desse metodologia para problemas gerais envolvendo o gerenciamento do estoque tenha importância significativa para o desenvolvimento de trabalhos acadêmicos que influenciem empresas e fábricas a considerar a limitações técnicas. Considerando principalmente o aspecto da preservação do meio ambiente e da utilização consciente dos recursos naturais, conclui-se que há um campo promissor a ser explorado por trabalhos futuros. 


\section{Referências bibliográficas}

ABRAF - Associação Brasileira de Produtores de Florestas Plantadas. Anuário estatístico 2013 ano base 2012 / ABRAF. - Brasília: 2013. 148 p.

ALVES, A. M.; PEREIRA, J. S.; SILVA, J. M. N. O Eucaliptal em Portugal - Impactes Ambientais e Investigação Científica. Lisboa: ISA Press. 2007.

Autoridade Florestal Nacional. (2010). Inventário Florestal Nacional 20052006. Lisboa: Autoridade Florestal Nacional.

AVERY, T.; BURKHART, H. Forest Measurements. Nova York: McGrawHill. 5 ed. 2002.

BACK, K. A. Course in Derivatives Securities - Introduction to Theory and Computation. Springer-Verlag Berlin Heidelberg. 2005. 355 p.

BARAN, F. D. Avaliação de uma floresta de eucaliptos na presença de um mercado de certificados para reduções de emissões de carbono: uma abordagem por Opções Reais. Rio de Janeiro - RJ, 2005. Dissertação (mestrado em Engenharia de Produção) - PUC-Rio.

BRASIL. Lei № 9.393, de 19 de Dezembro de 1996. Regulamentação do Imposto sobre a Propriedade Territorial Rural - ITR. Disponível em: http://www.planalto.gov.br/ccivil_03/LEIS/L9393.htm\#art11. Acessado em: 15/07/2016.

BRENNAN, M. J.; SCHWARTZ, E. S. Corporate Income Taxes, Valuation and the Problem of Optimal Capital Structure. The Journal of Business. 51 v. 1 ed. jan. 1978. 103-114p.

BRENNAN, M. J.; SCHWARTZ E. S.. Evaluating Natural Resource Investments. The Journal of Business, v. 58, n. 2, p. 135-157, abr. 1985.

BROBOUSKI, W. J. P. Teoria das opções reais aplicada a um contrato de parceria florestal com preço mínimo. Curitiba - PR, 2004. Dissertação (mestrado em Métodos Numéricos em Engenharia) - UFPR.

CAO, Q. V.; STRUB, M. Evaluation of Four Methods to Estimate Parameters of an Annual Tree Survival and Diameter Growth Model. Forest Science, 54 v. 6 ed. 617-624p. 2008.

CIESZEWSKI, C. J.; BELLA, I. E. Polymorphic height and site index curves for lodge pole pine in Alberta. Canadian Journal of Forest Resources, 19 v. 1151-1160p. 1989.

CONRAD, J. M. On the option value of old-growth forest. New York: Ecological Economics 22 v. nov. 1997. 97-102p. 
CORTAZAR, G.; SCHWARTZ E. S.; SALINAS, M.. Evaluating Environmental Investments: A Real Options Approach. Management Science: INFORMS, 44 v., 8 ed. ago. 1998. 1059-1070p.

DIAS, M. A. G. Análise de Investimentos com Opções Reais. Interciência. 2 v. 1 ed. 496p. 2015.

EMBRAPA.

Disponível

em:

https://www.embrapa.br/florestas/transferencia-de-

tecnologia/eucalipto/tema. Acesso em: 16/09/2016.

ENCINAS, J. I.; SILVA, G. F.; PINTO, J. R. R. Idade e crescimento das árvores. UNB - Comunicações Técnicas Florestais. v.7, n.1 Brasília, dez. 2005.

Florestar Estatistico. Conversão de unidades e custo da árvore. Disponível em: http://ambienteduran.eng.br/fatores-de-conversao. Acesso em: 05/05/2016. 7p. 2004.

Food and Agriculture Organization of the United Nations. (2010). Global Forest Resources Assessment 2010. Rome: FAO.

FORSYTH, M. On Estimating the Option Value of Preserving a Wilderness Area. The Canadian Journal of Economics. 33 v., 2 ed. mai. 2000. 413-434p.

GASTALDI, H. L. G.; MINARDI, A. M. A. F. Opções Reais em Investimentos Florestais. Insper. 2012.

GOES, F. A. Modelação do crescimento da árvore individual de Eucalyptus globulus Labill. Dissertação. Universidade Nova de Lisboa. nov. 2012.

HULL, J. C. Opções, Futuros e Outros Derivativos. 3ed. Bolsa de mercadorias \& futuros. 1997.

IBÁ. Indústria Brasileira de Árvores. Relatório IBÁ 2015. Disponível em: http://iba.org/images/shared/iba 2015.pdf. Acesso em: 01/07/2016. 80p. 2015.

IBÁ. Indústria Brasileira de Árvores. Relatório IBÁ 2014. Disponível em: http://www.ipef.br/estatisticas/relatorios/anuario-iba 2014.pdf. Acesso em: 01/07/2016. 100p. 2014.

INSLEY, M. A Real Options Approach to the Valuation of a Forestry Investment. Journal of Environmental Economics and Management v.44, p. $471-492$, jan. 2002.

KERR, R. B. Decisão ótima de corte de uma floresta de eucalipto, utilizando diferenças finitas totalmente implícitas com algoritmo PSOR. São Paulo, 2008. Tese (doutorado em Administração de Empresas) - Universidade Presbiteriana Mackenzie.

LEVI, S. H. G. Avaliação Econômica de Projetos de Exploração Florestal. Rio de Janeiro - RJ, 1996. Dissertação (mestrado em Engenharia de Produção) - PUC-Rio. 
LHOTKA, J.; LOEWENSTEIN, E. An individual-tree diameter growth model for managed uneven-aged oak-shortleaf pine stands in the Ozark Highlands of Missouri, USA. Forest Ecology and Management, 261 v. 770-778p. 2010.

MITCHELL, A. R.; GRIFFITHS, D. F. The Finite Difference Method in Partial Differential Equations. 284 p. Wiley: 1 ed. fev. 1980.

MORCK, R.; SCHWARTZ, E.; STANGELAND, D. The valuation of forestry resources under stochastic prices and inventories. Journal of financial and quantitative analysis. v. 24, n. 4, dez. 1989.

MOREIRA, A. R. B.; Reis, E. J.; Rocha, K.; Carvalho, L.. A valoração das concessões nas florestas nacionais da Amazônia: uma abordagem com opções reais. Pesquisa e Planejamento Economico, Rio de Janeiro, v. 30, n. 3, p. 327-354, dez. 2000.

OLIVEIRA, E. B. Um sistema computadorizados de prognose do crescimento e produção de Pinus taeda $L$., com critérios quantitativos para avaliação técnica e econômica de regimes de manejo. Curitiba PR, 1995. Tese (doutorado em Engenharia Florestal) - Setor de Ciências Agrárias, UFPR.

PENG, C. Growth and yield models for uneven-aged stands: past, present and future. Forest Ecology and Management, v. 132. 259-279p. Jul. 2000.

PERONI, N.; HERNÁNDEZ, M. I. M. Ecologia de Populações e Comunidades. Florianópolis: CCB/EAD/UFSC. 123 p. 2011.

PINDYCK, R. S. Uncertainty in the Theory of Renewable Resource Markets. The Review of Economic Studies, v. 51, n. 2, p. 289-303, abr. 1984.

ROCHA, K.; MOREIRA, A. R. B.; REIS, E. J.; CARVALHO, L. The market value of forest concessions in the Brazilian Amazon: a Real Option approach. Forest Policy and Economics v. 8, p. 149- 160, mai. 2004.

RODRIGUEZ, L. C. E., BUENO, A. R. S., RODRIGUES, F. Rotações de eucaliptos mais longas: análise volumétrica e econômica. Scientia Forestalis v. 51, p. 15-28, jun. 1997.

ROLLINS, K; FORSYTH, M.; BONTI-ANKOMAH, S.; AMOAH, B. A financial analysis of a White Pine improvement cut in Ontario. Forestry Chronicle 71 v. 466-471p. 1995.

SCHUMACHER, F.X. A new growth curve and its application to timber yield studies. Journal of Forestry, v.37, p.819-820, 1939.

Serviço Florestal Brasileiro - SFB. Disponível em: http://www.florestal.gov.br/. Acesso em: 06/06/2016. 2006.

SOARES, P.; TOMÉ, M.; SKOVSGAARD, J. P.; VANCLAY, J. K. Evaluating a growth model for forest management using continuous forest inventory data. Forest Ecology and Management, 71 v. 251-265p. 1995. 
TAVELLA, D. A. Quantitative Methods in derivatives pricing. California: Wiley Finance. mar. 2002. 285p.

TOMÉ, M.; SOARES, P.; BARREIRO, S.; PAULO, J. A.; LUÍS, M.; Cortiçada, A.; Valente, C. Curso Prático de Formação para Chefes de Brigada de Inventário Florestal. Lisboa: GIMREF - Grupo de Inventariação e Modelação de Recursos Florestais. 2 ed. 2005.

TOMÉ, M. Apontamentos da disciplina de Modelação dos Recursos Florestais. Lisboa: Instituto Superior de Agronomia. 2011.

TRIGEORGIS, L. Real Options: Managerial Flexibility and Strategy in Resource Allocation. The MIT Press. 427p. mar. 1996.

VANCLAY, J. Modelling Forest Growth and Yield: applications to mixed tropical forests. Wallingford UK: CAB International. 1994.

VITAL, M. H. F. Impacto Ambiental de Florestas de Eucalipto. Revista do BNDES, Rio de Janeiro, V. 14, N. 28, P. 235-276, dez. 2007.

WILMOTT, P. Paul Wilmott on Quantitative Finance. John Wiley \& Sons Ltd. 1 v. 2 ed. 2000. 


\section{Apêndice}

O software que aplica o Método de Diferenças Finitas explícitas (MDF explícitas) escrito em linguagem Java foi desenvolvido a partir de uma interface gráfica de forma a tornar amigável a manipulação dos dados de entradas para as diversas simulações.

A Figura A.1 a seguir mostra a tela principal do programa que contém:

- campos editáveis para os dados de entrada;

- opção de salvar os dados de entrada para posterior utilização, bem como opção de carregar dados de entrada salvos;

- campos com valores calculados pelo programa de acordo com as modelagens implementadas;

- opção para exportar os resultados gerados em planilha Excel para uma fácil manipulação como, por exemplo, criação de gráficos;

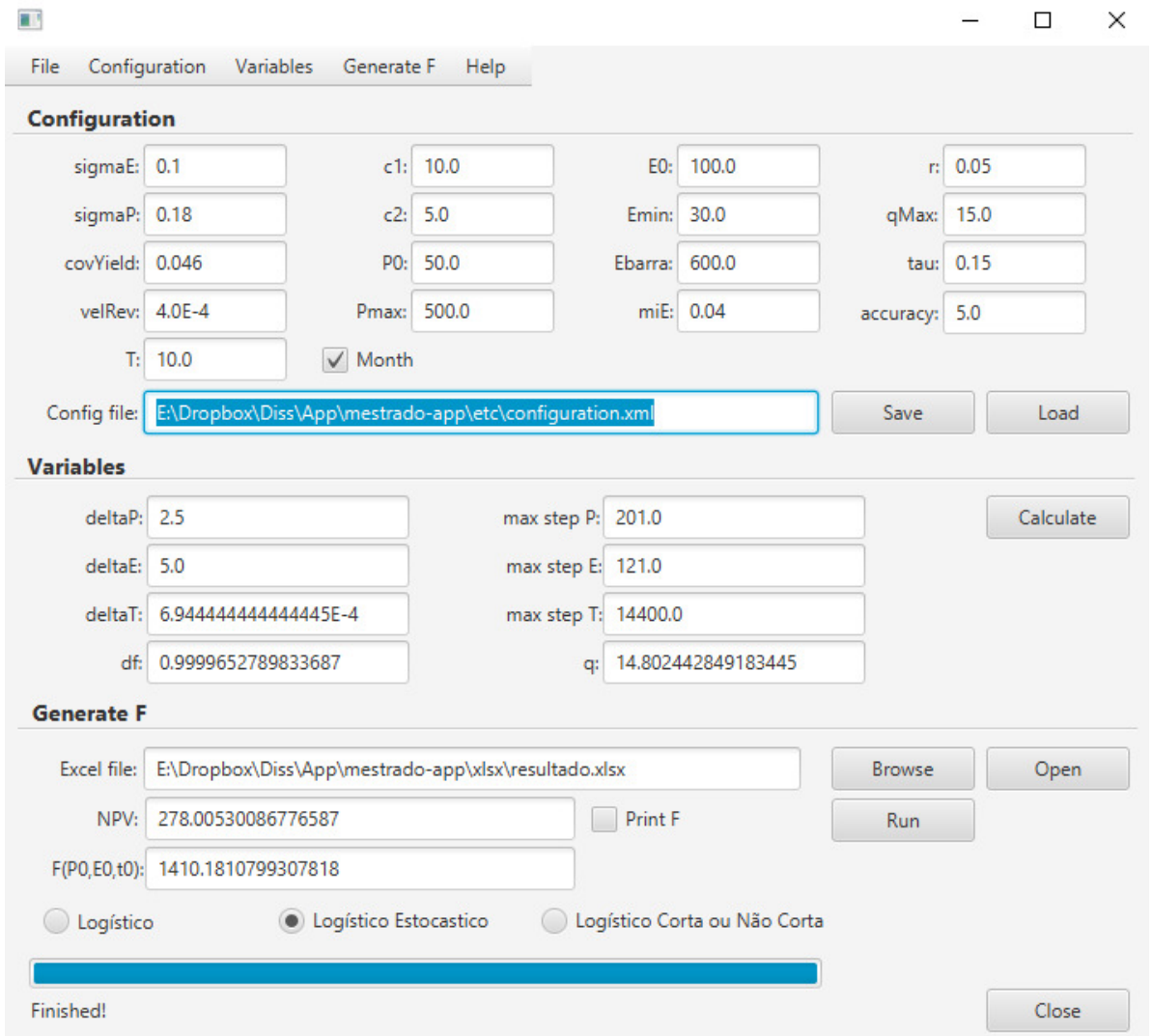

Figura A.1 - Tela principal do programa

Fonte: Elaboração própria

O código fonte do programa está disponível no seguinte link:

https://www.dropbox.com/s/513wpzhou8z7835/CodigoFonte.zip?dl=0 